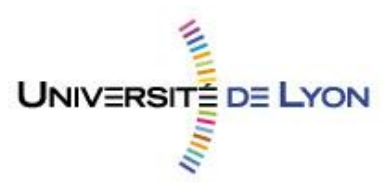

Diplôme de conservateur des bibliothèques

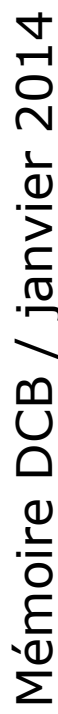

Co-construire les collections avec les usagers

\title{
Elise BRETON
}

Sous la direction de Bertrand CALENGE Directeur des études à I'ENSSIB

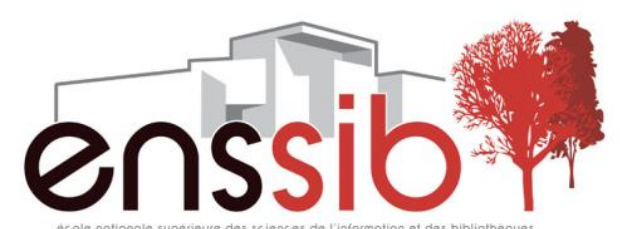





\section{Remerciements}

Mes remerciements vont en premier lieu à mon directeur de mémoire Bertrand Calenge pour tout son travail de suivi. Ce mémoire doit beaucoup à sa disponibilité, à sa rigueur intellectuelle et à ses conseils éclairés.

Je remercie également toutes les professionnels interrogés, qui ont participé, par leurs réponses, à nourrir la réflexion: Cécile Dérioz, directrice de la médiathèque de Rillieux-la-Pape, Lucile Humbert, responsable BD dans cette même médiathèque, Marc Bailly, de la bibliothèque Place des fêtes à Paris, Lionel Dujol, responsable de la médiation numérique à la médiathèque de Romans, Pascale Fontenille, directrice de la bibliothèque du 4ème arrondissement de Lyon, Christèle Bonny, responsable de la politique documentaire de la médiathèque départementale du Puy-de-Dôme, Jean-Christophe Lacas, chef de projet de la médiathèque intercommunale entre Dore et Allier, Cyril Titz, directeur de la médiathèque La Gare à Méricourt, et Valérie Beaugier, bibliothécaire responsable des projets adolescents à la bibliothèque de Montreuil.

Je les remercie pour le temps qu'ils m'ont consacré et pour l'aide précieuse que $m$ 'ont apportée leurs témoignages.

Une pensée particulière va à mes camarades de promotion, lesquels se reconnaîtront, ainsi qu'à mes proches pour leur présence et leur soutien pendant la rédaction de ce mémoire. Enfin, et surtout, merci à Pierre-Jean, pour ses encouragements et son appui sans faille. 


\section{Résumé :}

La co-construction des collections avec les usagers intéresse de nombreuses bibliothèques de lecture publique, d'une part pour augmenter la proximité de l'institution avec les citoyens et d'autre part dans le but de proposer des collections mieux adaptées aux besoins des lecteurs. Mais elle soulève également des réticences, notamment parce que la collection relève du domaine du professionnel et que l'idée de déléguer ces tâches aux usagers suscite des résistances. Ce mémoire a pour but de délimiter les contours de la co-construction, une notion très discutée mais encore peu définie, d'explorer et d'analyser les enjeux de son application au domaine des collections, et enfin de servir de guide pratique en donnant des lignes directrices et des conseils aux bibliothèques qui souhaitent mettre en place de tels projets.

\section{Descripteurs :}

Bibliothèques -- Gestion des collections

Bibliothèques publiques -- Publics

Relations administration-usagers

Services publics -- Participation des citoyens 


\begin{abstract}
:
Many public libraries take an interest in collections co-construction with library patrons, on one hand to get closer to the community, on the other to offer better collections that match patrons' needs. Some of them are also reluctant, partly because collections management is a professional skill and resistance can arouse when this task is delegated to patrons. This dissertation intends to circumscribe a notion that is often discussed but rarely defined, to examine and study its use in the field of collections, and finally to give guidelines and advices to libraries that wish to put such projects in practice.
\end{abstract}

Keywords :

Libraries collections management

Library users

Public utilities -- Citizen participation

\title{
Droits d'auteurs
}

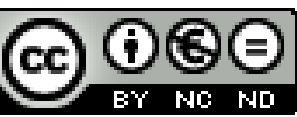

Cette création est mise à disposition selon le Contrat : «Paternité-Pas d'Utilisation Commerciale-Pas de Modification 2.0 France » disponible en ligne http://creativecommons.org/licenses/by-nc-nd/3.0/deed.fr ou par courrier postal à Creative Commons, 171 Second Street, Suite 300, San Francisco, California 94105, USA. 



\section{Sommaire}

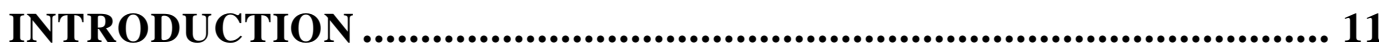

PARTIE 1 : CONTEXTE ET DEFINITION DE LA COCONSTRUCTION DES COLLECTIONS................................................. 15

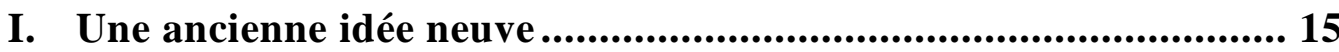

A. Une certaine frilosité des bibliothèques à faire participer les usagers aux collections ......................................................... 15

1. L'héritage de l'histoire des bibliothèques publiques françaises : la conservation des collections avant le souci du lecteur 15

2. La collection, domaine réservé du professionnel ? ............... 17

B. Une injonction à la participation qui renouvelle les modes d'association des usagers au fonctionnement des bibliothèques. 19

1. L'exigence d'une plus grande proximité entre l'institution et les citoyens 20

2. L'influence des bibliothèques anglo-saxonnes tournées vers la

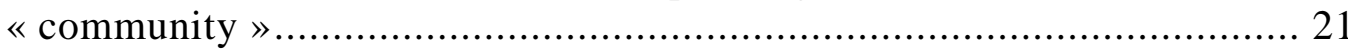

3. Des premières formes de participation : les comités d'usagers 22 II. Définir la co-construction des collections ............................... 24

A. Ce que la co-construction des collections n'est pas .................. 24

1. Tous les cas où l'usager reste passif ................................... 24

2. Toutes les formes de participation qui n'impliquent pas de démarche de construire en commun... 25

3. Toutes les formes de participation des usagers où la décision appartient au bibliothécaire.....

B. De la participation à la co-construction................................ 27

1. Passer d'un usager passif à un usager actif, acteur puis moteur de la collection

2. Renverser la logique de constitution des collections : ne plus construire pour, mais avec 28

3. Passer d'une logique verticale à un rapport horizontal avec l'usager 29

C. Typologie des formes de co-construction des collections ........... 31

1. La participation des usagers aux acquisitions..................... 31

2. La participation des usagers à la gestion et l'organisation de la collection 31

3. La co-création de contenus ......................................... 32

4. La médiation participative autour des collections................. 33 


\section{PARTIE 2 : LES ENJEUX DE LA CO-CONSTRUCTION DES}

I. Penser autrement la collection................................................... 35

A. Une collection plus proche de son public .............................. 35

1. Rapprocher le contenu de la collection des besoins et attentes du public $\quad 36$

2. Organiser la rencontre de la collection et des usagers ........... 37

B. Valoriser les compétences des usagers................................ 39

1. Considérer les usagers comme une ressource ...................... 39

2. Identifier et valoriser les « amateurs » ..............................40

3. Adopter des formes de recommandation par les pairs ........... 41

II. La reconquête du public.......................................................... 42

A. Une relation renouvelée de la bibliothèque à son public........... 42

1. Du point de vue de l'usager : prendre conscience de son droit à contribuer 42

2. Du point de vue de la bibliothèque : activer la communauté des usagers 45

B. $\quad$ Faciliter le lien entre les bibliothécaires et les usagers ............ 48

1. Donner des clés pour une meilleure compréhension de la bibliothèque......

2. Faciliter les contacts ....................................................... 49

III. Les questionnements soulevés ............................................ 50

A. L'appréhension d'une perte de contrôle sur les collections ....... 51

B. $\quad$ Un questionnement sur la place du bibliothécaire ................... 52

C. Des contraintes administratives et des marges étroites ............. 54

D. La question de la représentativité des usagers ....................... 55

PARTIE 3 : COMMENT CONDUIRE UN PROJET DE COCONSTRUCTION DES COLLECTIONS ?

I. Préparer le projet en amont .................................................. 58

A. Faire de la participation un axe fort de sa politique

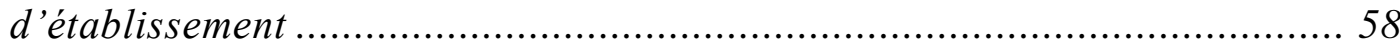

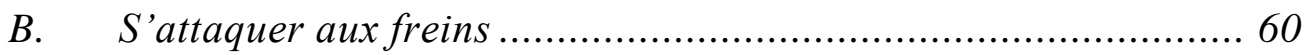

C. Encadrer la participation ................................................ 61

II. Organiser la participation................................................63 63

A. Comment mobiliser ?............................................................. 63

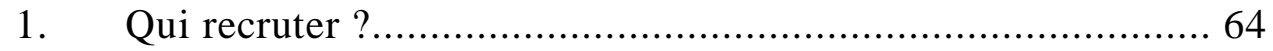

2. Trouver l'intérêt qui va susciter la participation ................... 66

3. Sous quelle forme ? ................................................. 69

B. $\quad$ Faire durer la participation ............................................. 69 


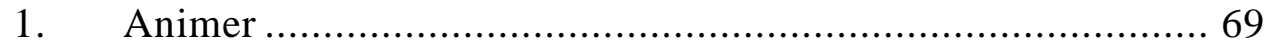

2. Valoriser, créer des liens et célébrer ................................. 71

III. Expérimenter et apprendre des expériences ............................ 72

CONCLUSION ................................................................................. 75

BIBLIOGRAPHIE .............................................................. 77

TABLE DES ANNEXES .............................................................. 83

TABLE DES MATIERES ............................................................ 87 



\section{INTRODUCTION}

L'intérêt pour les projets de collaboration avec les usagers semble aujourd'hui progresser dans de nombreux secteurs, à la fois publics et privés. Des projets de co-construction sont mis en œuvre par des prestataires de services pour répondre à deux injonctions principales : offrir un service plus adapté aux attentes et besoins du public et accroître la proximité de l'institution avec ses usagers. Ainsi, dans le monde économique, des entreprises associent leurs clients à la conception des produits pour faciliter l'appropriation de la marque par les consommateurs ${ }^{1}$. Dans le domaine des sciences, on s'interroge sur la co-production des savoirs, qui pourrait rapprocher le scientifique, expert, et le citoyen, néophyte, et ainsi permettre à la science de redevenir un débat de société ${ }^{2}$. Dans les services publics enfin, faire participer les usagers à la production du service est à la fois un enjeu de légitimité, en permettant à l'usager d'agir sur le fonctionnement du service, et d'efficacité, en essayant d'être au plus proche des besoins du public dans un contexte financier tendu. L'injonction d'implication des usagers se fait d'autant plus sentir par la comparaison avec le monde du web qui s'appuie beaucoup sur les modèles de contribution. Les logiciels construits en open source, les projets collaboratifs comme Wikipedia fonctionnent avant tout grâce aux participations des communautés d'internautes.

Du point de vue des usagers, la demande d'être associés à la décision semble également progresser. L'inadéquation de certaines décisions prises dans le système représentatif conduit des mouvements de démocratie participative à revendiquer l'instauration de processus de décision plus inclusifs et délibératifs. Un changement idéologique, que Loïc Blondiaux et Yves Sintomer nomment «l'impératif délibératif ${ }^{3}$ valorise les processus de participation et de concertation dans la pratique de décision des démocraties contemporaines. Dans le monde du web également, les internautes se sont habitués à avoir des possibilités de participer et d'affirmer leurs points de vue grâce aux outils coopératifs 2.0 (blogs, wikis, étiquetage social, etc.). Les usagers revendiquent le droit d'exprimer leurs attentes à l'égard d'un service, ressentent le besoin d'être pris en considération, et parfois demandent à participer à la prise de décision.

La co-construction intéresse aussi les bibliothèques, qui s'interrogent sur les possibilités de faire participer leurs usagers ${ }^{4}$.

Dans la plupart des bibliothèques publiques aujourd'hui, le souci des lecteurs a pris le pas sur le souci des livres ${ }^{5}$. Construites naguère autour du livre et pour le

1 Thierry Spencer, «Co-construction: un pari gagnant pour les entreprises!», [En ligne : http://room.sfrbusinessteam.fr/article/construction-pari-gagnant-pour-entreprises]. Consulté le 1 septembre 2013.

${ }^{2}$ Christine Vaufrey B, «Vulgarisation, médiation et co-construction des savoirs scientifiques et sociaux », Thot Cursus, 2012

${ }^{3}$ Loïc Blondiaux et Yves Sintomer, « L’impératif délibératif », Rue Descartes, n 63, avril 2009, p. 28-38.

${ }^{4}$ Voir Xavier Galaup, L'usager co-créateur des services en bibliothèques publiques : l'exemple des services nondocumentaires, Mémoire DCB sous la direction de Dominique Lahary, Enssib, 2007.

${ }^{5}$ Pour A. Chartier et J. Hébrard cette nouvelle ère du souci du lecteur avant celui du livre s'ouvre avec la construction de la BPI dont toutes les collections sont proposées en libre accès. Dans Anne Marie Chartier, Jean Hébrard, 
livre, les bibliothèques étaient à l'origine les lieux de la conservation, du classement et de l'organisation du savoir. De lieux uniquement documentaires, visant la préservation et la mise en valeur des collections, les bibliothèques d'aujourd'hui sont aussi devenues des lieux de vie, pensés pour le confort et pour les besoins de l'usager. La bibliothèque ne se définit pas seulement comme un « réservoir de livres »: les services proposés aux lecteurs, les projets d'animation et de médiation culturelles et documentaires, l'accueil et l'accompagnement des usagers tiennent aujourd'hui une place tout aussi importante. Dans ce contexte, la collection n'est plus uniquement considérée comme une accumulation de savoirs à conserver, mais doit être pensée avant tout pour le public desservi.

De lieux documentaires à lieux de vie, un nouveau pas pourrait être franchi en transformant les bibliothèques en lieux participatifs ${ }^{6}$. Du point de vue de l'offre documentaire, cela impliquerait de passer d'un modèle où l'on pense les collections pour le lecteur à la co-construction de celles-ci avec les usagers. On élabore aujourd'hui l'offre documentaire de la bibliothèque en essayant d'anticiper les besoins des lecteurs et en tenant compte de l'utilisation réelle des collections. Dans une démarche de co-construction, la collection n'est plus pensée pour l'usager mais bien avec lui, dans un rôle actif aux côtés du bibliothécaire. La démarche de co-construction de l'offre documentaire peut être envisagée comme une chance, à l'heure d'internet, pour renouer le lien avec une partie du public qui ne voit plus l'utilité de se déplacer à la bibliothèque, trouvant tout ce dont il a besoin sur la toile. Elle doit aussi permettre de faire vivre les collections des bibliothèques, qui souffrent de la comparaison avec l'accessibilité et l'apparent foisonnement infini des contenus disponibles en ligne.

Cependant, lorsque l'on évoque la possibilité de faire participer les lecteurs à la construction des collections, cette démarche soulève des questionnements et des frilosités professionnelles. Les tâches de constitution et d'organisation des collections constituent dans l'inconscient professionnel le «domaine réservé »du bibliothécaire, et des réticences émergent parfois lorsqu'on souhaite les déléguer aux usagers. Cela explique en partie pourquoi les initiatives de co-construction des collections avec les usagers sont aujourd'hui assez rares, et souvent encore limitées au stade expérimental. Néanmoins l'intérêt pour cette question est réel : dans un contexte de baisse du nombre de prêts, la co-construction des collections peut être vue à la fois comme un moyen de construire une offre de ressources plus proche des attentes de son public, et de toucher une communauté de lecteurs autour de la bibliothèque.

Ce mémoire a pour but d'analyser les enjeux de cette tendance émergente, de la remettre en contexte et d'en définir les contours. Il s'inscrit également dans une volonté pratique et doit pouvoir servir, pour les bibliothèques publiques, de support à la préparation et à la mise en œuvre de projets de co-construction des collections.

Emmanuel Fraisse[et al.], Discours sur la lecture (1880-1980), Service des études et de la recherche, Bibliothèque publique d'information, Centre Georges Pompidou, 1989, 536 p., p. 161

${ }^{6}$ Vincent Chapdelaine, «Vers une bibliothèque participative », Découvrir, le magazine de l'Afcas, mars 2013. 
Une précision quant à la délimitation de notre sujet : nous avons choisi de nous concentrer sur les enjeux de la co-construction des collections avec les usagers au sein des bibliothèques de lecture publique. Les bibliothèques universitaires utilisent également la co-construction des collections, en particulier avec les enseignants-chercheurs. Cependant, les enjeux sont différents : en simplifiant à l'extrême, on peut dire qu'elles sont plutôt dans la recherche d'une expertise que dans la volonté de créer une communauté d'usagers actifs au sein de la bibliothèque. Le spectre du sujet étant déjà large, nous avons préféré nous limiter à la co-construction des collections dans les bibliothèques de lecture publique. Nous exclurons également les collections patrimoniales qui ont des problématiques particulières ne s'intégrant pas dans notre sujet.

Nous nous interrogerons d'abord sur la notion de co-construction des collections : pourquoi cette idée émerge-t-elle aujourd'hui et que désigne-t-elle exactement?

Nous essayerons ensuite d'en cerner les enjeux : pourquoi vouloir impliquer les usagers dans la construction des collections ? Qu'est-ce qu'une telle démarche apporte à la bibliothèque ? Quels questionnements cela soulève-t-il ?

Enfin, nous verrons comment mettre en place un projet de co-construction des collections : quelles sont les questions à se poser ? Comment préparer puis mener un tel projet? 



\section{PARTIE 1 : CONTEXTE ET DEFINITION DE LA CO- CONSTRUCTION DES COLLECTIONS}

La co-construction: une «tendance lourde ${ }^{7}$, mais une notion encore indéfinie et aux contours incertains. En quoi co-construire est-il différent de faire participer? Est-ce que l'installation d'une simple boîte à suggestions est considérée comme de la co-construction avec les usagers? De nombreuses bibliothèques envisagent de faire participer les lecteurs, en réponse à un mouvement général de modernisation qui met l'usager au cœur du fonctionnement des établissements publics. Afin d'entamer ce type de démarche, il convient de définir les contours de cette notion complexe et d'en saisir tous ces aspects, après l'avoir replacée dans son contexte.

\section{UNE ANCIENNE IDEE NEUVE}

Il n'est pas naturel, pour les bibliothèques françaises, de faire participer les usagers au fonctionnement de la bibliothèque, et encore moins à l'organisation des collections, considérée comme le «domaine réservé » des professionnels. Malgré cet héritage socio-historique, les bibliothèques envisagent aujourd'hui des modes de participation des usagers, afin d'accroître la proximité de l'institution avec le public.

\section{A. Une certaine frilosité des bibliothèques à faire participer les usagers aux collections}

\section{L'héritage de l'histoire des bibliothèques publiques françaises : la conservation des collections avant le souci du lecteur}

D'un point de vue historique, le souci du lecteur est arrivé tard parmi les objectifs des bibliothèques municipales publiques en France, en particulier si on les compare aux bibliothèques anglo-saxonnes qui se sont attachées très tôt à répondre à la demande des usagers ${ }^{8}$. Au moment de la naissance des bibliothèques

${ }^{7}$ Anne-Sophie Novel, « Co-construire, ça veut dire quoi ? », Le Co-Lab, 2012.

${ }^{8}$ Anne-Marie Bertrand, Bibliothèque publique et public library: essai de généalogie comparée, Villeurbanne, France, Presses de 1'enssib, 2010, 229 p., (« Papiers. Série Généalogies »), p. 174. 
municipales françaises 9 , leur mission est avant tout celle de conserver le patrimoine issu des saisies révolutionnaires. La saisie en masse des biens du clergé, des émigrés, des universités et des sociétés savantes suite à la Révolution pose l'enjeu de la conservation de cet afflux de documents. La gestion de ces collections est alors confiée aux ancêtres de nos bibliothèques municipales, qui ont donc à l'origine une mission de préservation d'un patrimoine. La naissance des bibliothèques publiques française s'inscrit dans une société troublée, en proie à la guerre civile. Il s'agit donc plus de protéger le livre sacré des foules violentes que de diffuser les collections auprès d'un public large. D'une certaine manière, les bibliothèques révolutionnaires évitent le public, ou en tout cas le public qui n'est pas considéré comme un public « savant » 10 . Au XIXe siècle, le modèle de la bibliothèque "savante » domine. Destinée à un public d'érudits et tenue par des gens de lettres, la bibliothèque savante s'attache encore à préserver ses collections plutôt qu'à les diffuser :

Petit à petit, un modèle de bibliothèque se crée, dont le souci premier est la conservation des collections. Destinée aux familiers de l'écrit, cette bibliothèque «savante » concerne les érudits, les enseignants, les notables, voire les étudiants - en sont de fait exclus les femmes et les enfants. Le prêt de livres est rare, les horaires d'ouverture sont très réduits, 1'architecture même de la bibliothèque est austère et intimidante : la bibliothèque est dans un système d'évitement du public, dans une logique de club réservé à une petite minorité de lettrés. Les collections deviennent le domaine réservé d'une bourgeoisie érudite, soucieuse de se créer une nouvelle dignité à partir de la fréquentation d'une culture qu'elle s'était enfin appropriée. ${ }^{11}$

Toutefois, la bibliothèque savante, si elle s'adresse à un public restreint, n'exclut pas tout à fait la prise en compte des besoins des lecteurs : les responsables des collections et les publics appartiennent aux mêmes milieux sociaux, celui des gens de lettres et des érudits. Ce sont d'ailleurs parfois les mêmes personnes qui gèrent la bibliothèque et qui la fréquentent. La notion même de public est à relativiser dans une société où seule une minorité est en capacité de lire et de dégager du temps pour les loisirs.

A partir des années 1860, un modèle concurrent de la bibliothèque «savante » apparaît, et remet en cause sa dimension érudite. Le modèle de la bibliothèque «populaire » montre une volonté de prendre en compte le lecteur, et veut s'adresser à des catégories d'usagers différentes. Cependant, ces bibliothèques dédaignent toujours le plaisir de lire : le roman y est présent, mais seulement toléré. Les bibliothèques servent encore à diffuser l'instruction et le «bon livre ».

${ }^{9}$ Le décret du 28 janvier 1803 est généralement considéré comme leur acte de création : Anne-Marie Bertrand, Les bibliothèques, Paris, France, la Découverte, 2011, 126 p., (« Repères », 247), p. 21.

${ }^{10}$ Dominique Varry, «Les défis du siècle », in Histoire des bibliothèques françaises: 1789-1914, vol. 3, Paris, France, Éd. du Cercle de la librairie, 2009, p. 135.

${ }^{11}$ Henri-Jean Martin, Le Patrimoine : histoire, pratiques et perspectives, sous la dir. de Jean-Paul Oddos, Cercle de la Librairie, 1997 (Bibliothèques), cité dans Anne-Marie Bertrand, Les bibliothèques, La Découverte « Repères », 2011, p. 119 
Un changement s'opère au début du XXème siècle : alors que le potentiel public des bibliothèques s'élargit grâce au progrès de l'alphabétisation, on assiste à une véritable prise de conscience du retard des bibliothèques municipales françaises ${ }^{12}$. Leur organisation et leurs collections sont sans rapport avec les attentes du public. La fréquentation de ces bibliothèques est confidentielle, le secteur jeunesse n'existe pas. Eugène Morel compare les bibliothèques françaises à leurs semblables anglo-saxonnes ouvertes à tous les publics et pratiquant le prêt. Autour de lui, un mouvement se crée, qui milite pour mieux prendre en compte les besoins du public. Malgré ces efforts, les bibliothèques restent relativement inaccueillantes jusqu'aux années 1960, au moment où se développe le libre accès des collections et l'autonomisation de l'usager dans ses choix de lecture.

Dans l'histoire des bibliothèques municipales françaises, les collections ont donc longtemps été considérées comme un stock à conserver avant d'être pensées pour le lecteur. Le modèle de la bibliothèque française hérité de l'histoire est celui d'une bibliothèque où la connaissance sert à la maîtrise du monde, et qui doit répondre à toutes les demandes ${ }^{13}$. La collection est une construction intellectuelle, contrairement à la conception des bibliothèques anglo-saxonnes. Celles-ci, qui ont construit leur identité professionnelle autour de la grande mission de servir la communauté $^{14}$, sont moins préoccupées, dans la gestion des collections, par la cohérence d'un stock que par la capacité d'un flux à suivre la demande ${ }^{15}$. Même si les bibliothèques territoriales françaises se sont aujourd'hui rapprochées de la conception anglo-saxonne, plus attentive à la satisfaction des besoins des usagers, cet héritage explique en partie pourquoi l'implication du public dans l'organisation et le fonctionnement de la bibliothèque n'est pas toujours naturelle aujourd'hui.

\section{La collection, domaine réservé du professionnel?}

Les amateurs éclairés qui participaient à l'organisation des premières bibliothèques municipales, ont progressivement été remplacés par des professionnels. D'un point de vue historique, la gestion des bibliothèques s'est donc professionnalisée pour remplacer le système où celles-ci étaient cogérées par les usagers ${ }^{16}$. Aujourd'hui encore, la collection constitue le cœur de métier du bibliothécaire. La plus-value du professionnel des bibliothèques est de savoir gérer les acquisitions, l'organisation de l'offre documentaire et les transactions de prêts. Ainsi, la constitution et la gestion des collections sont souvent perçues comme le «secteur réservé » du bibliothécaire, sur lequel il exerce une compétence symbolique. Il est parfois difficile pour les bibliothécaires d'imaginer ce que

\footnotetext{
${ }^{12}$ Cité dans Dominique Varry, op. cit., p. 374.

${ }^{13}$ Anne-Marie Bertrand, op. cit.

${ }^{14}$ Olivier Tacheau, Bibliothèque publique et multiculturalisme aux Etats-Unis. Jalons pour repenser la situation française, mémoire DCB sous la direction de Martine Poulain, Enssib, 1998, p.16

${ }^{15}$ Ibidem.

${ }^{16}$ Hughes Van Besien, « Comités d'usagers : le retour? », Bulletin d'informations de l'ABF, 2000.
} 
l'usager aurait à y apporter, ce qui fait dire à Jean-Luc Gautier-Gentès, sur la question de la mise en place de conseils consultatifs d'usagers :

Et si les bibliothécaires sont si peu pressés de voir des conseils consultatifs refleurir à leur côté, n'est-ce pas aussi - osons dire ce que chacun sait bien - parce que, comme tout groupe professionnel, ils n'éprouvent aucun plaisir à l'idée que l'on empiète sur leur champ de compétence, autrement dit, sur le territoire où s'exerce leur pouvoir propre, réel et symbolique $?^{17}$

La constitution des collections produit du sens, c'est pourquoi elle peut en effet être comparée à un territoire sur lequel s'exerce une compétence symbolique. Cette production de sens en fait un domaine sensible, et donne lieu à des questionnements sur la «légitimité » de certains ouvrages à figurer dans les collections. Dans l'histoire de la lecture, les institutions ont souvent voulu guider les choix du lecteur, le diriger vers les lectures «autorisées», vers le «bon livre $»^{18}$. Toutes les lectures n'avaient donc pas leur place en bibliothèque, et dans le même temps, la mise en bibliothèque équivalait à une certaine reconnaissance pour l'auteur. Les bibliothèques françaises ont depuis largement évolué sur leur façon de construire les collections, en réponse aux demandes d'un public qui ne se reconnaissait pas dans leur offre documentaire. La conception selon laquelle la bibliothèque ne devait proposer que des lectures «légitimes » a été remise en cause, notamment au moment des débats sur l'introduction de la BD dans les collections. Il est aujourd'hui généralement admis que la politique documentaire d'une bibliothèque est une composante des politiques publiques définies par sa collectivité de tutelle, et qu'elle est donc au service des citoyens qu'elle dessert ${ }^{19}$. Les responsables des collections s'attachent désormais à satisfaire les attentes du public et l'idée selon laquelle il faut acheter prioritairement les ouvrages qui circulent le plus s'est progressivement ancrée. La normalisation des pratiques de désherbage montre également qu'on a remis en cause l'idée que la bibliothèque doit tout conserver pour préserver un patrimoine littéraire et intellectuel. La mission de conservation ne disparaît pas pour autant, mais on distingue désormais la collection courante, qui doit être renouvelée, et les collections patrimoniales, à préserver pour les générations futures. La collection courante, qui nous intéresse ici, n'est plus un stock, mais un flux et la politique documentaire est une constante recherche d'équilibre entre les entrées et les sorties des documents ${ }^{20}$.

Malgré ces évolutions, le discours sur l'exigence de qualité des collections est encore très présent chez les professionnels des bibliothèques, mais aussi parfois dans la conception que les tutelles et les usagers se font de la vocation de la bibliothèque. Ces derniers sont même parfois plus sévères que le bibliothécaire sur ce qui «mérite » ou non d'être acquis. Même si la priorité est de satisfaire les besoins du lecteur, il est difficile de se défaire de l'idée que tous les documents

\footnotetext{
${ }^{17}$ Jean-Luc Gautier-Gentès, «Réflexions exploratoires sur le métier de directeur de bibliothèque », Bulletin des Bibliothèques de France, vol. 44 / 4, 1999.

${ }^{18}$ Anne Marie Chartier[et al.], op. cit.

${ }^{19}$ Bertrand Calenge, Bibliothèques et politiques documentaires à l'heure d'Internet, Paris, France, Éditions du Cercle de la librairie, 2008, 264 p., (« Bibliothèques »).

${ }^{20}$ Ibidem
} 
n'ont pas leur place dans les collections. La question de la légitimité de certaines lectures et de leur place en bibliothèque se pose encore aujourd'hui, par exemple sur l'achat en masse de certains best-sellers ou sur la présence de la presse people dans les collections ${ }^{21}$.

De plus, la participation du public aux collections soulève généralement des craintes d'atteinte à l'équilibre et à la neutralité des collections ${ }^{22}$. Les ingérences de certaines municipalités d'extrême-droite dans les acquisitions des bibliothèques municipales à la fin des années 1990 ont profondément ancré dans les consciences des professionnels le fait que la collection peut être manipulée à des fins politiques ou prosélytes. Suite à ces affaires, les associations professionnelles ont défendu, avec raison, le rôle du bibliothécaire comme garant de l'expression du pluralisme au sein de la collection ${ }^{23}$. Mais cela a créé en même temps une tendance à penser que la collection doit être uniquement l'affaire du professionnel et que toute tentative extérieure d'agir sur le contenu de la collection est une ingérence dangereuse.

Enfin, une autre frilosité professionnelle à faire participer l'usager à la collection tient à la vocation collective de l'offre documentaire de la bibliothèque. En effet, la bibliothèque doit pouvoir satisfaire toute la population d'un territoire et elle doit garder à l'esprit cette vocation collective lorsqu'elle répond à des demandes individuelles. Ainsi, les suggestions d'acquisition individuelles sont traitées en tenant compte de l'ensemble de la collection et de la population qu'elle doit desservir. Le rôle du bibliothécaire est là aussi primordial grâce à son point de vue global sur l'ensemble de la collection. En faisant participer les usagers à la construction de la collection, on risque donc de perdre de vue la vocation collective de l'offre documentaire, et de prioriser des demandes individuelles. Nous verrons dans la deuxième partie comment résoudre cette contradiction.

\section{B. Une injonction à la participation qui renouvelle les modes d'association des usagers au fonctionnement des bibliothèques}

Malgré les freins que nous venons d'évoquer, les formes de participation des usagers intéressent les bibliothèques, en réponse deux injonctions principales : donner l'image d'un service public plus proche et plus participatif, et se mettre au service de la communauté locale, comme le font les public libraries anglosaxonnes. Des modes de participation du public, sous forme de comités d'usagers, ont déjà été mis en place pour y répondre mais cette forme de participation est renouvelée par la notion de co-construction.

\footnotetext{
${ }^{21}$ Mathilde Peyrou, La presse people dans les bibliothèques municipales, Mémoire DCB sous la direction de Denis Merklen, Enssib, 2013.

${ }^{22}$ Voir par exemple cet échange sur le forum AgoraBib : «Participation du public aux acquisitions - Les publics - agoraBib », http://www.agorabib.fr/index.php/topic/45-participation-du-public-aux-acquisitions/ Consulté le 10 octobre 2013

${ }^{23}$ Voir par exemple le Code de déontologie du bibliothécaire élaboré par l'ABF en 2003, disponible ici : http://www.abf.asso.fr/6/46/78/ABF/code-de-deontologie-du-bibliothecaire Consulté le 10 novembre 2013.
} 


\section{L'exigence d'une plus grande proximité entre l'institution et les citoyens}

La participation des usagers à la définition et à l'organisation du service public s'impose de plus en plus comme un enjeu majeur des politiques publiques. En effet, certaines décisions des institutions publiques, certains services qu'elles proposent sont supposés inefficaces car mal adaptés à la réalité des situations. Le sociologue Antonio Tosi met en avant l'inertie que peut générer ce qu'il appelle la «théorie administrative des besoins », c'est-à-dire l'incapacité, dans laquelle se trouvent souvent les institutions de connaître intimement l'ensemble de leurs territoires, et d'en percevoir les besoins non exprimé ${ }^{24}$. Les décisions des institutions publiques sont également parfois considérés comme illégitimes, car imposées par le haut d'une manière qui ne prend pas en compte les intérêts de toute la population. Globalement, l'impression donnée peut être celle d'un centre de décision lointain, en décalage avec la réalité.

La participation est donc d'abord un enjeu d'efficacité pour les services publics, dont les bibliothèques font partie, afin de leur permettre d'être plus réactifs face aux besoins des usagers ${ }^{25}$. L'association de l'usager à la conception et à la mise en œuvre d'un service permet de faire la démarche d'essayer de se mettre à la place de l'usager, et de prendre en compte son point de vue. A force de travailler dans la bibliothèque, on peut avoir tendance à garder une vision uniquement professionnelle sur le fonctionnement de l'institution et se retrouver en décalage avec la perception qu'en ont les usagers. L'ouverture d'un espace d'échange, de délibération permet de mettre en perspective ces différents points de vue, et d'adapter le service proposé à la réalité de la situation.

La participation des citoyens est aussi un enjeu démocratique, qui s'inscrit dans un processus plus large de modernisation de l'action publique ${ }^{26}$. La prise de décision est parfois jugée plus légitime lorsque les citoyens y sont directement associés. Selon l'approche de la démocratie délibérative, dérivée de la philosophie de Jürgen Habermas, la prise de décision n'est légitime que si elle résulte d'un processus de délibération inclusif et équitable, auquel tous les citoyens peuvent participer et dans lequel ils sont conduits à coopérer librement ${ }^{27}$. Il s'agit donc de tenir compte des préoccupations des citoyens, notamment les populations socialement exclues dont la voix est rarement entendue. La participation ouvre des espaces de dialogue, qui contribuent à l'intensification de l'échange entre les citoyens et les institutions publiques.

L'association des citoyens au fonctionnement de l'institution doit enfin permettre d'accroître la proximité entre celle-ci et ses usagers. C'est un enjeu de citoyenneté, en ce sens que les citoyens doivent prendre conscience de leur droit à

${ }^{24}$ Giovanni Allegretti, «Les défis de la démocratie participative : Une refondation politique et culturelle », Le Monde diplomatique, octobre 2011.

${ }^{25}$ Gilles Jeannot, Les usagers du service public, Paris, France, Presses universitaires de France, 1998, 126 p., («Que sais-je? », 3359), p. 26.

${ }^{26}$ Marie-Hélène Bacqué et Mohamed Mechmache, «Pour une réforme radicale de la politique de la ville », Le pouvoir d'agir, 2013.

${ }^{27}$ Loïc Blondiaux et Yves Sintomer, op. cit. 
participer. Cependant, la participation ne doit pas être mise en place de façon «prétexte ». Ainsi, les citoyens doivent être considérés comme de véritables codécideurs et non comme de simples informateurs ${ }^{28}$. Dans le cas contraire, la participation risque d'être instrumentalisée afin de justifier, par les informations apportées dans l'espace de dialogue, des décisions imposées par le haut.

\section{L'influence des bibliothèques anglo-saxonnes tournées vers la «community»}

Les bibliothèques françaises s'intéressent à la co-construction également parce qu'elles sont influencées par le modèle anglo-saxon de public libraries, entièrement tourné vers son public, c'est-à-dire la communauté locale. Contrairement au modèle français, la public library américaine est construite autour de la notion de «community», que nous traduirons par «communauté » même si le mot français n'a pas la même richesse de sens ${ }^{29}$. La public library américaine s'est construite historiquement comme un établissement au service de la communauté locale ${ }^{30}$. La priorité est moins celle des collections et des services que celle de répondre aux besoins de la communauté. En ce sens, les collections, les services, les animations de la bibliothèque doivent être pensées pour l'usage de la communauté locale.

Ainsi, les public libraries anglo-saxonnes ont, parmi le personnel, des fonctions de community librarians, poste qui n'a pas de véritable équivalent en France. Le rôle des community librarians est de construire des relations entre la bibliothèque et la communauté locale. Ils mettent en place des programmes et des initiatives pour que les services et les ressources de la bibliothèque puissent servir aux segments de la communauté visés. Ils sont en contact avec les organismes extérieurs pouvant être liés avec la bibliothèque au niveau local et créent des partenariats avec ces acteurs qui ont déjà un rôle actif dans la communauté. Contrairement aux personnels en charge du service public qui n'ont pas nécessairement de qualification, les community librarians sont des bibliothécaires professionnels possédant un diplôme de premier cycle spécialisé dans les sciences de l'information et des bibliothèques ${ }^{31}$.

Les bibliothécaires anglo-saxons mettent en avant ce rôle central joué par la bibliothèque au sein de la communauté, notamment pour expliquer en quoi la public library est encore nécessaire à l'heure de la dématérialisation des contenus et des menaces des coupes budgétaires ${ }^{32}$. En effet, si la mission de la bibliothèque est à l'origine celle de fournir de l'information, elle joue aussi un rôle de

${ }^{28}$ Giovanni Allegretti, op. cit.

${ }^{29}$ Anne-Marie Bertrand, op. cit., p. 18.

${ }^{30}$ David Morris, «The Public Library Manifesto: Why Libraries Matter, and How We Can Save Them », YES! Magazine, 6 mai 2011.

${ }^{31}$ Lucie Henry, Les partenariats des bibliothèques publiques en France et au Royaume-Uni: Des instruments stratégiques?, Mémoire de Master 2 Sciences de l'Information et de la Communication Métiers du livre (option bibliothèque), Université Paris Ouest Nanterre La Défense, 2009, p. 18.

${ }^{32}$ Julie Biando Edwards, Melissa S. Rauseo et Kelly Rae Unger, « Community Centered: 23 Reasons Why Your Library Is the Most Important Place in Town », Public Libraries Online, 30 avril 2013. 
«ciment» de la communauté, parce qu'elle est un lieu d'échanges et de rencontres : "People may go to the library looking mainly for information, but they find each other there. ${ }^{33}$ (Les gens peuvent aller à la bibliothèque principalement pour rechercher de l'information, mais ils s'y retrouvent également entre eux.)

Les bibliothèques françaises peuvent s'inspirer de ce rôle de la bibliothèque anglo-saxonne comme ciment de la community. Elles sont en effet confrontées aujourd'hui à la problématique de «faire communauté » ${ }^{34}$. Alors qu'internet propose plus de contenus dématérialisés qu'une bibliothèque physique ne pourra jamais en contenir, la plus-value des bibliothèques territoriales, qui doit être mise en avant pour défendre leur existence, est celle d'animatrice de la communauté des usagers. En ce sens, la co-construction des collections peut être envisagée comme un moyen de donner à la bibliothèque ce rôle central au cœur de la communauté.

\section{Des premières formes de participation : les comités d'usagers}

Les bibliothèques françaises s'inspirent déjà de ce modèle anglo-saxon, et bien souvent aujourd'hui, on s'attache principalement à répondre aux besoins de la communauté. L'idée que la collection ne doit pas être pensée pour elle-même, mais bien par rapport à un public, s'est progressivement diffusée et est aujourd'hui plutôt bien admise dans la profession. En effet, une collection est étroitement dépendante d'un contexte et ne peut être analysée que par rapport au public qu'elle dessert. Il est courant et naturel aujourd'hui dans la plupart des bibliothèques de mener des analyses des prêts et des enquêtes de public, ceci dans le but de faire coïncider le contenu de la collection aux besoins des usagers. L'utilisation de cahiers de suggestions s'est également normalisée, afin de recueillir les avis et demandes des lecteurs, sans pour autant y accéder de manière automatique. Dès 1999, Jean-Luc Gautier-Gentès écrivait, à propos des systèmes de suggestions d'acquisitions :

Nous considérons comme acquis que ce mode d'association minimal va de soi, qu'il convient bel et bien non seulement d'entendre doléances et demandes, mais de les susciter, de les prendre en considération, d'y faire droit quand il y a lieu, d'y répondre dans tous les cas. ${ }^{35}$

Cette volonté de prendre en compte les demandes des usagers dans la construction des collections a parfois conduit à envisager des modes de participation des lecteurs, notamment sous la forme de comités d'usagers. L'instauration de ces comités a été proposée en réponse à trois besoins principaux :

${ }^{33}$ Cité dans Ibidem.

${ }^{34}$ Hervé Le Crosnier, «Web inscriptible et pratiques coopératives», in Franck Queyraud, Jacques Sauteron, (éds.). Outils Web 2.0 en bibliothèque: manuel pratique, éds. Franck Queyraud et Jacques Sauteron, Paris, Association des bibliothécaires de France, 2008, p. 111.

${ }^{35}$ Jean-Luc Gautier-Gentès, op. cit. 
le premier, évoqué plus haut, est la nécessité qui s'est fait sentir d'un rapprochement des institutions publiques avec leurs administrés ; le second est un besoin d'expertise extérieure sur certains domaines des collections; enfin, l'implication des citoyens a été envisagée en réponse à un besoin d'une légitimation démocratique de l'action de la bibliothèque.

D'abord, nous avons vu que la participation des usagers à la définition et à l'organisation du service public s'est imposée comme un enjeu majeur des politiques publiques. Dès les années 1980, des «comités de sages » ont été instaurés pour encadrer les décisions publiques et y apporter le point de vue de personnalités choisies pour leurs compétences ou leurs fonctions ${ }^{36}$. Au niveau local, il a été envisagé d'associer les usagers au fonctionnement de certaines institutions dans le contexte de réforme de l'administration à la fin des années 1990 - début des années 2000. Suite à la loi Chevènement du 12 juillet 1999 qui institue la possibilité de créer des « comités consultatifs sur toutes affaires d'intérêt intercommunal », Hughes van Besien s'interrogeait en 2000 sur les avantages et inconvénients d'instaurer ce type de structure pour les bibliothèques intercommunales ${ }^{37}$.

Ensuite, le bibliothécaire, s'il est spécialiste de la gestion des documents, n'est pas expert dans chacun des thèmes de la collection. Pour certains sujets, il peut avoir recours à des partenaires, reconnus pour leur compétence dans un domaine et à même de le conseiller dans ses acquisitions : pour les bibliothèques de lecture publique, ce sont des experts-conseils identifiés parmi les usagers de la bibliothèque et les membres de la collectivité; pour les bibliothèques universitaires, on les appelle commissions scientifiques consultatives de la documentation $^{38}$. Dans les deux cas, leur rôle est d'apporter un éclairage sur un domaine qu'ils maîtrisent, afin d'aider le bibliothécaire dans sa sélection. Le professionnel doit dans ce cas vérifier que les conseils de ces «partenairesexperts » sont bien adaptés au public de sa bibliothèque, qu'il connaît mieux.

La création de comités d'usagers a également été évoquée dans un autre but, celui d'appuyer les choix des bibliothécaires et de leur fournir un soutien dans une optique de légitimation démocratique face aux pressions des élus :

Si les risques que présente un comité consultatif sont réels, (...) il est également susceptible (...) de présenter des avantages. Ainsi, il peut aider le directeur de la bibliothèque à faire face aux pressions d'une municipalité trop insistante. Ou encore, dans le cas (...) de documents dont l'éventuelle acquisition peut poser problème, quelle que soit la nature de ce problème, il peut être le lieu d'un débat utile et qui ne se conclura pas nécessairement par le choix de la solution la plus malheureuse. Il peut enfin appuyer les demandes de moyens présentées par la bibliothèque. ${ }^{39}$

\footnotetext{
${ }^{36}$ Loïc Blondiaux et Yves Sintomer, op. cit.

${ }^{37}$ Hughes Van Besien, op. cit.

${ }^{38}$ Bertrand Calenge, Conduire une politique documentaire, Paris, France, Éd. du Cercle de la librairie, 1999, 386 p., («Bibliothèques »), p. 202.

${ }^{39}$ Jean-Luc Gautier-Gentès, op. cit.
} 
En effet, aucun texte ne donne au directeur de bibliothèque la responsabilité du contenu de la collection, qui revient légalement à l'élu. Bien que le directeur organise la politique documentaire de son établissement dans les faits, la responsabilité de la politique documentaire constitue une «zone grise », c'est-àdire une zone où les frontières entre la compétence technique du fonctionnaire territorial et la légitimité politique de l'élu sont indéterminées ${ }^{40}$. Un comité représentatif d'usagers peut dans ce cas être un atout déterminant pour justifier une politique documentaire auprès de la tutelle.

On le voit donc, des modes de participation des usagers sous la forme de comités institutionnalisés ont déjà été envisagés. Cependant, des projets de participation des usagers naissent aujourd'hui, dans une optique renouvelée : l'idée n'est plus d'assister le bibliothécaire dans ses choix documentaires par un comité consultatif, constitué de représentants choisis en raison de la fonction qu'ils occupent ou de leurs compétences. Au lieu de passer par un système de représentation, on construit la collection directement avec les usagers, sans institutionnalisation de cette participation.

\section{DEFINIR LA CO-CONSTRUCTION DES COLLECTIONS}

La co-construction des collections, au sens où nous l'entendons dans ce mémoire, peut se définir comme la situation dans laquelle les citoyens (usagers ou potentiels usagers de la bibliothèque) participent activement, dans le cadre d'une démarche de construction en commun, à une ou plusieurs étapes de la gestion d'une collection ou d'un segment de celle-ci, et dans laquelle la bibliothèque leur transfère le processus de décision, dont elle a préalablement défini l'objectif et le cadre.

\section{A. Ce que la co-construction des collections n'est pas}

En suivant cette définition, nous pouvons exclure plusieurs domaines qui ne relèvent pas, à notre sens, de la co-construction des collections.

\section{Tous les cas où l'usager reste passif}

Les responsables de la politique documentaire dans les bibliothèques s'efforcent d'adapter la collection aux besoins et attentes du public. Pour cela, ils analysent les statistiques de prêts et de réservations et/ou conduisent des enquêtes

\footnotetext{
${ }^{40}$ Ibidem.
} 
de public. Les bibliothécaires responsables des collections consultent ces statistiques pour identifier les documents les plus empruntés et ceux qui au contraire ne sortent jamais, et déduisent à partir de cela les besoins du public. Certains établissements mettent également en place des systèmes d'acquisitions automatiques de documents réservés plus de $\mathrm{x}$ fois. Les politiques documentaires peuvent aussi prendre en compte les caractéristiques du public de la bibliothèque à travers des analyses statistiques et des enquêtes.

Ce travail sur les statistiques a pu donner lieu à une « illusion technophile ${ }^{41}$, selon laquelle la politique documentaire serait une science appliquée utilisant des formules et équations normalisées pour répondre aux besoins d'un public. Cette vision est remise en cause aujourd'hui, mais l'analyse des statistiques reste fondamentale pour gérer et organiser une collection. Cela importe également pour justifier une politique documentaire, qui comme toute politique publique doit apporter des résultats. La question des indicateurs - et de leurs biais - reste cependant ouverte.

Le travail sur les indicateurs permet donc au gestionnaire de collection d'adapter les acquisitions aux besoins des usagers. Mais ce n'est pas, à notre sens, une forme de co-construction des collections, puisque toute la démarche est conduite par le bibliothécaire et l'usager est cantonné dans un rôle passif.

\section{Toutes les formes de participation qui n'impliquent pas de démarche de construire en commun}

La co-construction des collections permet de rapprocher l'offre de la bibliothèque des besoins et attentes des usagers. Mais, à travers la démarche de construire ensemble, elle permet également de créer des liens, de donner conscience aux usagers de leur droit à participer, de rapprocher les usagers des bibliothécaires. C'est pourquoi certaines démarches de participation des usagers aux collections ne sont pas de la co-construction au sens où nous l'entendons ici.

Ainsi, le modèle des «patron driven acquisitions » (PDA) ou «acquisitions conduites par les usagers » n'entre pas selon nous dans cette catégorie. La PDA est un système qui permet à la bibliothèque, par un accord avec un fournisseur, de proposer une offre très large d'ebooks dans son catalogue et de n'acheter que les livres qui sont consultés un certain nombre de fois par les usagers. Dans ce modèle, la collection est donc uniquement constituée par les usagers et par leurs comportements de lecture. Le système de PDA a été expérimenté par plusieurs bibliothèques universitaires aux Etats-Unis ${ }^{42}$ et est également envisagé dans des bibliothèques de lecture publique. Cependant, dans la plupart des modèles de PDA, les usagers ne se rendent même pas compte qu'ils participent à l'achat du livre en le consultant. S'ils participent effectivement à la construction de la collection, la démarche de construire ensemble, conjointement entre la bibliothèque et l'usager, est absente de ce système.

${ }^{41}$ Caroline Rives, Bertrand Calenge, «Bibliothèques et politiques documentaires à l'heure d'internet », Bulletin des Bibliothèques de France, vol. 54 / 3, 2009, p. 102.

42 David A. Swords, Patron-driven acquisitions: history and best practices, Berlin, Allemagne, 2011, 205 p., («Current topics in library and information practice»). 
De la même manière, les dons des usagers à la bibliothèque peuvent être considérés comme de la co-construction seulement dans la mesure où ils font l'objet d'une démarche concertée. Ainsi, la plupart des dons reçus aujourd'hui par les bibliothèques ne sont pas de la co-construction : l'usager apporte des livres qu'il souhaite donner et la bibliothèque les trie en choisissant selon ses propres critères ceux qu'elle souhaite garder pour sa collection. En revanche, dans le projet de future médiathèque de Lezoux, les dons des habitants sont envisagés d'une autre manière. Une résidence menée par le collectif « La $27^{\mathrm{e}}$ région » a permis de faire un diagnostic des usages de lecture sur le territoire. Il est apparu que le point lecture actuel de Lezoux propose 40000 documents, mais que sur le territoire intercommunal, chez les habitants, on recense 1,2 millions de documents. Sept à huit habitants de l'intercommunalité ont été identifiés comme de gros lecteurs, et donc acheteurs, de romans policiers. Ces personnes rencontrées par le collectif sont prêtes à faire don de leurs ouvrages, une fois les avoir lus, à la communauté. La future médiathèque envisage donc, avec ces habitants, de constituer le fonds de romans policiers grâce à leurs dons, ce qui lui permettrait notamment d'être plus réactive sur l'achat de nouveautés.

\section{Toutes les formes de participation des usagers où la décision appartient au bibliothécaire}

Les suggestions d'acquisition ne sont pas, à notre sens, considérées comme une forme de co-construction des collections. Celles-ci sont souvent évoquées en premier comme le moyen le plus simple et le plus courant de faire participer le lecteur aux collections. Cependant, dans ce système, la relation du bibliothécaire au lecteur reste inégale. Que les suggestions soient faites sous forme écrite à travers un cahier ou un formulaire en ligne, ou bien sous forme orale lors des discussions au bureau de prêt, c'est toujours au bibliothécaire que revient la décision :

[D]ans ce mode d'association du public à la marche de la bibliothèque, le public est cantonné au plus petit rôle possible. Quel que soit son nom, doléance ou suggestion, sa prise de parole tient peu ou prou de la supplique. L'usager propose, le bibliothécaire dispose. ${ }^{43}$

De plus, la parole donnée au lecteur, affichée comme libre, est en réalité très encadrée, comme le fait remarquer Olivier Chourrot :

[Il] convient de délaisser l'image idyllique du lecteur qui rédige en toute liberté une demande qui, sauf cas exceptionnel, sera exaucée. La présentation matérielle, l'emplacement, le type de mise à disposition d'un cahier de suggestions sont autant de contraintes qui, s'imposant au lecteur, limitent sa capacité d'expression. En définissant tel ou tel mode de participation du lecteur, le bibliothécaire délimite le dicible et l'exprimable. Autrement dit, il

${ }^{43}$ Jean-Luc Gautier-Gentès, op. cit. 
confectionne sur mesure l'outil de participation aux acquisitions qui convient à son établissement. ${ }^{44}$

La co-construction des collections implique donc, pour le bibliothécaire, de transférer la prise de décision, même s'il définit le cadre de cette délégation.

\section{B. De la participation à la co-construction}

La co-construction ne se résume pas à la simple participation, c'est une ambition plus importante.

\section{Passer d'un usager passif à un usager actif, acteur puis moteur de la collection}

Dans la co-construction, l'usager devient actif, dans une démarche de construire ensemble.

Il existe plusieurs degrés d'implication et de participation du public dans la bibliothèque, que l'on peut désigner sous le vocable suivant: l'usager actif, l'usager acteur et l'usager moteur de la collection.

Dans le premier cas, l'usager devient actif, s'implique dans la constitution des collections mais cette participation est entièrement organisée et menée par la bibliothèque. Par exemple, la bibliothèque crée un cercle de lecteurs qui participera aux offices de lecture pour tel segment de la collection. C'est elle qui organise le recrutement des lecteurs, la communication autour du projet, elle fixe et mène les réunions du club et elle pré-choisit les livres qui seront présentés lors de l'office de lecture participatif. Les ouvrages choisis par les lecteurs sont ensuite soumis à l'appréciation des bibliothécaires qui en valident l'achat ou non.

Le degré suivant est celui de l'usager acteur: la bibliothèque conçoit conjointement avec les usagers un projet de participation des lecteurs à la construction des collections. Dans ce cas, les usagers sont également impliqués dès la phase de définition et d'organisation du projet. Par exemple, la bibliothèque mène en amont du projet une réflexion conjointement avec les habitants du territoire sur les besoins de sa population en termes de collection. Cette réflexion mène à l'organisation d'un fonds participatif, dont le nom est choisi par les usagers. La bibliothèque définit conjointement avec les lecteurs le contenu de ce fonds, mais aussi la façon dont les ouvrages seront mis en espace. Les bibliothécaires et les lecteurs écrivent ensemble une charte des collections qui formalise l'orientation de ce fonds et fixe des principes pour en organiser la constitution.

Dans le troisième modèle, celui de l'usager moteur de la collection, la bibliothèque s'efface et laisse les usagers gérer et organiser le projet sans

${ }^{44}$ Olivier Chourrot, «La place du lecteur dans le processus d'acquisitions », Bulletin d'informations de l'ABF, $\mathrm{n}^{\circ} 175,1998, \mathrm{p} .42-44$. 
intervention de sa part. Le rôle de la bibliothèque n'est plus d'organiser ni de coordonner, mais seulement d'offrir le cadre dans lequel la participation peut s'exercer. Par exemple, la bibliothèque laisse une étagère à disposition du public pour en faire un fonds participatif. Les habitants viennent y déposer des livres qu'ils souhaitent partager avec la communauté. Autre exemple, la bibliothèque met à disposition des habitants un centre d'écriture et de publication ou lab d'écriture, où les usagers peuvent imprimer et relier leurs écrits sous forme de livres qui peuvent être ensuite intégrés dans la collection.

Ces trois modèles d'implication des lecteurs sont définis de manière schématique et ils ne sont pas toujours si distincts en réalité. Ils ont cependant le mérite de définir des grandes étapes qui séparent le user centric model du user driven model ${ }^{45}$. Le user centric model signifie, de façon littérale, le «modèle centré sur l'utilisateur »: dans ce modèle, on définit les collections en fonction des besoins et attentes des usagers. Le user driven model, ou "modèle dirigé par l'utilisateur » est le modèle le plus poussé en matière de participation des usagers et correspond au troisième cas : la bibliothèque se contente de fournir le cadre à la participation et celle-ci est organisée et conduite par les lecteurs eux-mêmes.

Le terme d' "usager», dans ce contexte, peut être repensé. Celui-ci sousentend en effet que le public reste dans un rôle passif, dans une posture de consommateur de bibliothèque. Gilles Jeannot écrit, à propos des usagers du service public : "L'usager apparaît en première lecture comme une figure antithétique $d u$ citoyen entendu en ce sens, tant comme consommateur passif que comme assisté. ${ }^{46}$. Plutôt que d' «usager», il conviendrait mieux de parler d' « habitant» ou de «citoyen ${ }^{47}$. Le premier terme désigne une population plus large que les seules personnes qui viennent à la bibliothèque et implique, de la part de la bibliothèque, une volonté de s'adresser aussi aux publics qui lui échappent. Le terme de «citoyen » est également plus approprié car en s'impliquant dans la bibliothèque, le public participe à construire la vie de la cité.

\section{Renverser la logique de constitution des collections : ne plus construire pour, mais avec}

Co-construire les collections implique également de renverser le processus de construction des collections: au lieu d'essayer d'anticiper les demandes des lecteurs en imaginant à leur place ce qu'ils souhaitent trouver à la bibliothèque, on définit avec eux, dans une démarche de construire en commun, le contenu de la collection. Deux points nous paraissent importants pour définir cette logique de constitution des collections : concevoir la collection en fonction des usages du public, et se placer de leur point de vue en les impliquant dans la démarche de construction.

\footnotetext{
${ }^{45}$ Lionel Dujol, « La bibliothèque, un espace de participation », 2013. Diapo 80

${ }^{46}$ Gilles Jeannot, op. cit., p. 114.

${ }^{47}$ Intervention de Françoise Dublosclard lors de l'atelier «Une vision désirable de la future médiathèque nouveaux usages et démarches participatives » dans le cadre du 59e Congrès ABF à Lyon, jeudi 6 juin 2013
} 
La vocation d'une collection de bibliothèque de lecture publique, excepté pour certains établissements, n'est pas de proposer une offre encyclopédique, en achetant «un peu de tout ». Une collection n'a pas de valeur pour elle-même, elle se définit toujours par rapport à un public. En faisant participer les usagers à la réflexion sur la collection, on se place au plus près des pratiques et des usages de lecture de la communauté desservie par la bibliothèque. Il convient donc de poser la question des collections de la bibliothèque en fonction des usages du territoire et non par rapport à ce qu'une bibliothèque « se doit d'offrir » dans l'absolu.

Afin d'identifier les usages et les pratiques de lecture, il ne suffit pas de mener des enquêtes de public. Il convient d'associer directement les habitants à la discussion, en les faisant participer à la conception du projet et en leur laissant la possibilité de mettre en pratique leurs idées. Pour cela, on peut mettre en place une démarche de design de services ou design intégré ${ }^{48}$. Cette démarche consiste à se placer, pour évaluer ou améliorer un service, du point de vue de l'utilisateur final :

On ne cherche plus à imposer des produits de consommation, mais à comprendre les attentes et les besoins des utilisateurs. Ceux-ci ne sont d'ailleurs plus perçus comme de simples consommateurs, mais comme des acteurs à part entière. ${ }^{49}$

Le design de services, issu au départ du monde économique, est désormais également mis en œuvre dans les services publics :

Le design de services répond à un objectif : comprendre le comportement des usagers et saisir leurs attentes. (...) Mais le design de services dépasse également le cadre de l'entreprise et fait des émules. Le design social, autre tendance actuelle du design, en découle et vise - très largement - la conception de nouveaux modes relationnels entre les citoyens, pour un «vivre ensemble » plus intelligent, plus solidaire également. ${ }^{50}$

En rencontrant les habitants, en leur permettant d'imaginer, d'expérimenter et de définir les usages de lecteurs, il est possible de faire entrer ces pratiques en résonnance dans les collections de la bibliothèque.

\section{Passer d'une logique verticale à un rapport horizontal avec l'usager}

La co-construction implique enfin de repenser la façon dont le lecteur appréhende la collection.

\footnotetext{
${ }^{48}$ Marie D. Martel, «Construire et rénover des bibliothèques en Amérique en 2012 : ça prend une communauté », Bibliomancienne, 2012.

${ }^{49}$ Antoine Bayet et Yvane Jacob, «Le «design de services » : quand le design veut permettre de mieux vivre ensemble », Regards sur le numérique, 2010.

${ }^{50}$ Ibidem.
} 
Le premier pas est de sortir du modèle de l'offre, qui induit une relation verticale entre le bibliothécaire et l'usager. Ce modèle repose sur le postulat selon lequel il revient à la bibliothèque de guider le lecteur en lui proposant une offre documentaire de qualité. Dans le domaine des sciences, ce modèle de transmission de l'information s'appelle l'information deficit model ou simplement le deficit model : l'expert, le savant produit une connaissance qui descend vers le public, profane et ignorant ${ }^{51}$. Mais ce modèle est remis en cause dans le nouveau contexte d'accès à l'information: d'un modèle directionnel où l'information est produite par les médias traditionnels (radio, télévision, imprimé), on est passé à un modèle de circulation en réseau où l'information est produite, diffusée et commentée par les lecteurs eux-mêmes ${ }^{52}$. Michel Callon appelle le deficit model le modèle de l'instruction publique et propose de le remplacer par le modèle du débat public ou le modèle de la coproduction des savoirs ${ }^{53}$. Dans ce dernier modèle, les connaissances des profanes sont également considérées comme légitimes et les savoirs sont coproduits par scientifiques et simples citoyens.

Dans l'approche de la co-construction, on considère effectivement que l'usager peut être une richesse, qu'il a des connaissances, des compétences dont on peut vouloir bénéficier. Ces compétences ne sont pas toujours telles qu'on les entend habituellement :

[Dans l'approche de la co-conception,] on considère que l'expérience du quotidien acquise par les utilisateurs est aussi importante que l'expertise des spécialistes $^{54}$.

En d'autres termes, aucune compétence particulière n'est nécessaire : on considère qu'être usager d'un service suffit pour avoir le droit d'exprimer son avis et ses attentes par rapport à celui-ci, et que ceux-ci soient pris en compte.

Pour les bibliothèques, co-construire les collections implique de sortir d'une logique verticale où le bibliothécaire propose une offre au lecteur, qui ne peut intervenir que de façon marginale sur le contenu de la collection, par exemple à travers les suggestions d'acquisition.

Sortir de la logique de l'offre a deux principales implications pour les bibliothèques. D'abord, cela revient à reconnaître que les bibliothécaires ne sont pas des experts dans tous les domaines des collections qu'ils ont à gérer. Certains usagers ont des compétences plus poussées sur certains sujets et les bibliothèques gagneraient à exploiter ces domaines de connaissance. Ensuite, tous les lecteurs sont légitimes à dire ce qu'ils souhaitent trouver dans la collection. Nous insistons cependant sur un point: le bibliothécaire et le lecteur sont mis sur un pied

\footnotetext{
${ }^{51}$ Marine Soichot, «Le deficit model : "Les gens ne savent rien, il faut y remédier" », Pris $(m)$ e de tête, 2009.

${ }^{52}$ Hervé Le Crosnier, «Web inscriptible et pratiques coopératives », in Franck Queyraud, Jacques Sauteron, (éds.). Outils Web 2.0 en bibliothèque: manuel pratique, éds. Franck Queyraud et Jacques Sauteron, Paris, Association des bibliothécaires de France, 2008, p. 107-116.

${ }^{53}$ Marine Soichot, op. cit.

54 Vidéo de la $27^{\mathrm{e}}$ région, «Méthodes ingénieuses pour Régions heureuses (3/3)», 2013. http://www.youtube.com/watch?v=2ZxO5ke0tmw\&feature=youtube gdata player Consulté le 11 novembre 2013
} 
d'égalité pour co-créer la collection, mais le bibliothécaire reste reconnu comme professionnel de l'information, avec une vision globale sur la collection et le public qu'elle dessert. Nous développerons ce point dans la deuxième partie.

\section{Typologie des formes de co-construction des collections}

Selon nous, la co-construction des collections avec les usagers peut s'exercer dans quatre domaines différents, qui ne sont pas exclusifs les uns des autres.

\section{La participation des usagers aux acquisitions}

La co-acquisition consiste à faire participer les usagers à la sélection des documents achetés par la bibliothèque. Silvère Mercier, en 2008, proposait dans un article de son blog Bibliobsession de fusionner les clubs de lecteurs et les offices de lecture et de permettre aux usagers de choisir les documents acquis par la bibliothèque lors d'offices de lecture participatifs ${ }^{55}$. C'est souvent sous cette forme que sont organisés les projets de participation des lecteurs aux acquisitions. Par exemple, le club Lékridézados ${ }^{56}$ à Montreuil est à la fois un club de lecture et un office participatif. Les adolescents qui y participent lisent et choisissent les ouvrages qui seront acquis pour le fonds "Passage», dédié à ce public. Ils produisent également des critiques, écrites ou filmées, de leurs dernières lectures. A la bibliothèque de Chemillé, un cercle d'amateurs de musique, destiné au départ à proposer des animations autour d'un projet de discothèque qui allait ouvrir, s'est transformé en cercle d'acquisitions participatives ${ }^{57}$. Une partie du budget de ce nouveau fonds a été consacré à l'achat de titres proposés par les membres du club.

\section{La participation des usagers à la gestion et l'organisation de la collection}

Cela consiste à faire participer les usagers à tout ce qui concerne la gestion et l'organisation des collections: le classement, le référencement, l'indexation, l'agencement des collections en salle, l'amélioration de l'océrisation de textes numérisés, voire le désherbage, etc.

Par exemple, certaines bibliothèques utilisent les possibilités de classification collaborative des contenus, appelée folksonomie, sur internet. Ainsi, la bibliothèque municipale de Toulouse a mis en ligne un fonds de photographies

\footnotetext{
${ }^{55}$ Silvère Mercier, « Les bibliothèques participatives restent à inventer ! », Bibliobsession, 2008.

${ }^{56}$ http://fr.scribd.com/doc/101647451/rencontre-avec-le-club-lecture-de-montreuil-lekridezados Consulté le 20 octobre 2013

${ }^{57}$ Message de William Noyer sur la liste de diffusion discothecaires_fr@listes.ircam.fr «RE: Achat de CD par un groupe d'usagers ? », 5 avril 2014
} 
d'Eugène Trutat sur Flickr ${ }^{58}$ (site de partage en ligne d'images et de photographies), en suivant l'exemple de la bibliothèque du Congrès américain ${ }^{59}$. L'objectif était que les internautes puissent ajouter des tags et des commentaires sur les photographies, et ainsi participer à l'identification des lieux photographiés par Trutat ${ }^{60}$. Plusieurs bibliothèques font également participer les communautés d'internautes à des projets de correction collaborative. Le projet Trove ${ }^{61}$, de la National Library of Australia a réussi à créer une communauté d'internautes particulièrement active pour la correction de l'océrisation d'articles de journaux numérisés. Le lab de la New York Public Library ${ }^{62}$ fait aussi souvent appel aux bonnes volontés des internautes pour des projets de correction collaborative : le projet «What's on the menu? ${ }^{63}$ par exemple a recours aux internautes pour transcrire les plats de menus photographiés parmi sa collection de 45000 menus de restaurants datant des années 1840 à nos jours.

Autre exemple, cette fois pour des collections physiques, la bibliothèque Hoorn aux Pays-Bas a fait participer les enfants à la création de mobilier pour l'espace jeunesse et également au classement et à l'agencement de ses collections en salle. Les collections de cette bibliothèque étaient auparavant classées par ordre alphabétique. Les enfants ont choisi de les classer thématiquement, avec leur propre logique. Par exemple, les ouvrages de peinture, classés par les bibliothécaires en section «sport et loisirs » ont été déplacés par les enfants dans la section « histoire » car, selon eux, tous les peintres connus sont morts donc il est normal de placer les livres de peinture avec les livres d'histoire ${ }^{64}$.

\section{La co-création de contenus}

Une autre forme de co-construction des collections, plus difficile à appréhender et à mettre en place, est l'intégration au sein de la collection de contenus produits par les usagers eux-mêmes :

Le contenu généré par les utilisateurs (en anglais User-generated content, ou UGC) se réfère à un ensemble de médias dont le contenu est principalement, soit produit soit directement influencé par les utilisateurs

${ }^{58}$ http://www.flickr.com/people/bibliothequedetoulouse/ Consulté le 20 octobre 2013

${ }^{59}$ http://www.flickr.com/photos/library_of_congress/ Consulté le 20 octobre 2013

${ }^{60}$ Patrick Hernebring, «Présence sur Flickr: l'expérience toulousaine », in Bibliothèque 2.0 à l'heure des médias sociaux, Paris, France, Éd. du Cercle de la librairie, 2012, («Bibliothèques »).

${ }^{61} \mathrm{http}: / /$ trove.nla.gov.au/ Consulté le 11 novembre 2013

${ }^{62}$ http://www.nypl.org/collections/labs Consulté le 11 novembre 2013

${ }^{63}$ http://menus.nypl.org/ Consulté le 11 novembre 2013

${ }^{64}$ Intervention de Miranda Corbiere, «Children's participation in the architecture of the library », Enssib, 2012, (« Journée d'études "Enfants et jeunes en bibliothèque : regards européens" »). 
finaux. Il est opposé au contenu traditionnel produit, vendu ou diffusé par les entreprises de média traditionnelles ${ }^{65}$.

Plusieurs types de projets font appel à des contenus produits par les usagers. Le projet «Photographes en Rhône-Alpes » ${ }^{66}$, impulsé par la bibliothèque municipale de Lyon, a pour objectif de compléter les collections de photographies numérisées de la bibliothèque. Celle-ci a fait appel aux contributions des photographes amateurs et professionnels, afin de constituer conjointement avec eux les mémoires collectives de la Région Rhône-Alpes. La grande base de photographies ainsi constituée mêle les collections numérisées de la bibliothèque municipale de Lyon et les contenus produits par les contributeurs. Ce projet s'accompagne d'un référencement contributif puisque les internautes sont invités à aider à décrire les photographies pour mieux les identifier.

Autre exemple, des bibliothèques organisent parfois des projets de « human library » ou «human book», traduits par «bibliothèque humaine » ou «bibliothèque vivante » en français. Dans ce cas, c'est l'usager lui-même qui devient une partie de la collection. Les «human book», littéralement livres humains, sont des personnes identifiées sur le territoire comme ayant une histoire particulière, un métier particulier, une caractéristique qui leur est propre. Ces personnes, volontaires, se rendent à la bibliothèque et peuvent être « empruntés » par un lecteur qui réserve un créneau horaire pour rencontrer le «livre humain » et échanger avec lui.

De nombreux autres moyens d'intégrer à la collection des contenus produits par les usagers sont à inventer. Par exemple, la médiathèque Monnaie et la MJC Monnaie ont organisé des ateliers de cuisine avec des femmes du quartier. Ces échanges autour de plats de différents pays ont donné lieu à la production d'un livre de recettes «Melting popotes ${ }^{67}$, évidemment mis en valeur dans la médiathèque.

\section{La médiation participative autour des collections}

La médiation participative en rapport avec les collections consiste à choisir avec les usagers les documents à mettre en avant et à valoriser.

Plusieurs bibliothèques permettent à leurs lecteurs de donner leurs avis sur les livres et de rédiger quelques lignes de critique qui seront collées au dos de l'ouvrage et permettront aux autres lecteurs de faire leur choix. La médiathèque Boris Vian de Chevilly-Larue (94) a également mis en place une opération «pochettes surprises ${ }^{68}$ au moment de Noël : les usagers pouvaient constituer une pochette de quatre documents qu'ils souhaitaient partager. Les autres lecteurs

\footnotetext{
65 Définition $\mathrm{du}$ «contenu généré par les utilisateurs » sur wikipédia : http://fr.wikipedia.org/wiki/Contenu_g\%C3\%A9n\%C3\%A9r\%C3\%A9_par_les_utilisateurs Consulté le 11 novembre 2013

${ }^{66}$ http://collections.bm-lyon.fr/photo-rhone-alpes Consulté le 11 novembre 2013

${ }^{67} \mathrm{http}: / /$ bonnerecette.wordpress.com/a-propos/ Consulté le 12 novembre 2013

${ }^{68}$ David Sandoz, Repenser la médiation culturelle en bibliothèque publique participation et quotidienneté, Mémoire DCB sous la direction de Bernard Huchet, Enssib, 2010, p. 37.
} 
empruntaient ces pochettes, placées sous un sapin, en plus de leurs documents habituels mais sans avoir connaissance de leur contenu avant de les ouvrir chez eux. A la bibliothèque Louise Michel ${ }^{69}$ à Paris, les habitants sont étroitement associés aux animations de la bibliothèque. Des usagers volontaires participent à une «ciné-habitants», où tous les mois, un volontaire choisit un film de la collection qu'il souhaite diffuser et présenter ${ }^{70}$.

D'autres systèmes sont à inventer : par exemple, la bibliothèque peut, sur une thématique particulière, proposer aux usagers d'aller choisir eux-mêmes, parmi les collections, les documents qui leur paraissent intéressant de rattacher à cette thématique. Les documents ainsi choisi seraient mis en avant de la même manière que s'ils avaient été sélectionnés par les bibliothécaires.

La co-construction des collections s'inscrit donc comme une forme renouvelée de la participation des citoyens au fonctionnement de la bibliothèque. Elle peut prendre des formes variées, comme nous l'avons montré ici. Dans tous les cas cependant, elle implique de repenser la relation de la bibliothèque à la communauté ce qui soulève de nombreuses problématiques que nous allons explorer maintenant.

${ }^{69}$ http://equipement.paris.fr/bibliotheque-louise-michel-6320 Consulté le 23 octobre 2013

${ }^{70} \mathrm{http}$ ://patricialemoulec.wordpress.com/les-usagers-acteurs-de-leur-bibliotheque/ Consulté le 23 octobre 2013 


\section{PARTIE 2 : LES ENJEUX DE LA CO- CONSTRUCTION DES COLLECTIONS}

Co-construire, certes, mais pourquoi ? Quel intérêt les bibliothèques auraientelles à impliquer leurs usagers dans l'organisation des collections ? Les bibliothécaires sont des professionnels, dont le métier est, entre autres, celui de gérer les collections : pourquoi vouloir transférer cette compétence aux usagers ? Ne risque-t-on pas de perdre le contrôle des collections ? Quel est la place du bibliothécaire dans la co-construction ? Comment concilier les multiples intérêts d'usagers et d'usages différents ? De multiples enjeux, qui découlent de la nouveauté intellectuelle et organisationnelle engendrée par la co-construction, sont à interroger et à préciser.

\section{Penser autrement la Collection}

Co-construire les collections avec les usagers change la façon d'appréhender les ressources de la bibliothèque : la collection est envisagée avant tout en fonction des usages et du public, et les usagers sont considérés non plus comme une «demande » mais comme des ressources potentielles qui peuvent être mobilisées pour le développement de la collection.

\section{A. Une collection plus proche de son public}

Impliquer le public dans les collections permet d'abord de mieux répondre aux besoins et attentes des lecteurs.

La bibliothèque est soumise, comme les autres administrations publiques, à une tension entre une quête de performance, qui passe par l'uniformisation des services proposés, et l'adaptation aux besoins des usagers, qui signifie ne plus se limiter à des prestations rigides ${ }^{71}$. Pour les collections, cela signifie ne pas proposer partout la même offre, mais adapter la sélection à la population desservie. Pour Bertrand de Quatrebarbes, il est important d'ajuster le service offert aux besoins des usagers. Selon lui, les logiques institutionnelles verticales dans les services publics impliquent un gaspillage d'intelligence et de ressources si elles prennent mal en compte les besoins. S'appuyer sur « l'usager-citoyen » permettrait de sortir de ces logiques verticales, et de proposer un service public plus légitime et efficace ${ }^{72}$.

\footnotetext{
${ }^{71}$ Gilles Jeannot, op. cit., p. 17.

${ }^{72}$ Bertrand de Quatrebarbes et Claude Gruson, Usagers ou clients?: écoute, marketing et qualité dans les services publics, Paris, France, Éd. d’organisation, 1998, 391 p., («Collection Service public »), p. 377.
} 
Selon Anne-Marie Bertrand, une des raisons de l'abandon des bibliothèques tient au fait que les politiques d'acquisition ne correspondent pas toujours aux besoins locaux ${ }^{73}$. Co-construire les collections avec les usagers peut être envisagé comme un moyen pour mieux cibler les besoins de la population.

\section{Rapprocher le contenu de la collection des besoins et attentes du public}

Les bibliothèques de lecture publique n'ont pas une vocation encyclopédique dans la constitution de leurs collections. Au contraire, la logique de vouloir mettre « un peu de tout partout » est inefficace : certains fonds restent inutilisés alors que d'autres ne sont pas assez développés par rapport aux attentes du public. C'est particulièrement vrai pour les petites et moyennes bibliothèques qui n'ont pas de budget assez conséquent pour pouvoir proposer une collection encyclopédique, et qui risqueraient d'offrir une collection médiocre dans tous les domaines. C'est suite à ce constat que la bibliothèque de la Croix Rousse $\left(4^{\mathrm{e}}\right.$ arrondissement de Lyon) a souhaité associer ses usagers à la constitution d'une nouvelle discothèque. La position de cette bibliothèque au sein du réseau des bibliothèques de la ville de Lyon a immédiatement conduit à écarter l'idée de faire une discothèque proposant tous les styles de musique : d'une part parce que le budget était trop restreint ; d'autre part parce que d'autres bibliothèques à Lyon proposent des collections de disques plus conséquentes et diversifiées, et sont mieux à même de répondre à des besoins particuliers. L'objectif de la participation des usagers était donc de rendre les acquisitions conformes aux demandes du public.

Vouloir proposer une offre encyclopédique de manière indifférenciée semble d'autant moins utile à l'heure d'internet, alors que la bibliothèque se trouve concurrencée dans son offre documentaire. Internet propose une abondance de contenus qu'une bibliothèque physique ne peut égaler en quantité. Pour être une alternative, la bibliothèque doit penser sa collection pour l'usager en proposant des contenus plus ciblés et mieux adaptés à ses besoins et permettre ce que permet le web (une personnalisation des contenus, des activités participatives et une organisation horizontale ${ }^{74}$ ).

Il convient donc, avant de se poser la question du contenu de la collection, de s'interroger sur les usages et les pratiques de lecture du public auquel la bibliothèque s'adresse. Ce sont ces usages et pratiques qui doivent guider la constitution des collections. Par exemple, l'institution GlobLivres ${ }^{75}$ organise une bibliothèque d'ouvrages en langues étrangères à destination de publics d'origine immigrée, en partant du postulat que la reconnaissance de la langue maternelle favorise l'appropriation de la langue du pays de résidence. Sur la question du contenu de la collection, l'importance du volume consacré à chaque langue dans les rayons est déterminée par la sollicitation des publics.

${ }^{73}$ Anne-Marie Bertrand, Les bibliothèques municipales: enjeux culturels, sociaux, politiques, Paris, France, Éd. du Cercle de la librairie, 2002, 147 p., («Bibliothèques »).

${ }^{74}$ Lionel Dujol, op. cit.

${ }^{75}$ http://www.globlivres.ch/ Consulté le 12 décembre 2013 
Les bibliothèques que nous avons rencontrées mettent toutes en avant l'intérêt de faire participer les usagers à la construction des collections. Les bibliothécaires reconnaissent que les lecteurs leur ont fait envisager des références qu'ils n'auraient pas eux-mêmes intégrées spontanément dans la collection. Dans tous les cas, les participants sont arrivés avec des idées surprenantes, mais pertinentes.

\section{Organiser la rencontre de la collection et des usagers}

La co-construction permet donc en premier lieu d'adapter la collection aux besoins locaux. Cependant, il existe d'autres outils (analyse des prêts, enquêtes de public, etc.) que la co-construction pour rapprocher la collection des demandes des usagers. De plus, Anne-Marie Bertrand rappelle que «La co-présence d'une collection et d'usagers ne suffit pas à susciter leur rencontre ${ }^{76}$. L'avantage de la co-construction est que la manière de susciter la demande se fait de manière plus directe, et permet de faire rencontrer la collection et la demande, d'abord d'un point de vue géographique, en organisant des collections hors les murs; d'autre part de manière plus co-constructive, en organisant un échange autour des collections.

\section{a) La co-construction hors les murs}

Rendre la collection plus proche des citoyens, au-delà des seuls usagers, s'entend aussi au sens spatial du terme. C'est pourquoi les projets de coconstruction des collections avec les usagers s'accompagnent souvent d'une réflexion sur le lieu «bibliothèque ». La participation du public ne doit pas concerner les seules personnes qui viennent déjà à la bibliothèque. Un des moyens de toucher ce «non-public » est d'organiser des projets de collection hors les murs.

De nombreux programmes de ce type, qui font participer les citoyens à la diffusion des collections de la bibliothèque dans la ville ont déjà été mis en place. Les bibliothèques wallones font ainsi appel à des « relais-lecture citoyens »: des habitants qui accueillent chez eux des collections et participent à leur diffusion dans les zones mal desservies par les bibliothèques. Le prêt/retour s'effectue chez eux, ainsi que des animations organisées avec la bibliothèque. A Rillieux-la-Pape en banlieue lyonnaise, les commerçants de la ville se voient confier des livres désherbés par la bibliothèque, qu'ils mettent à disposition de chacun dans leur magasins, avec le slogan : «Lisez, rendez quand vous voudrez!». A Lezoux, des malles itinérantes ont été mises en place pendant une résidence de l'association «la $27^{\mathrm{e}}$ région ${ }^{77}$ : les habitants pouvaient placer dans de grandes malles des livres qu'ils avaient envie de partager. Ces malles ont circulé chez les habitants,

\footnotetext{
${ }^{76}$ Anne-Marie Bertrand, «Collections et publics en bibliothèque », ADBDP : journées 1999, 1999.

${ }^{77}$ http://blog.la27eregion.fr/-A-propos- Consulté le 3 novembre 2013
} 
qui pouvaient prendre connaissance de leur contenu et/ou partager à nouveau d'autres lectures.

Organiser des collections hors les murs s'entend également de manière dématérialisée. La bibliothèque du Congrès américain a numérisé ses collections d'images et a choisi de les mettre en ligne sur Flickr ${ }^{78}$, site de partage en ligne de photos qui utilise des techniques collaboratives. En effet, Flickr permet de faire participer les internautes à l'enrichissement de la collection par des tags, commentaires, par des réutilisations d'image, etc. La bibliothèque du Congrès a ainsi considérablement multiplié l'audience de cette collection d'images, qui comptait un demi-million de consultations mensuelles en $2008^{79}$.

\section{b) Un moyen de dépasser l'opposition entre offre et demande?}

Faire participer les usagers à la construction des collections permettrait de dépasser une question abondamment discutée et débattue à propos des collections des bibliothèques : la collection doit-elle permettre d'affirmer des choix culturels et éducatifs (modèle de l'offre) ou bien doit-elle avant tout suivre les demandes des lecteurs (modèle de la demande) ? Dans la réalité, la frontière entre ces deux modèles est plus floue : les tenants de l'offre sont aussi attentifs à la réaction des publics, alors que les tenants de la demande ne suivent jamais aveuglément les exigences des lecteurs ${ }^{80}$. De plus, Bertrand Calenge a montré que ces modèles se rejoignent parfois : un livre entré dans la collection suite à la demande d'un lecteur devient ensuite une offre puisqu'il peut être emprunté par d'autres usagers ${ }^{81}$.

La co-construction des collections avec les usagers permet de dépasser cette opposition. Contrairement à ce que l'on peut penser, faire participer le public aux collections ne revient pas à une politique de la demande. Certes, on leur ouvre une nouvelle possibilité d'exprimer leurs attentes et leurs envies, qu'on essaye généralement de suivre. Mais, dans une démarche de co-construction, l'échange est mutuel : la démarche de construire ensemble permet tout autant d'exprimer une demande que de faire découvrir d'autres œuvres. Cet échange se fait même de façon beaucoup plus efficace car on organise la rencontre de l'offre avec le public. Selon Valérie Beaugier, qui organise le club Lékridézados, l'apport est mutuel : les bibliothécaires ont de belles découvertes de livres défendus par des adolescents, mais l'échange permet aussi d'amener les jeunes participants vers d'autres lectures, présentées soit par les bibliothécaires, soit par les autres adolescents. Pour le cercle des auditeurs de la bibliothèque de la Croix Rousse, chargé de monter une nouvelle discothèque participative, les motivations des participants sont à la fois la possibilité de partager leurs goûts musicaux et celle de découvrir de nouvelles musiques présentées à chaque séance par les autres auditeurs. On est donc à la fois

\footnotetext{
${ }^{78}$ http://www.flickr.com/photos/library of congress/ Consulté le 20 octobre 2013

79 Cécile Touitou, «La bibliothèque 2.0 vue par les usagers : aperçu des principales études américaines », in Bibliothèque 2.0 à l'heure des médias sociaux, Paris, France, Éd. du Cercle de la librairie, 2012, (« Bibliothèques »), p. 71-82.

${ }^{80}$ Bertrand Calenge, « La collection entre offre et demande ? », Bulletin des Bibliothèques de France, vol. 46 / 2 , 2001.

${ }^{81}$ Ibidem.
} 
dans le souhait d'exprimer une demande et la volonté de découvrir une nouvelle offre.

\section{B. Valoriser les compétences des usagers}

Dans l'entreprise de co-construction, les usagers ne sont pas considérés comme de simples «consommateurs » de bibliothèque mais comme de véritables ressources que la bibliothèque gagnerait à mettre en valeur et à exploiter.

\section{Considérer les usagers comme une ressource}

Faire appel à la participation des usagers suppose de reconnaître que ceux-ci ont des compétences que les bibliothèques peuvent utiliser :

Peut-être faut-il s'interroger sur les publics moins en terme de « demande » à satisfaire qu'en terme de « ressource » potentielle à activer, les associer à la définition des services et au fonctionnement, moins penser l'établissement en terme d'offre que de projet culturel global appuyé sur une réelle proximité avec le territoire et sa population. ${ }^{82}$

Cette reconnaissance de l'usager comme ressource potentielle est d'autant plus nécessaire qu'il est déjà reconnu comme tel sur internet. Dans le nouveau système de transmission de l'information, en particulier sur le web, la frontière entre consommateur et producteur se brouille. Avec des outils 2.0 comme les wikis, l'internaute lecteur peut aussi devenir contributeur et participer à l'élaboration de la publication en ligne. Le succès de Wikipédia montre ce qu'il est possible de faire en mutualisant les ressources d'un public large, qui n'est pas un public sélectionné au départ sur des compétences reconnues.

L'utilisation que les bibliothèques font $\mathrm{du}$ service Babelthèque est également révélatrice. Les internautes se servent du site Babelio pour partager des listes de livres, ainsi que des avis et critiques sur leurs lectures. Plusieurs bibliothèques réutilisent, grâce au service Babelthèque, les notices de Babelio afin d'enrichir leurs catalogues avec des critiques écrites par les internautes ${ }^{83}$. Babelthèque n'est pas un projet de co-construction car il n'y a pas de démarche de construction en commun avec les usagers dans la récupération des notices. Cependant cette réutilisation montre une reconnaissance, de la part de la bibliothèque, de ce que les usagers peuvent lui apporter.

${ }^{82}$ Patricia Remy, «Ouvrir un espace d'intervention aux usagers... », Bulletin des Bibliothèques de France, vol. 48 / 1, 2003.

${ }^{83}$ Slideshare Babelio, «Babelthèque, le service d'enrichissement de catalogues de bibliothèques », 2013. En ligne: [http://fr.slideshare.net/Babelio/babelthque-le-service-denrichisse ment-pour-bibliothques-publiques-de-babelio] Consulté le 4 décembre 2013 
Les ressources peuvent aussi être des compétences très techniques, dont la bibliothèque a ponctuellement besoin et pour lesquelles les connaissances des usagers peuvent être très utiles. Par exemple, dans la bibliothèque interculturelle de l'association GlobLivres, les usagers sont sollicités pour l'organisation des collections, par exemple pour le catalogage des livres dans d'autres alphabets que l'alphabet latin.

\section{Identifier et valoriser les « amateurs »}

Parmi le public de chaque bibliothèque, il est possible d'identifier des usagers ayant des compétences particulières, liées à leur intérêt personnel pour un domaine ou un sujet. Bernard Stiegler, qui s'intéresse aux évolutions du monde de l'information et qui a développé toute une théorie autour de l'économie de la contribution, valorise particulièrement la «figure de l'amateur, qui aime ce qu'il fait et s'y investit complètement. " ${ }^{84}$. L'intérêt pour un sujet peut être une motivation pour l'usager à participer à un projet de co-construction. Par exemple, un groupe "Participer à la discothèque » avait été mis en place à la médiathèque de Chemillé, au moment de la création d'un fonds de CD. Ce groupe réunissait des usagers qui avaient souvent un intérêt particulier pour la musique, et étaient parfois spécialistes de jazz, de musiques de fanfares ou de rock indépendant, etc. ${ }^{85}$

Outre que son intérêt pour un sujet le motive à s'investir dans un projet, « l'amateur » constitue une ressource précieuse à exploiter pour la bibliothèque, pour les connaissances et les compétences que cet usager peut lui apporter. En 2004, Charles Leadbeater et Paul Miller ont mis en lumière le phénomène des «pro-am», ces amateurs ou «enthusiasts» qui, passionnés par un sujet, acquièrent dans ce domaine des compétences qui deviennent comparables à celles des professionnels ${ }^{86}$. Nous avons déjà soulevé le fait que le bibliothécaire ne peut être spécialiste de tous les domaines de la collection. Certains usagers « amateurs » peuvent être d'une aide particulière sur certains sujets. Ainsi, la bibliothèque Place des fêtes ${ }^{87}$ à Paris a proposé à ses usagers de participer au choix des acquisitions lors d'un projet appelé «Shopping book ${ }^{88}$ ». A cette séance était venu un spécialiste du monde japonais qui a donné de précieux conseils sur ce domaine qui était trop peu développé dans les collections et pour lequel les bibliothécaires manquaient de compétences spécialisées. Ces compétences apportées par les usagers peuvent être du savoir, des connaissances mais aussi du savoir-faire ou du savoir-être. Les projets de «human library» ou «bibliothèque vivante » permettent ainsi de mettre en valeur des individus au parcours particulier. Si on enregistre leur contribution, on participe également à la construction de la mémoire d'un territoire, en même temps qu'on enrichit les collections.

\footnotetext{
${ }^{84}$ Quentin Noirfalisse, «Vers une économie de la contribution », OWNI, 30 novembre 2011.

${ }^{85}$ Message de William Noyer sur la liste de diffusion discothecaires_fr@listes.ircam.fr « RE: Achat de CD par un groupe d'usagers? », 5 avril 2014

${ }^{86}$ Charles Leadbeater et Paul Miller, The pro-am revolution: how enthusiasts are changing our society and economy, London, Royaume-Uni, Demos, 2004, 77 p.

${ }^{87}$ http://equipement.paris.fr/bibliotheque-place-des-fetes-1746/ Consulté le 12 décembre 2013

${ }^{88}$ Silvère Mercier, « Trois idées simples pour des bibliothèques plus accueillantes », Bibliobsession, 2011.
} 
En raison de ces «richesses » à exploiter parmi les usagers, les projets de coconstruction doivent être précédés d'un travail, de la part de la bibliothèque, de repérage et d'identification des ressources sur son territoire :

Faire « avec» les habitants, cela renvoie à la connaissance du territoire qu'ont les professionnels, cela interpelle sur leur capacité d'envisager et d'identifier «l'usager » comme richesse culturelle et ressource potentielle. ${ }^{89}$

Par exemple, la bibliothèque de la Croix Rousse a choisi de faire participer les usagers sur un projet lié à la musique également parce qu'elle savait que la population du quartier compte beaucoup de musiciens, professionnels ou amateurs.

\section{Adopter des formes de recommandation par les pairs}

Faire appel aux ressources des usagers revient aussi à adapter à l'usage de la bibliothèque le modèle de la recommandation par les pairs. Par la navigation sur internet, les usagers ont pris l'habitude de consulter et de suivre les avis des autres internautes. Sur les sites de commerce de produits culturels en ligne, cette recommandation par les pairs prend différentes formes. Les usagers peuvent noter des produits et laisser des avis, que les autres internautes consultent pour déterminer leurs propres achats. La recommandation par les pairs prend aussi des formes telles que : "Les internautes ayant acheté ce livre ont également acheté... » ou «Quels sont les autres articles que les clients achètent après avoir regardé cet article ?...». L'intérêt de la recommandation par les pairs est qu'elle peut être beaucoup plus efficace que la recommandation d'une institution: $90 \%$ des internautes déclarent faire confiance à des recommandations d'amis, 70\% d'entre eux à des recommandations d'internautes inconnus (blogs, forums) mais ils ne sont que $42 \%$ à déclarer faire confiance à la publicité. Ce sondage ne dit pas la confiance que les internautes accordent à la recommandation d'une bibliothèque, mais il montre bien l'importance que les personnes accordent aux conseils de leurs pairs $^{90}$.

Sans être institutionnalisées, les pratiques de recommandation par les pairs existent déjà également dans le lieu physique de la bibliothèque. Ainsi, on observe des usagers qui prennent l'habitude de consulter les documents sur le chariot de retour, afin de savoir ce que les autres ont précédemment emprunté. Autre exemple, l'intérêt du cahier de suggestions pour l'usager est parfois autant celui de relayer ses demandes individuelles que de lire ce que les autres ont demandé... La recommandation par les pairs est appréciée par les usagers, car elle est souvent estimée comme plus proche de leurs goûts personnels, contrairement à la recommandation du bibliothécaire, soupçonnée - à tort ou à raison - d'être plus institutionnelle ou élitiste.

Les projets de co-construction des collections peuvent faire appel à des modes de recommandation par les pairs. Nous avons déjà évoqué les avis rédigés

\footnotetext{
${ }^{89}$ Patricia Remy, op. cit.

${ }^{90}$ Lionel Dujol, «La médiation numérique au service de la politique documentaire », 2011. Diapositive $n^{\circ} 30$
} 
par des usagers et collés sur la quatrième de couverture des livres pour faciliter le choix des autres lecteurs. A la médiathèque de Rillieux-la-Pape, les bandes dessinées choisies par les usagers lors du cercle Conciliabulle sont mises en valeur dans les rayons par une pastille collée sur la couverture du livre qui mentionne : «Choisi par les lecteurs ». Les bibliothécaires ont remarqué un effet de cette pastille, car les livres qui en sont munis attirent plus l'attention des usagers que les autres livres. La recommandation par les pairs peut aussi se faire dans le cadre de projet de médiation participative autour des collections. L'exemple développé plus haut des «pochettes surprises » pour Noël permettait de faire découvrir au public des disques choisis et conseillés par d'autres usagers.

\section{LA RECONQUETE DU PUBLIC}

L'implication des usagers dans les collections peut donc résulter en un enrichissement documentaire. Cependant, nous allons voir maintenant que l'enrichissement vient aussi, voire surtout, de la transformation de la relation avec les usagers. «La reconquête du public » est une expression employée par Marc Maisonneuve, à propos des enjeux du catalogue 2.0. Faire participer les usagers à travers des outils 2.0 (mais nous pouvons l'étendre à d'autres formes de coconstruction) doit permettre aux bibliothèques de reconquérir un public formaté par les usages d'internet, et notamment des fonctionnalités de Google et d'Amazon'.

\section{A. Une relation renouvelée de la bibliothèque à son public}

Les projets de co-construction des collections impliquent une relation renouvelée entre la bibliothèque et les usagers: de son côté, l'usager prend conscience de son droit à participer et à intervenir dans les collections ; de l'autre, la bibliothèque doit redéfinir son rôle au cœur de la vie de la cité et se positionner comme animatrice de la communauté.

\section{Du point de vue de l'usager : prendre conscience de son droit à contribuer}

La participation des citoyens aux services publics est un enjeu de citoyenneté. Selon Gilles Jeannot, dans la relation à l'administration se joue pratiquement l'appartenance à la cité ${ }^{92}$. En faisant participer les usagers au fonctionnement d'une administration, on leur reconnaît un rôle de citoyen, plus

\footnotetext{
${ }^{91}$ Cécile Touitou, op. cit., p. 72.

${ }^{92}$ Gilles Jeannot, op. cit., p. 72.
} 
gratifiant que le rôle de simple «consommateur» de service public. Bertrand de Quatrebarbes définit trois profils-types d'usagers des services publics, l'usager «3C ${ }^{93}$ : l'usager consommateur, l'usager contribuable et l'usager citoyen. Le premier, l'usager consommateur, a un comportement d'achat du service public. Il compare la qualité du service fourni à celle du secteur privé et est exaspéré par les dysfonctionnements. L'usager contribuable est sensible au gaspillage et veut savoir l'utilisation qui est faite de l'argent des impôts. Il ne veut pas de service public cher et non-utilisé. L'usager citoyen veut faire connaître ses attentes et ressent le besoin d'être pris en considération. Il souhaite être invité à participer à la conception du service public.

Aujourd'hui l'usager est souvent considéré comme un simple « consommateur » de bibliothèque, qui compare les services et les collections à l'offre du secteur privé, notamment les librairies physiques et en ligne (les publics des bibliothèques étant en majorité les mêmes que les publics des librairies ${ }^{94}$ ). Nous avons vu que la co-construction des usagers aux collections répond en partie aux attentes de l'usager contribuable, en proposant un offre plus proche des besoins du public, et donc en offrant un service public plus efficace.

Cependant, elle répond surtout au besoin du troisième profil-type d'usager, l'usager citoyen, qui veut être pris en considération et participer à la conception du service public. Ainsi, la co-construction permet de faire sortir l'usager de son rôle passif de consommateur et lui offre la possibilité d'exprimer ses attentes, ses besoins et de devenir acteur du service. Au-delà du résultat de la co-construction des collections, c'est-à-dire une collection plus adaptée au public de la bibliothèque, la réussite se trouve plus souvent dans la démarche de participation que dans le résultat obtenu. L'intérêt de l'entreprise de co-construction est surtout de faire prendre conscience aux usagers-citoyens de leur droit à contribuer :

Il arrive que le résultat le plus important de la planification des services en collaboration avec la communauté n'est pas les produits ou services qui en résultent, mais plutôt le sens qu'acquièrent les membres de la communauté socialement exclue de leur propre importance dans la bibliothèque, de leur droit de contribuer, et de leurs capacité et confiance de participer. ${ }^{95}$

L'intérêt d'associer le public à la conception des collections est de rappeler que la bibliothèque est un service public, dont l'offre doit être pensée pour les usagers. Au-delà d'une offre de ressources, la bibliothèque est aussi un espace d'échange et de citoyenneté. La co-construction permet de faire sentir que la collection est un bien collectif. Elle doit conduire les participants à une plus grande proximité avec l'offre de la bibliothèque, à une appropriation des collections par les usagers. Par exemple, la future médiathèque de Lezoux souhaite développer particulièrement ce sentiment de collection comme bien collectif et veut mettre en place de nombreuses actions dans ce but. Certaines collections de la médiathèque seront ainsi entièrement constituées de livres prêtés par les habitants

\footnotetext{
${ }^{93}$ Bertrand de Quatrebarbes et Claude Gruson, op. cit., p. 103.

${ }^{94}$ Héloïse Marill, Transmettre le livre: pratiques professionnelles en librarie et en bibliothèque, mémoire DCB sous la direction de François Rouet, Enssib, 2009, p. 18.

95 « Trousse d'outils pour des bibliothèques à l'écoute de la communauté », Projet Working Together, 2008, p. 19.
} 
et rassemblées dans une zone de la bibliothèque identifiée comme «bibliothèque des habitants ». Symboliquement, le premier livre exemplarisé dans la future bibliothèque sera un livre collectif, écrit par une dizaine d'usagers dans le cadre d'un atelier d'écriture. Dans le lieu physique de la bibliothèque, sera installée une étagère de ce qui a été créé à la bibliothèque. Autre projet, des potiers vont créer des récipients dans lesquels les habitants pourront déposer des objets : écrits, photographies, clés, etc. Ceci constituera une bibliothèque d'objets que la médiathèque de Lezoux conservera selon les souhaits des habitants.

Ces différents exemples sont autant de manières de valoriser l'apport des usagers à la bibliothèque. L'idée est de permettre aux usagers de pouvoir dire, en visitant la bibliothèque : «ceci est à moi. ». C'est à la fois une façon de mettre en valeur leur participation, de faire prendre conscience que la collection est un bien collectif, et une manière de les inclure dans la «communauté » de la bibliothèque :

Le développement des collections en collaboration pourrait en fin de compte être la meilleure façon de s'assurer que les membres de la communauté se sentent représentés à la bibliothèque. Quand quelqu'un choisit lui-même un ouvrage qui sera placé dans la collection, il se voit personnellement représenté sur les rayons de la bibliothèque. Il peut dire : « J'ai choisi ce livre pour la bibliothèque, c'est ma bibliothèque. ${ }^{96}$

Développer le sentiment de collection comme bien collectif peut également se faire sur le terrain numérique, à travers une co-construction avec les usagers sur internet. La bibliothèque numérique Gallica utilise ainsi régulièrement des méthodes de médiation participative pour encourager l'appropriation de ses collections par les internautes. Les médiateurs de Gallica proposent aux usagers de réutiliser des images libres de droit dans leurs articles de blogs, ou bien comme photo de profil sur les réseaux sociaux. Ils font voter les «Gallicanautes » pour le choix de la photo de couverture de Gallica. Une «chasse au trésor » est également organisée à chaque mise en ligne de nouveaux documents dans Gallica : les internautes sont invités à signaler les «trésors » qu'ils ont pu découvrir parmi les nouveaux documents grâce au hashtag \#Chasseauxtrésors sur Twitter. Les trouvailles des internautes sont valorisées par un retweet sur le fil de Gallica ${ }^{97}$. Ces initiatives permettent de valoriser les apports des usagers et développer le sentiment que les usagers peuvent s'approprier les collections.

\footnotetext{
${ }^{96}$ Citation de Randy Gatley, bibliothécaire spécialiste du développement communautaire dans le projet Working together, «Trousse d'outils pour des bibliothèques à l'écoute de la communauté », op. cit. p.105

97 L'équipe@GallicaBnF, «Une bibliothèque numérique sur les réseaux sociaux: 1'exemple de Gallica », Bulletin des Bibliothèques de France, vol. 57 / 5, 2002, p. 31 - 38.
} 


\section{Du point de vue de la bibliothèque : activer la communauté des usagers}

La bibliothèque s'adresse toujours à un public ciblé. Les services qu'elle propose, comme ses collections, doivent être pensées en fonction de la communauté qu'elle dessert :

La communauté, dans toutes ses dimensions, notamment historique et géographique, [est le] critère de référence du bibliothécaire lorsqu'il tente de légitimer des projets de services, une politique culturelle. ${ }^{98}$

R. David Lankes a exprimé dans un tweet son idée de l'importance que la bibliothèque doit accorder à la relation à la communauté : «Bad Libraries build collections. Good libraries build services (of which a collection is only one). Great libraries build Communities » (les mauvaises bibliothèques construisent des collections ; les bonnes bibliothèques construisent des services (dont la collection fait partie) ; les grandes bibliothèques construisent des communautés). R. David Lankes a développé l'idée de ce tweet dans un article ${ }^{99}$, où il explique qu'il n'est pas bon que la bibliothèque s'intéresse seulement, ou de façon disproportionnée, à sa collection. Les bonnes bibliothèques s'intéressent avant tout à leurs usagers, et orientent les services, dont les collections font partie selon lui, pour les utilisateurs. Mais il différencie les bonnes bibliothèques des «grandes» bibliothèques, qui vont plus loin : le travail sur les collections doit permettre aux bibliothécaires d'activer la communauté et d'aider à satisfaire leurs aspirations ${ }^{100}$ :

You see a good library sees the collection as a service and therefore monitors and plans for its use. A great library sees the collection as only a tool to push a community forward, and more than that, they see the library itself as a platform for the community to produce as well as consume. The library member co-owns the collection and all the other services offered by the librarians. The library services are part of a larger knowledge "ecosystem" where members are consuming information yes (a user), but also producing, working, dreaming, and playing. That is the focus of a great library. They understand that the materials a library houses and acquires is not the true collection of a library - the community is. ${ }^{101}$

(Vous voyez, une bonne bibliothèque voit la collection comme un service, et donc organise et supervise son usage. Une grande bibliothèque voit la collection seulement comme un outil pour activer la communauté et même plus, ils voient la bibliothèque elle-même comme une plate-forme pour

\footnotetext{
98 Bertrand Calenge, Accueillir, orienter, informer : l'organisation des services aux publics dans les bibliothèques. Paris, Ed. du Cercle de la Librairie, 1999. p. 40

${ }^{99}$ R. David Lankes, «Beyond the Bullet Points: Bad Libraries Build Collections, Good Libraries Build Services, Great Libraries Build Communities », Virtual Dave...Real blog, 2012. notes, 2013

${ }^{100}$ Bertrand Calenge, «Construire des collections ou construire des connexions ? », Bertrand Calenge : carnet de

${ }^{101}$ R. David Lankes, op. cit.
} 
que la communauté puisse produire autant qu'elle consomme. Les usagers de la bibliothèque sont co-propriétaires de la collection et de tous les autres services proposés par les bibliothécaires. Les services de la bibliothèque font partie d'un plus grand «éco-système » de la connaissance dans lequel les membres certes consomment de l'information (en tant qu'usagers), mais aussi produisent, travaillent, rêvent et jouent. C'est sur ce point qu'une grande bibliothèque se focalise. Ils comprennent que les ressources que la bibliothèque abrite et acquiert ne sont pas la collection de la bibliothèque, mais la communauté des usagers.)

Il ne suffit donc pas, selon R. David Lankes, de permettre aux usagers de «consommer» la collection, mais il faut aussi offrir la possibilité à la communauté de devenir active et de produire des contenus au sein de la bibliothèque. Les grandes bibliothèques sont focalisées sur la communauté plutôt que sur la collection, qui doit être organisée comme les autres services pour le public.

Il peut sembler paradoxal de parler de communauté autour de la bibliothèque, c'est-à-dire autour de la lecture. Comme le souligne Renaud Aïoutz ${ }^{102}$, la notion de communauté de lecture est très paradoxale. La lecture est avant tout une activité solitaire. De plus, dans la bibliothèque, on valorise l'organisation qui permet l'autonomie du lecteur. Cependant, l'activité de lecture, solitaire à première vue, permet aussi l'échange et le partage :

Il y a toujours une communauté qui lit en nous et par qui nous lisons. Lire s'apprend au sein d'un groupe, d'une culture qui conditionne nos choix et notre accès au texte. Nous lisons en fonction de nos compétences, de nos habitudes, de pratiques de lecture acquises au sein d'une communauté. ${ }^{103}$

L'échange autour de la lecture est possible, comme le montre le succès des nombreuses communautés de lecteurs (par exemple le site Babelio, ou plus simplement les clubs de lecteurs en bibliothèque). Il n'est donc pas impertinent de chercher à activer une communauté d'usagers autour de la bibliothèque. Celle-ci touche potentiellement différents types de communautés : la communauté de ses usagers, la communauté de son territoire, la communauté d'intérêt (cf. Annexe 2 p. 86).

La communauté des usagers est celle qui utilise déjà les services et les collections de la bibliothèque, et elle mérite de se voir donner un rôle plus actif. La communauté du territoire est probablement la communauté la plus importante pour la bibliothèque, car c'est par principe le public auquel elle s'adresse. En effet, les bibliothèques de lecture publique sont quasiment toujours rattachées à un territoire administratif, sur lequel s'exerce la compétence de sa tutelle. Les habitants de ce territoire constituent le public qu'elle a vocation à desservir. Or, aujourd'hui les taux de fréquentation des bibliothèques sont très rarement supérieurs à $20 \%$ de la population d'un territoire. Fort de ce constat, quatre bibliothèques canadiennes ont

${ }^{102}$ Renaud Aïoutz, «Les communautés de lecteurs et les outils coopératifs : place et plus-value des médiations institutionnelles », médiathèque départementale de l'Hérault, 2011.

${ }^{103}$ Roger Chartier, entretien accordé à Réseaux, février 1992, cité dans Ibidem. 
entrepris une démarche très ambitieuse afin de comprendre et d'éliminer les obstables à la venue en bibliothèque. Ce projet, appelé Working Together, s'est appuyé sur des techniques de co-conception qui ont été mises en œuvre par des bibliothécaires spécialement missionnés pour activer la communauté. Ces bibliothécaires, nommés «spécialistes du développement communautaire » sont allés à la rencontre de la population du territoire desservi par la bibliothèque afin d'identifier les freins à la fréquentation. Puis, suite à ces constats, ils ont travaillé en collaboration avec les communautés socialement exclues afin de déterminer leurs besoins et leurs attentes relatifs aux services de bibliothèques et de définir des moyens d'y répondre. Ce projet a donné lieu à la rédaction d'une " trousse d'outils ${ }^{104}$ qui explique la démarche et donne des instruments de travail pour les bibliothèques qui souhaitent mettre en œuvre des projets de collaboration avec la communauté, en particulier à destination des populations socialement exclues.

Sans forcément se lancer dans une démarche aussi ambitieuse, qui s'appuie sur une équipe de personnels spécialement chargés du développement communautaire, il est nécessaire, pour une bibliothèque qui met en place un projet de co-construction de garder à l'esprit qu'elle s'adresse à toute la communauté sur le territoire, et pas seulement à la population de ses usagers. La co-construction des collections peut être une réponse à la désaffection de certains publics, en permettant de définir avec eux les raisons qui les poussent à ne pas venir à la bibliothèque et ce qu'ils aimeraient y trouver pour avoir envie de la fréquenter. Pour Patricia Remy, l'ouverture d'un espace de participation aux usagers peut être une réponse à la désaffectation des publics:

Si $82 \%$ des populations ne se reconnaissent pas dans notre offre, je fais moins l'hypothèse d'un échec que celle de la limite d'une logique et de ses effets bloquants (...) Assurer l'accès aux savoirs, certes, mais aussi prendre en compte les cultures vivantes présentes sur un territoire, tout en travaillant à la construction du sentiment d'appartenance des habitants à la collectivité. C'est peut-être là que les bibliothèques trouveront de nouvelles résonances avec leurs publics, actuels et futurs. ${ }^{105}$

Plusieurs actions peuvent être envisagées pour toucher les «non-usagers ». Lors de la résidence de la $27^{\mathrm{e}}$ région, les intervenants étaient installés dans un local à Lezoux. Leur première action a été de sortir les tables et les chaises dans la rue, afin d'aller à la rencontre des passants et de les interpeler au cœur de leur mode de vie. Ils se sont alors rendu compte que seulement 3\% des habitants rencontrés fréquentaient le point lecture de Lezoux. Il était donc absolument nécessaire de ne pas limiter leur action aux seuls usagers, et d'aller à la rencontre de la population pour échanger autour de leurs usages de lecture.

Enfin, la bibliothèque peut chercher à toucher des communautés d'intérêt. Ces communautés, définies non plus par un territoire, mais par un intérêt qu'elles partagent. Elles se confondent parfois avec les communautés sur le territoire (par exemple un club local d'amateurs de bandes dessinées) mais peuvent être bien plus

\footnotetext{
104 « Trousse d'outils pour des bibliothèques à l'écoute de la communauté », op. cit.

${ }^{105}$ Patricia Remy, op. cit.
} 
larges, en particulier grâce aux médias numériques. Sur internet, de nombreuses communautés se forment autour d'un même centre d'intérêt. Les bibliothèques devraient s'intéresser plus souvent à ces communautés, déjà formées et déjà actives, lorsqu'elles mettent en place un projet de co-construction.

\section{B. Faciliter le lien entre les bibliothécaires et les usagers}

Le résultat de la co-construction des collections est souvent de rendre plus simples les contacts entre la bibliothèque et les usagers : d'une part, les usagers sont mieux informés du fonctionnement de la bibliothèque, qui leur paraît plus transparent; d'autre part, la co-construction crée un espace pour les échanges entre le personnel et les usagers qui n'existe pas par ailleurs.

\section{Donner des clés pour une meilleure compréhension de la bibliothèque}

Les actions de co-construction sont l'occasion de rapprocher la bibliothèque de ses usagers. Elles permettent notamment de faire découvrir la bibliothèque du point de vue de son fonctionnement interne, de le rendre plus transparent pour le public. Ainsi, l'action du cercle des auditeurs de la bibliothèque Croix Rousse a été l'occasion pour les usagers de se rendre compte des contraintes très concrètes auxquelles la bibliothèque est soumise, notamment les contraintes liées aux budgets et aux règles de fonctionnement des administrations publiques. La plupart des participants ont découvert qu'elle était liée à un fournisseur par un marché public, et qu'elle ne pouvait pas simplement aller acheter un CD au disquaire du quartier, notamment pour les $\mathrm{CD}$ qui ne sont plus édités. Cela a aussi permis d'expliquer la manière dont les bibliothécaires font les acquisitions, mettant en lumière tout un travail interne normalement invisible pour les usagers. Les bibliothécaires ont également pu rappeler que la vocation de la collection est de s'adresser à une communauté, et que la bibliothèque ne pouvait répondre à toutes les demandes individuelles, en particulier si elles ne sont pas susceptibles d'intéresser les autres usagers. La participation des usagers peut donc être en quelque sorte un moment de «pédagogie de la bibliothèque » et de mise en avant du «travail de l'ombre». Ainsi, des usagers, qui auraient eu tendance à critiquer la bibliothèque pour l'absence de tel ou tel titre, peuvent aussi devenir plus indulgents lorsqu'ils comprennent les contraintes auxquelles la bibliothèque est soumise.

Cette découverte du fonctionnement interne peut s'accompagner d'une démarche de qualification des usagers. Pour que la participation soit efficace, il est parfois nécessaire de développer les capacités des usagers, en leur donnant quelques outils : 
Cette démarche [de participation de la communauté] (...) a plutôt comme but de développer et de renforcer les capacités des membres de la communauté socialement exclue pour qu'ils puissent prendre part aux activités de la bibliothèque. ${ }^{106}$

Lors du projet Shopping book ${ }^{107}$ à la bibliothèque place des Fêtes ${ }^{108}$, les bibliothécaires ont fait découvrir aux usagers les outils qu'ils utilisent pour procéder aux acquisitions (liste des titres présents dans les collections, liste des commandes en cours, revues Livres Hebdo, Lire, Le Magazine Littéraire, Télérama, etc.). Autre exemple à Méricourt, où un collectif d'habitants a été créé, non pas autour d'un projet de collection mais autour du projet de construction d'une nouvelle médiathèque. Pour que les usagers puissent définir de manière plus efficace ce qu'ils souhaitaient dans la future bibliothèque, des visites d'établissements ont été organisées avec le collectif. Les bibliothécaires avaient préparé des grilles d'observation, avec différents critères et différents aspects de la bibliothèque visitée à observer. Le collectif devait aussi donner son avis sur des projets de bâtiments. Afin de pouvoir échanger avec les architectes, un «dictionnaire des mots nouveaux» a été créé, puis publié dans le journal municipal. Les habitants ont également découvert les différentes étapes de la procédure d'un concours d'architecture.

Les usagers peuvent beaucoup apporter à la bibliothèque mais, pour cela, il faut parfois les accompagner, les initier, les former à des connaissances de base afin que la co-construction donne des résultats pertinents et enrichissants. Cette démarche de qualification des usagers peut aller assez loin, jusqu'à ce qu'on s'interroge sur ce que devient la frontière entre le simple usager et le professionnel. Nous verrons par la suite comment conserver cet équilibre et définir la place du professionnel dans les actions de co-construction. Cependant, dans les exemples que nous avons étudiés, la démarche d'éducation des usagers s'inscrivait avant tout dans un processus de familiarisation plus que de véritable qualification, afin de rendre la participation efficace. De plus, cette démarche est toujours conduite et encadrée par les professionnels.

\section{Faciliter les contacts}

La démarche de co-construction permet d'abattre les barrières entre la bibliothèque et son public, et de faciliter les échanges. Les bibliothèques aujourd'hui sont organisées de manière à ce que le lecteur soit le plus autonome possible. Alors que les bibliothèques sont en principe un lieu de d'échanges, cette organisation rend parfois les contacts plus difficiles: "L'instauration du libre accès dans les bibliothèques a placé les bibliothécaires dans une position

\footnotetext{
106 « Trousse d'outils pour des bibliothèques à l'écoute de la communauté », op. cit., p. 19.

107 Silvère Mercier, «Trois idées simples pour des bibliothèques plus accueillantes », Bibliobsession, 2011.

${ }^{108}$ http://equipement.paris.fr/bibliotheque-place-des-fetes-1746/ Consulté le 12 décembre 2013
} 
inconfortable : être au cœur d'un dispositif conçu pour se passer d'eux ${ }^{109}$. En temps normal il n'est donc pas toujours facile pour le bibliothécaire d'aller vers le public, qui recherche l'autonomie. Dans le même temps, Anne-Marie Bertrand montre que la présence des bibliothécaires au bureau d'accueil dans les salles n'est pas toujours bien comprise par les usagers et les lecteurs n'osent pas forcément «déranger» les bibliothécaires ${ }^{110}$. La démarche de co-construction permet d'aménager des instants d'échange autour des collections, qui rendent alors les contacts plus faciles des deux côtés.

Les bibliothécaires que nous avons contactés et qui organisent des projets d'acquisitions participatives, notent à chaque fois l'amélioration des contacts avec les usagers participants. Le lien créé entre bibliothécaires et les lecteurs est très net et les contacts se font de manière beaucoup plus naturelle. L'entreprise de coconstruction permet d'augmenter la proximité avec les usagers, ce qui est souvent recherché lors de la mise en place d'un tel projet. Les bibliothécaires remarquent également la qualité des échanges lors des réunions et des débats avec les usagers sur le choix des titres à acquérir. Sur les collections numériques, le sentiment de proximité avec les usagers peut aussi se trouver amélioré. Lorsque la bibliothèque municipale de Toulouse a mis en ligne les photographies d'Eugène Trutat, elle a reçu, par voie de commentaires sur Flickr, de nombreux remerciements de la part des internautes pour avoir diffusé cette collection ${ }^{111}$.

Les échanges sont donc facilités entre bibliothécaires et usagers, mais également entre les usagers eux-mêmes. En effet, si la bibliothèque est en théorie un lieu d'échanges, beaucoup de publics s'y croisent sans jamais se rencontrer. Les réunions organisées dans la démarche de co-construction les amènent à s'exprimer et à échanger entre eux. Dans les projets de participation aux acquisitions, ils sont conduits à présenter et défendre des œuvres qu'ils souhaitent voir achetées par la bibliothèque, ce qui donne lieu à des discussions constructives. D'autres moyens de faciliter les contacts entre usagers peuvent être imaginés. Par exemple, si la bibliothèque organise avec les usagers une collection constituée uniquement de leurs dons, un signet peut être ajouté dans les ouvrages mis en valeur, en laissant les coordonnées du propriétaire d'origine. Si le lecteur suivant le souhaite, il peut ainsi échanger avec l'ancien propriétaire, qui a fait don de ce livre parce qu'il souhaitait le partager.

Le résultat de ces échanges facilités est souvent la fidélisation d'usagers. Les bibliothèques interrogées n'ont jamais eu de mal à faire revenir les usagers aux réunions des cercles régulièrement organisées, alors que ces participations ne sont pas institutionnalisées et qu'elles reposent en totalité sur le volontariat.

\section{LES QUESTIONNEMENTS SOULEVES}

La co-construction des collections peut donner lieu à des inquiétudes, des réticences, que nous avons regroupées en quatre questions principales : la crainte

\footnotetext{
109 Anne-Marie Bertrand, Bibliothécaires face au public, Paris, France, Bibliothèque publique d'information, Centre Georges-Pompidou, 1995, 248 p., («Études et recherche »).

${ }^{110}$ Ibidem, p. 71.

${ }^{111}$ Patrick Hernebring, op. cit.
} 
de perdre la mainmise sur les collections, la peur d'avoir à gérer des pressions de la part des usagers, l'inadéquation de l'entreprise de co-construction avec le fonctionnement administratif et institutionnel de la bibliothèque et le manque de représentativité des usagers participants.

\section{A. L'appréhension d'une perte de contrôle sur les collections}

Il peut être difficile de faire accepter l'ouverture d'une possibilité d'intervention aux usagers dans la collection, qui est un domaine réservé au professionnel en temps normal et un point sensible à forte valeur symbolique. C'est pourquoi transférer une partie des prérogatives du bibliothécaire aux usagers pose des questionnements.

Laisser un espace d'intervention aux usagers dans les collections suscite plusieurs craintes, sur les éventuelles interventions ou pressions des usagers sur le contenu des collections, sur la perte de maîtrise des collections et sur les réutilisations qui peuvent en être faites. Par exemple, la bibliothèque municipale de Toulouse craignait, lorsqu'elle a mis en ligne sur Flickr son fonds de photographies d'Eugène Trutat, de perdre le contrôle sur ces collections. La possibilité d'ajout de tags et de commentaires, ainsi que de réutilisation des photographies par les internautes risquait, selon elle, d'éloigner les photographies de leur appartenance d'origine et des descriptions bibliographiques labellisées ${ }^{112}$. De même, lorsqu'une bibliothèque veut utiliser les possibilités d'indexation collaborative pour améliorer le référencement d'une collection, la crainte est souvent celle de devoir gérer et censurer des contributions malveillantes. Dans le cadre d'un office participatif, on craint de devoir gérer des suggestions difficiles de la part des usagers. A chaque fois les craintes tiennent à l'appréhension de ne plus parfaitement contrôler la gestion et la circulation des collections.

Dans ce cas, la tentation est souvent celle de vouloir filtrer les interventions a priori. Par exemple, le bibliothécaire présélectionne les ouvrages qui sont présentés aux usagers pendant les offices participatifs. On perd alors l'intérêt de faire participer les usagers, dont les choix sont en réalité pré-validés par les bibliothécaires. L'implication des usagers devient une participation prétexte, qui perd son caractère enrichissant. De même, la tentation peut aussi être de contrôler a priori les contributions dans les projets participatifs en ligne. On oblige les internautes à créer un compte avant de pouvoir effectivement contribuer, ceci afin de pouvoir enregistrer leurs actions. Cependant, cela décourage très souvent la participation et le risque est de se retrouver avec une participation très faible, ce qui rend les résultats décevants.

Plutôt que de vouloir filtrer et contrôler a priori les interventions des usagers, d'autres solutions peuvent être envisagées. D'abord, il faut parier sur l'intelligence des usagers participants. Prenons exemple sur le modèle de Wikipédia, qui fonctionne sur un pari : les personnes de bonne volonté, majoritaires en nombre, prendront le pas sur la minorité de personnes malveillantes. En effet, si une minorité de personnes, pour des raisons diverses, ont des interventions néfastes

112 Ibidem. 
dans l'encyclopédie en ligne, la majorité des contributeurs sont bienveillants. Ce rapport de forces permet de contenir et de réguler les interventions malveillantes et permet au projet d'avancer. Il faut garder à l'esprit que, dans les bibliothèques, les usagers qui se portent volontaires pour les actions de participation ne le font pas dans le but de nuire. Des interventions malveillantes peuvent effectivement arriver, mais elles ne se produiront qu'à titre exceptionnel. La plupart du temps, les usagers ont d'autres préoccupations que celle de vouloir polluer les collections de la bibliothèque.

Ensuite, il convient de se demander : que risque-t-on réellement? Dans le cas d'un office de lecture participatif, la crainte est souvent celle de devoir gérer des suggestions difficiles. Difficiles pour quelles raisons ? Parce qu'elles touchent à des questions de sociétés sensibles ou polémiques, parce qu'elles sont l'objet du dada d'un usager qui n'est intéressé que par un sujet, etc.. De la même manière, ces craintes légitimes ne doivent pas remettre en cause le projet de co-construction. D'une part, les suggestions exprimées par un usager pendant une réunion seront sûrement plus réfléchies que celles du cahier de suggestion, où l'usager est protégé par le media de l'écrit et parfois par l'anonymat. Le fait que les propositions d'acquisition soient discutées par le groupe oblige à argumenter et les discussions seront probablement plus constructives. D'autre part, et surtout, un projet de coconstruction des collections ne signifie pas que toutes les suggestions sont acceptées. Les contributions des usagers s'inscrivent dans le cadre de la politique documentaire de la bibliothèque, ce qui autorise celle-ci à refuser des suggestions qui pourraient porter atteinte au pluralisme des collections, ou à leur vocation collective. Ce type de suggestions «problématiques» ne doit donc pas être redouté. Au contraire, il peut même donner lieu à des échanges très enrichissants entre bibliothécaires et usagers, qui sont l'occasion de débattre de la vocation d'une bibliothèque, en rappelant ces principes de pluralisme et de neutralité.

Dans tous les cas, il vaut mieux préférer un filtrage a posteriori, plutôt que de vouloir contrôler les contributions avant même qu'elles soient formulées, au risque de décourager la participation. Pour cela, on peut s'appuyer sur des chartes, en particulier la charte de politique documentaire qui, si ce n'est déjà fait, doit être formalisée pour les collections. Pour d'autres projets, il est possible de créer des chartes spécifiques. Par exemple pour des projets de co-création de contenus, une charte doit rappeler des principes juridiques de droit d'auteur et définir les possibilités de réutilisations des contenus. Dans le cas des projets collaboratifs en ligne, on peut, de même, produire une charte des conditions de participation, et même utiliser les possibilités de collaboration pour contrôler les contributions a posteriori, par exemple en donnant la possibilité aux internautes de signaler des contenus inappropriés.

\section{B. Un questionnement sur la place du bibliothécaire}

Le travail de gestion et d'organisation des collections est au cœur du métier de bibliothécaire. C'est pourquoi, pour certains, la co-construction avec les usagers ne doit pas se faire dans le domaine des collections : 
Quant à la co-construction avec le public, il me semble qu'elle est vouée à l'échec si on se concentre sur les collections ; c'est bien plus dans les animations et les services offerts au public qu'il faut tenter des choses. Demander au public de travailler sur les collections, c'est lui demander de travailler pour nous. ${ }^{113}$

$\mathrm{Si}$ on laisse le public intervenir dans ce domaine, que devient la frontière entre l'usager et le professionnel ? Cette question se pose d'autant plus lorsque la démarche de co-construction s'accompagne d'un processus de qualification des usagers, décrit plus haut, qui leur permet de se familiariser avec les outils professionnels utilisés par les bibliothécaires. Peut-on alors dire que le bibliothécaire est remplacé dans son rôle?

Nous ne le pensons pas, car la co-construction des collections doit toujours être envisagée dans le cadre d'un projet. L'élaboration d'un projet de coconstruction doit s'accompagner d'une réflexion sur le sens de cette participation : pourquoi veut-on impliquer ce public ? quel type de public ? pour quel projet ? sur quels types de collections? Il ne s'agit pas, alors, de vouloir remplacer le professionnel, mais bien d'associer l'usager à la réflexion, dans le cadre d'un projet défini. Si cette réflexion sur le sens de la participation n'est pas conduite, le risque est de faire de la participation «prétexte» et de perdre les possibilités d'enrichissement mutuel. En revanche, préparer le projet à l'avance en définissant ce qu'on attend de cette participation, permet d'éviter cet écueil.

Dans cette optique, le rôle du bibliothécaire dans les projets de coconstruction s'inscrit en complémentarité de celui de l'usager :

Associer les habitants aux décisions visant à définir l'offre de la bibliothèque, ce n'est pas souhaiter le retour du bénévolat : c'est utiliser des compétences spécifiques, c'est rendre la bibliothèque plus proche des gens quand ils savent qu'ils y ont un espace d'intervention, reconnu et utilisé. (...) Les habitants ne prendront pas la place du personnel, ne le remplaceront pas dans ses compétences techniques strictes. Il s'agit de se mettre professionnellement dans une posture d'écoute active des populations que l'on doit servir, de valoriser, d'optimiser et d'intégrer des ressources que l'on ne trouve pas au sein de la bibliothèque. ${ }^{114}$

Le rôle du professionnel est nécessaire dans les projets de co-construction. Les usagers se voient donner la possibilité de participer, et une partie du pouvoir de décision et/ou de gestion leur est transférée. Cependant, le rôle du bibliothécaire reste fondamental car il garde la vision globale de la collection et des publics auxquels celle-ci s'adresse. Le bibliothécaire permet de contenir les contributions au sein du cadre prédéfini, et veille au respect de la charte de politique documentaire. Le bibliothécaire doit cependant se repositionner : il ne doit plus limiter ses tâches à l'organisation et à la gestion des collections. Son rôle, repensé, est moins celui d'un gestionnaire que celui d'un animateur et d'un médiateur qui

113 Commentaire en réaction au billet de blog: Bertrand Calenge, « Des publics utilisateurs aux publics collaborateurs : une fausse bonne idée ? », Bertrand Calenge : carnet de notes, 2012.

${ }^{114}$ Patricia Remy, op. cit. 
identifie les richesses sur le territoire, qui amène les usagers à participer et qui fait le lien avec la communauté.

\section{Des contraintes administratives et des marges étroites}

Les projets de co-construction des collections doivent également être compatibles avec le cadre administratif et réglementaire dans lequel la bibliothèque s'inscrit. La bibliothèque est en effet tenue d'exercer ses missions à la fois dans le respect de l'ensemble des textes (lois, décrets, règlements) qui s'appliquent, ainsi que dans le contexte des projets politiques locaux, de la vision de sa tutelle.

En temps normal la lecture est souvent considérée comme un enjeu secondaire aux yeux des élus locaux ${ }^{115}$, pour lesquels la gestion de la cité connaît d'autres priorités. Elle peut cependant les intéresser si on lui donne une dimension participative citoyenne. Les projets de participation, qui renforcent la proximité entre les citoyens et les services publics, bénéficient généralement d'une bonne image auprès des élus. La co-construction des collections peut alors être un moyen de faire de la lecture un enjeu politique et démocratique en laissant les citoyens se saisir de cette question. Mais cette participation ne peut passer outre l'inscription dans un contexte politique et doit se faire avec l'appui de la tutelle.

En effet, le directeur de bibliothèque n'est pas, dans les textes, le responsable de la collection :

La vocation des conservateurs et des bibliothécaires à constituer les collections s'inscrit dans le respect des compétences du conseil municipal en la matière. C'est du conseil municipal, en effet, que relève la politique de la bibliothèque, y compris sa politique d'acquisitions documentaires. Et c'est par une délégation du conseil, soit explicite soit implicite, que le directeur, conservateur ou bibliothécaire, remplit la mission que son statut lui assigne : en l'occurrence, constituer les collections. Il en résulte semble-t-il que le maire ne peut pas, de sa seule autorité, interdire ou ordonner des acquisitions. Il est non moins vrai qu'on voit mal le conseil, autrement dit la majorité dont procède le maire, se désolidariser de sa politique. ${ }^{116}$

Si les élus sont les véritables responsables de la collection, il est difficile en théorie de penser un projet de co-construction dans ce domaine qui soit mis en œuvre contre leur avis. Les projets de participation peuvent être très appréciés des élus, pour l'image inclusive et citoyenne qu'ils renvoient. Cependant, la participation peut aussi devenir revendicative pour l'élu car les initiatives de démocratie directe se construisent parfois en opposition à la traditionnelle démocratie représentative. C'est pourquoi il vaut mieux s'assurer d'avoir l'aval

${ }^{115}$ Laurence Tarin, «Des lecteurs aux élus : des représentations de la lecture. aux politiques de lecture », Bulletin d'informations de l'ABF, 1998, p. 56-65.

${ }^{116}$ Jean-Luc Gautier-Gentès, op. cit. 
des élus avant de lancer un projet de co-construction (voir partie 3 sur la préparation du projet). A l'inverse, de nombreuses actions de co-construction des collections en bibliothèque ont aussi été mises en œuvre à la demande des élus. En effet, elles s'inscrivent parfois dans un projet politique global d'augmenter la participation des usagers aux services publics sur le territoire administratif.

Les actions de co-construction doivent aussi tenir compte des contraintes administratives et institutionnelles. Bertrand Calenge a montré, dans un billet de blog au sujet des outils 2.0, que les ambitions collaboratives sont nécessairement limitées par le caractère institutionnel de la bibliothèque :

Or il ne faut pas oublier [...] une réalité qu'on me pardonnera de qualifier d'objective : même si nous sommes pleinement au service de nos concitoyens, nous le sommes dans le cadre contraignant d'administrations publiques régies par un complexe agencement de règles écrites (lois, décrets et circulaires) et d'objectifs politiques au sein desquels nous ne sommes que des rouages organisateurs de services. Dans ces circonstances, le "web 2.0." n'est pas une révolution : c'est une modalité d'action, possible mais limitée. En clair, c'est un outil de travail au sein d'une structure d'offre - la bibliothèque institutionnelle - qui ne peut jamais avoir l'ambition de renverser les limites structurelles imposées par les règles administratives et institutionnelles ! ${ }^{117}$

Les projets de co-construction ne visent donc pas à être totalement spontanés et s'inscrivent nécessairement dans un cadre.

Enfin, la co-construction implique d'y consacrer des moyens humains et matériels, pour lesquels les marges de manœuvre des bibliothèques sont généralement étroites. Si on ne peut garantir la pérennité des moyens tout au long du projet, le risque est de lancer un projet avec une bonne dynamique, qui devra cependant être abandonné faute de moyens. C'est d'autant plus regrettable que la participation des lecteurs suscite chez eux une attente par rapport à la bibliothèque et cette attente risque d'être déçue, même si les usagers peuvent être compréhensifs par rapport aux contraintes de moyens. La pérennité de certains projets de co-construction est constamment remise en question sous la menace de coupes budgétaires. Un projet comme Shopping book ${ }^{118}$ à la bibliothèque place des fêtes qui avait pourtant été très apprécié, à la fois par les usagers et les bibliothécaires, a dû être abandonné à cause de réductions de budget l'année suivante.

\section{La question de la représentativité des usagers}

Enfin, une critique récurrente relative aux actions de participation est le fait que les personnes volontaires sont une minorité active, mais non-représentative de

117 Bertrand Calenge, «Ambition collaborative et projet politique: quel espace pour une bibliothèque? », Bertrand Calenge : carnet de notes, 2008.

${ }^{118}$ Silvère Mercier, « Trois idées simples pour des bibliothèques plus accueillantes », Bibliobsession, 2011. 
l'ensemble des usagers. Ainsi, une personne répondait, en commentaire d'un article qui propose de donner la possibilité aux clubs de lecture de la bibliothèque de participer aux acquisitions :

L'idée est intéressante, mais présente un inconvénient notable du fait que le «club de lecture » ne représente pas, loin s'en faut, l'ensemble des publics fréquentant la bibliothèque mais seulement les «plus motivés »ou, plus prosaïquement, ceux ayant du temps libre. ${ }^{119}$

Ce commentaire met en lumière une limite de la co-construction, qui est qu'elle ne touche pas également l'ensemble des usagers. Sur le forum Agorabib, une réponse à un sujet sur la participation des usagers aux acquisitions soulevait un risque semblable :

Le pire ce sont les clubs de lecteurs ou associations d'usagers aux noms divers. A fuir comme la peste. On finit par y retrouver des profs, des élus, des présidents d'associations et autres huiles et gratins, qui finissent par constituer un lobby exerçant une pression importante sur la politique générale d'acquisitions, se pensant représentatifs du lectorat. (...) A mon avis la communauté des lecteurs d'une structure sera toujours mieux représentée par un professionnel que par un comité de personnes qui ne représenteront toujours qu'elles-mêmes. ${ }^{120}$

Il est en effet difficile, lorsque l'on souhaite mener des actions de participation, d'éviter l'écueil du manque de représentativité des usagers volontaires. La tentation peut alors être celle de laisser la décision au professionnel, dont le statut garantit la neutralité de son action. Le manque de représentativité des participants a deux causes principales. D'abord, comme nous l'avons vu, les projets de participation ne s'adressent pas qu'aux usagers de la bibliothèque mais potentiellement à toute la communauté. Cependant, on manque souvent de moyens pour toucher les «non-usagers », qui ne fréquentent pas la bibliothèque. Ensuite, parmi les usagers, il faut essayer de mettre en œuvre des solutions pour toucher au-delà du cercle des « habitués », ceux qui sont déjà actifs, qui connaissent les codes de la bibliothèque et qui participent régulièrement aux animations.

Le manque de représentativité des usagers volontaires est une vraie limite, mais des réponses peuvent être apportées afin de contourner cet écueil. Celles-ci seront développées dans la $3^{\mathrm{e}}$ partie, mais certains éléments peuvent déjà être apportés ici. Il nous semble que c'est à la bibliothèque de faire en sorte de susciter des participations variées. Au lieu d'un projet généraliste, il vaut mieux cibler le public visé ou les domaines de collections concernés, ce qui permet de toucher des communautés d'âges ou d'intérêt, qui vont mobiliser au-delà des « habitués » des animations. Si on construit par exemple un projet de co-construction autour des

${ }^{119}$ Commentaire en réaction au billet de blog : Hubert Guillaud, « Le lecteur : agent actif », La feuille - L'édition à l'heure de l'innovation, 2004.

${ }^{120}$ Echange sur le sujet «Participation du public aux acquisitions - Les publics - agoraBib », op. cit. 
bandes dessinées, il est possible de motiver des amateurs et connaisseurs de BD, qui n'auraient pas forcément participé à d'autres types d'animations. Un vrai travail doit aussi être mené, en suivant l'exemple du projet Working together, pour mobiliser les habitants de façon plus large que les seuls usagers. Un diagnostic de territoire doit être mené, pour identifier les ressources et les potentialités.

La question des pressions exercées par un groupe d'usagers se pensant représentatif doit aussi être réglée. Des pistes ont déjà été évoquées, notamment celle de toujours penser le rôle du bibliothécaire en complémentarité, et de reconnaître son rôle de professionnel, gardant un œil sur la cohérence de la collection dans sa globalité. Les pressions sur l'offre de la bibliothèque renvoient à la première limite, celle d'une perte de contrôle sur les collections. Là aussi, il convient de cadrer la participation avec une charte de politique documentaire formalisée pour éviter les débordements.

Les différentes limites que nous avons développées dans ce paragraphe ne doivent toutefois pas décourager les projets de co-construction. Il convient, comme nous allons le voir maintenant, de bien préparer ces projets en amont pour que ces éventuels dérapages soient évités. 


\section{PARTIE 3 : COMMENT CONDUIRE UN PROJET DE CO-CONSTRUCTION DES COLLECTIONS ?}

La co-construction des collections peut apporter beaucoup à la bibliothèque, mais nécessite un véritable travail de préparation et d'organisation du projet. La difficulté principale, selon nous, est la mobilisation des participants au projet et la prolongation de leur implication dans la durée. Comment intéresser les habitants aux enjeux des collections, qui sont, au fond, des préoccupations professionnelles ? Comment mobiliser des acteurs non-professionnels et volontaires au quotidien dans la vie de l'établissement? Des pistes de réponse à ces questions seront données pour chacune des étapes de la démarche de co-construction, qui, comme tout projet, se structure en trois temps : la préparation du projet, sa mise en œuvre, puis son évaluation.

\section{Preparer le Projet EN AMONT}

Pour éviter les écueils soulevés dans la partie précédente, il est fondamental de bien préparer un projet de co-construction des collections avant de le mettre en œuvre. Nous allons développer trois points qui nous semblent importants dans cette phase de préparation: penser la participation de façon globale dans sa politique d'établissement, désamorcer par avance les éventuels freins et obstacles à la participation et définir le cadre dans lequel celle-ci pourra s'exercer.

\section{A. Faire de la participation un axe fort de sa politique d'établissement}

La co-construction avec les usagers implique un changement plus global de la relation de la bibliothèque à son public. Elle ne peut donc pas être pensée comme une action isolée, déconnectée du reste de l'activité de la bibliothèque. La co-construction doit ainsi être prise en compte de façon globale dans l'établissement, en accord avec les missions et les projets de la bibliothèque. Pour s'assurer du soutien des élus, il est possible d'inscrire l'objectif de faire participer les usagers dans le projet d'établissement présenté à la tutelle. En faisant de la coconstruction une priorité de l'institution, elle doit aussi être mise en lien avec les autres activités de la bibliothèque. Dans tous les exemples que nous avons étudiés, les actions de co-construction ne se limitent pas aux collections et sont le plus souvent prolongées par d'autres projets dans la bibliothèque qui mobilisent la participation des usagers. La co-construction dans les collections est souvent prolongée par des actions d'animation, faisant également appel aux contributions des usagers. Parfois, la participation des usagers s'inscrit même dans un ensemble plus large, à l'échelle de toute la collectivité. A Méricourt, la municipalité a une volonté forte de développer des actions de démocratie participative. La mairie est à 
l'origine de la création du «collectif médiathèque », qui a été complété par de nombreux autres collectifs faisant appel aux participations citoyennes. Par exemple un collectif appelé « et si on faisait un bout de chemin ensemble » a pour objectif de créer ou valoriser des itinéraires piétons sécurisés et agréables. La coconstruction avec les habitants est envisagée ici au-delà de la bibliothèque, à l'échelle de toute la cité.

Choisir de faire de la co-construction avec les usagers un principe fort de la bibliothèque ou de la municipalité ne suffit pas, il faut également conduire une réflexion sur les moyens, à la fois humains et matériels qu'on peut lui consacrer. Même si la participation est affichée comme une priorité de l'établissement, il est difficile de la prendre en compte si ce n'est pas un objectif formalisé dans l'organisation de la bibliothèque. Cette formalisation de l'objectif passe par l'inscription dans les fiches de poste de la mission d'organiser des actions de coconstruction des collections et par la libération de temps de travail que l'on peut consacrer à ces projets. Il est également possible de créer un poste dans l'organigramme dédié aux projets de participation, qui aurait une compétence transversale. Le travail d'animation d'une communauté peut rapidement devenir très «chronophage », c'est pourquoi il est important de dégager de temps de travail aux agents qui sont en charge de ces programmes. Cependant, certains projets simples peuvent être menés qui ne demandent pas d'y consacrer des moyens considérables. Par exemple, pour le projet Conciliabulle à la médiathèque de Rillieux-la-Pape (office de lecture participatif pour le choix des bandes dessinées, avec une dizaine de lecteurs pour un rendez-vous de $2 \mathrm{~h}$ une fois par trimestre), les deux bibliothécaires qui animent ce club ont estimé leur temps de travail à 36h annuelles (préparation et animation des séances). Le budget annuel d'acquisitions est de $1200 €$, représentant un tiers du budget des acquisitions en bande dessinée (3500€). Certaines actions simples de co-construction des collections peuvent donc être mises en place et sont à la portée de toutes les bibliothèques, y compris celles qui ont peu de moyens. D'autres types de démarches beaucoup plus poussées en termes de participation mobilisent en revanche des moyens très importants, en particulier lorsqu'on souhaite mobiliser au-delà du cercle des usagers et aller à la rencontre du «non-public » pour le faire venir à la bibliothèque. La réflexion sur les moyens est indispensable, pour le lancement du projet mais aussi pour sa pérennisation dans le temps. De nombreux projets de co-construction des collections sont ainsi lancés au moment de la création d'un nouveau fonds ou de l'ouverture d'une bibliothèque, car cela nécessite d'avoir prévu des moyens importants qui rendent possibles les actions de participation.

La phase de préparation en amont doit aussi être l'occasion d'une réflexion sur l'objectif du projet de co-construction des collections, ceci afin d'éviter la «participation pour la participation ». En effet, la co-construction, la participation sont des thèmes très actuels, dont on entend beaucoup parler en bibliothèque. Beaucoup d'établissements envisagent de mener des actions en collaboration avec les habitants, afin de renforcer leur proximité avec le territoire et de répondre aux exigences de faire plus de place à la démocratie participative. Mais la coconstruction n'est pas une fin en soi, c'est un moyen au service d'un objectif. C'est pourquoi il faut toujours s'interroger, avant de mettre en place un projet, sur l'objectif, sur les résultats attendus de l'entreprise de co-construction des collections, qui ne doit être qu'un outil. Par exemple, à Rillieux-la-Pape, un élu souhaitait, dans une volonté de développer la démocratie participative au sein de la commune, mettre en place un comité d'usagers à la bibliothèque. Ne voyant pas 
l'intérêt d'un comité d'usagers aux compétences générales, dont le rôle aurait été de donner des avis sur le fonctionnement global de la médiathèque, la directrice a proposé plutôt d'utiliser la participation dans un autre objectif : la mise en valeur du fonds de bandes dessinées, ce qui a donné naissance au club Conciliabulle. Les objectifs peuvent être très divers : développer un domaine de la collection comme ici, travailler avec un public cible, faire venir les «non-usagers » à la bibliothèque, augmenter l'audience d'une collection, enrichir une collection particulière par des contributions d'usagers, etc. Nous reprenons ici des exemples étudiés mais bien d'autres actions sont possibles et sont encore à inventer.

\section{B. S'attaquer aux freins}

Lorsqu'on prépare un projet de co-construction des collections, il vaut mieux désamorcer les éventuels obstacles et réticences avant qu'elles n'émergent.

D'abord, il est possible selon les bibliothèques, se retrouver confronté à des réticences au sein de l'équipe de bibliothécaires. En effet, la participation des usagers au fonctionnement interne de la bibliothèque, et en particulier aux tâches concernant les collections peut soulever certaines inquiétudes : crainte de perdre la mainmise sur les collections, crainte de devoir gérer des contributions compliquées de la part des usagers, crainte que certains usagers fassent pression sur la politique documentaire, etc. (cf. III. de la Partie 2). Il faut donc convaincre les collègues, qui doivent accepter de renoncer à une partie de leurs prérogatives sur la gestion des collections, compétence à haute valeur symbolique comme nous l'avons vu. Certains personnels peuvent également considérer cette démarche comme une remise en cause de leur travail :

Quand la planification des programmes en collaboration avec la communauté est entreprise pour la première fois, il y aura sans doute une certaine résistance du personnel qui a l'impression que ses compétences sont remises en question. ${ }^{121}$

La co-construction signifie que l'on délègue une partie de la décision aux usagers, ce qui peut donner lieu à des hésitations. En effet, si les bibliothécaires sont dans le principe, très favorables à la participation, à la prise en compte des contributions des usagers et au renforcement de leur proximité avec le public, ils aiment aussi la prescription et peuvent avoir des réticences à y renoncer. Il s'agit alors d'expliquer que la co-construction n'est pas une politique de la demande, mais qu'elle doit donner lieu à un échange enrichissant sur les collections. Afin de réduire les craintes relatives aux atteintes à la neutralité et au pluralisme des collections, une charte de collection (si elle n'existe pas déjà) peut être formalisée. Enfin, il faut rappeler le principe fort suivant: le positionnement de la bibliothèque est au service de la satisfaction du plus grand nombre et non de

\footnotetext{
121 « Trousse d'outils pour des bibliothèques à l'écoute de la communauté », op. cit., p. 93.
} 
quelques usagers réguliers. Au fond, il s'agit de reconfigurer, en partenariat avec le bibliothécaire, son positionnement : d'un rôle de gestionnaire des collections à celui d'un animateur/médiateur des collections.

D'autres éventuels freins à la participation peuvent être désamorcés à l'avance, mais cette fois du côté des usagers. Le projet Working Together a engagé toute une réflexion sur les obstacles systémiques qui empêchent les communautés socialement exclues de fréquenter la bibliothèque ${ }^{122}$. Le travail de collaboration avec la communauté est fondamental car ces obstacles, qui relèvent à la fois de perceptions très subjectives (impression de ne pas être bienvenu à la bibliothèque) ou d'éléments très concrets (horaires de bus qui ne correspondent pas à celle d'une animation), sont très difficiles à identifier sans dialogue direct avec les habitants. La réflexion sur les obstacles dépend du projet de co-construction. Si celui-ci implique des réunions, il faut s'interroger sur les horaires de celles-ci : par exemple, les usagers seront peut-être plus disponibles un dimanche qu'un mercredi soir ? Une réflexion doit aussi être menée sur les espaces. On peut avoir tendance à programmer ces séances dans une salle de réunion le soir, lorsque la bibliothèque est fermée. Pourquoi ne pas les faire au contraire pendant un temps d'ouverture, dans un espace au milieu des collections afin que l'action collaborative soit visible de tous ? Aurait-on également intérêt à programmer des interventions hors les murs ? Par exemple, lors de choix d'acquisitions participatifs, pourquoi ne pas programmer la séance directement en librairie ? Est-ce que les habitants de ce quartier participeraient à la co-création de ce livre si les séances avaient lieu làbas? En effet, la réflexion sur les espaces concerne également la place du lieu «bibliothèque » sur tout le territoire. Par exemple, dans le projet Working Together, un bibliothécaire spécialiste du développement communautaire ${ }^{123}$ a pu identifier, par son travail en collaboration avec des communautés défavorisées, un obstacle concernant les ressources pour la recherche d'emploi. Certaines de ces collections, dans les succursales de quartier de la bibliothèque, étaient cruciales pour les habitants, mais parfois lacunaires. Cette collaboration avec les habitants a permis d'engager une réflexion sur la politique d'acquisition de ces ressources (développer des collections exclues du prêt pour éviter que les ouvrages soient toujours sortis) et sur leur répartition sur le territoire (mieux répartir les collections dans les succursales de quartier).

\section{Encadrer la participation}

Il peut sembler paradoxal, après avoir plaidé pour la suppression de tous les freins à la participation, de vouloir encadrer l'entreprise de co-construction. Le paradoxe n'est cependant qu'apparent, car le fait d'encadrer la participation n'est pas incompatible avec le projet de co-construction, il est même nécessaire. En effet, faire participer les usagers ne signifie pas accéder à toutes leurs demandes. Dans la définition de la co-construction des collections donnée dans ce mémoire (Partie 1, II), nous avons d'ailleurs évoqué le fait que, si la bibliothèque transfère le processus de décision aux usagers, elle en définit préalablement l'objectif et le

\footnotetext{
122 « Trousse d'outils pour des bibliothèques à l'écoute de la communauté », op. cit., p. 20-23.

${ }^{123}$ Ibidem, p. 107.
} 
cadre. La co-construction s'inscrit dans une ambigüité, que l'on peut rapprocher de celle du projet du pédagogue : je te donne une liberté maximale dans le cadre que j'ai prescrit. La prise de décision est réellement transférée, c'est-à-dire que les usagers peuvent statuer à la place du bibliothécaire, mais cette délégation ne peut concerner que le domaine prédéfini, dans les limites fixées à l'avance.

Certaines ambitions collaboratives au contraire partent du postulat que toute expression et toute contribution sont bonnes à entendre et par conséquent, la participation doit être spontanée et non-encadrée. Ces ambitions s'inscrivent dans une théorie utopiste du peuple souverain, qui exprime nécessairement une vérité. Cependant, la co-construction des collections en bibliothèque se fait obligatoirement au sein d'une structure institutionnelle, soumise elle-même à des contraintes $^{124}$. Les projets de participation sans aucune limite ne semblent pas réalisables, parce qu'une des parties au projet est elle-même une institution, qui applique des règles et qui en produit.

L'encadrement de la participation relève néanmoins d'un subtil équilibre à trouver: si les programmes de co-construction des collections s'exercent nécessairement au sein de cadres, les appels à participation qui fonctionnent le mieux sont aussi ceux qui imposent le moins de contraintes. Ce phénomène a pu être observé lors des entreprises de collaboration à travers des outils 2.0. Des projets qui fonctionnent très bien, tels Trove ${ }^{125}$, de la National Library of Australia ou ceux du New York Public Library Labs ${ }^{126}$ permettent de contribuer sans aucune inscription préalable (sur le modèle de Wikipédia). En revanche, les internautes sont incités à s'inscrire et ouvrir un compte pour suivre et comptabiliser leurs contributions. Les meilleurs contributeurs sont mis en valeur par des classements.

Les projets qui font appel aux contributions des internautes réussissent mieux lorsqu'ils ne sont pas modérés, ni rattachés à une institution. Par exemple, l'ajout de fonctionnalités 2.0 aux catalogues des bibliothèques a rarement fonctionné. La plupart du temps, les usagers ne se sont pas emparés de ces fonctionnalités et la participation a souvent été confidentielle ${ }^{127}$. En revanche, le catalogage social sur 1'application Librarything fonctionne très bien ${ }^{128}$. Cette application web propose, comme pour les catalogues 2.0, d'ajouter des commentaires ou des tags sur des notices de livres. Les internautes peuvent créer leurs propres bibliothèques grâce à des notices des livres récupérées, les classer et les identifier. Selon Cécile Touitou, les raisons qui expliquent le succès des «tags » sur Librarything sont, d'une part, le fait qu'il n'y ait aucune modération des contributions, et d'autre part, le fait que l'application ne soit liée à aucune institution en particulier ${ }^{129}$. La co-construction des collections doit aussi préférablement utiliser des licences libres, afin de favoriser la diffusion et les réutilisations des collections mises en ligne ou des contributions ${ }^{130}$.

\footnotetext{
${ }^{124}$ Bertrand Calenge, op. cit.

${ }^{125}$ http://trove.nla.gov.au/ Consulté le 11 novembre 2013

${ }^{126}$ http://www.nypl.org/collections/labs Consulté le 11 novembre 2013

${ }^{127}$ Lionel Dujol, «Le catalogue 2.0 ou le mythe de l'usager participatif? », La bibliothèque apprivoisée, 2009

${ }^{128}$ Hubert Guillaud, op. cit.

${ }^{129}$ Cécile Touitou, op. cit.

${ }^{130}$ Lionel Dujol, op. cit. Diapositive ${ }^{\circ} 42$
} 
La nécessite d'utiliser le moins de filtres possible s'applique aussi pour les projets de co-construction dans la bibliothèque «physique » avec les usagers. En effet, il vaut mieux éviter, afin de ne pas décourager la participation, d'exiger des engagements de la part des usagers. Cela fait partie des éléments difficiles à gérer lorsqu'on construit le projet mais il faut l'organiser de manière à ce que des usagers puissent se joindre à l'entreprise alors qu'elle est déjà commencée, et également pouvoir revenir même s'ils ont manqué une séance. Par exemple, le collectif médiathèque de Méricourt a pu accueillir jusqu'à 70 personnes, mais parmi eux, les bibliothécaires ont pu s'appuyer sur un noyau d'une trentaine de participants assidus. La fidélisation des usagers participants ne doit pas se faire à travers un engagement «institutionnalisé », qu'ils ont pris au départ car la participation contrainte est moins enrichissante. La fidélisation se fera naturellement si les usagers trouvent un intérêt à revenir participer au projet.

Il faut donc chercher à « institutionnaliser » le moins possible la participation et à laisser le maximum de libertés. Cela n'empêche pas, comme nous l'avons vu, de fixer des cadres, sous la forme d'une charte de politique documentaire, ou d'une formalisation des conditions de participation ${ }^{131}$, qui empêchent les dérapages. Les contributions qui ne respectent pas ces chartes peuvent être censurées a posteriori. Cependant, si une contribution d'un usager doit être rejetée, il convient d'expliquer clairement les raisons pour lesquelles elle n'est pas retenue. Il y a plus à gagner à assumer la transparence et à expliquer les raisons des actions de contrôle des contributions. Dans le cas contraire, on risque de susciter l'incompréhension et de décourager la participation.

\section{ORgANISER LA PARTICIPATION}

Sachant que les projets de co-construction s'appuient sur une participation volontaire et non-rémunérée de la part des usagers, il faut trouver des moyens de susciter l'adhésion des usagers. L'enjeu est d'abord de recruter des participants au projet de co-construction, mais surtout de faire en sorte de maintenir leur engagement sur la durée.

\section{A. Comment mobiliser ?}

Pour mobiliser des usagers autour d'un projet de co-construction, il faut bien cerner quel public on veut toucher et identifier leurs attentes par rapport à ce projet.

131 Par exemple, les «terms of use» de Trove: http://trove.nla.gov.au/general/termsofuse Consulté le 15 


\section{Qui recruter?}

Le premier public auquel s'adresser pour mener des projets de coconstruction des collections est naturellement celui des usagers. L'enjeu est ici de mobiliser au-delà des usagers déjà «actifs », ceux qui participent aux clubs de lectures, aux animations et qui ont déjà un lien fort avec la bibliothèque. L'idée n'est pas de les écarter, au contraire, mais de recruter également d'autres types d'usagers, qui ont en temps normal un rôle plus «passif » dans la bibliothèque. La motivation des usagers à participer passe d'abord par un travail de communication autour du projet de co-construction. Outre les formes de communication écrite classiques (affiches, flyers, emails aux usagers, informations dans le bulletin municipal, voire dans la presse locale, etc.), le recrutement des usagers doit s'appuyer sur les relations de personne à personne : lors des contacts établis avec les usagers dans la bibliothèque, par exemple lors des transactions de prêt, ou des demandes de renseignements, de conseils. L'avantage de ce mode de recrutement direct est qu'il permet d'avoir déjà «brisé la glace » et peut motiver des usagers qui n'auraient pas osé franchir le premier pas et s'engager d'eux-mêmes à participer. Une autre technique est de s'appuyer sur des usagers déjà actifs pour en toucher d'autres : par exemple, engager une conversation avec un parent qui vient à la bibliothèque seulement pour accompagner son enfant et lui demander ce que lui aimerait trouver dans la collection.

Ensuite, il est très important, pour recruter des participants, de s'appuyer sur des relais et des communautés préexistantes. Cela permet d'une part de recruter audelà du cercle des usagers de la bibliothèque, et surtout de motiver de façon plus efficace en s'appuyant sur des liens déjà constitués. S'appuyer sur des communautés permet en effet d'économiser le travail qui consiste à créer soimême un groupe en ne partant d'aucun lien déjà établi, et il vaut mieux dans ce cas solliciter des associations préexistantes. La bibliothèque peut s'appuyer sur de nombreux relais sur le territoire, avec lesquels des partenariats existent souvent déjà $^{132}$ : associations, écoles, maisons de quartier, centres sociaux, hôpitaux, conservatoires d'enseignement artistiques, etc. Par exemple, Wiki-Rennes, l'encyclopédie collaborative de la ville de Rennes ne pourrait exister sans le travail de l'association Bug $^{133}$, qui permet de mobiliser un réseau de 350 adhérents/bénévoles ${ }^{134}$.

Cette nécessité de s'appuyer sur des relais est aussi valable pour les projets de co-construction des collections qui impliquent des contributions en ligne. Plusieurs bibliothèques se sont appuyées par exemple sur le site Flickr (site de partage d'images) pour mettre en ligne des collections d'images numérisées, notamment à travers le programme The Commons ${ }^{135}$. Ce programme s'adresse à des établissements publics comme les bibliothèques, les archives, etc. et leur propose de diffuser leurs collections sur le site Flickr, en étant identifiés et mis en valeur en tant qu'institution et non en tant que contributeur lambda. Cela permet

\footnotetext{
${ }^{132}$ Lucie Henry, op. cit., p. $65-74$.

${ }^{133}$ Fabien Eychenne et Marine Albarede, «Ville 2.0 : favoriser l'accès à la ville et faire du numérique un facteur de lien social », in Bibliothèque 2.0 à l'heure des médias sociaux, Paris, France, Éd. du Cercle de la librairie, 2012, («Bibliothèques »), p. 177-186.

${ }^{134}$ http://www.asso-bug.org/lequipe Consulté le 18 novembre 2013

${ }^{135}$ http://www.flickr.com/commons/institutions/ Consulté le 18 novembre 2013
} 
aux bibliothèques d'utiliser la communauté d'internautes déjà constituée autour du site, ce qui a deux avantages. D'une part cela augmente fortement l'audience de la collection auprès d'une communauté qui partage déjà un intérêt pour les images et photographies. D'autre part, les collections sont enrichies par les internautes qui peuvent identifier et référencer les photographies par l'ajout de commentaires et de tags, de manière là-aussi beaucoup plus efficace car cette communauté est déjà habituée à ce type d'usages sur le site :

La présence des bibliothèques sur ce type de sites tiers leur permet d'exposer leurs ressources dans des espaces virtuels où les communautés d'internautes sont déjà constituées et où le ferment est justement l'activité des contributeurs - stratégie plus efficace que celle d'aller à la recherche aléatoire de contributions hypothétiques de la part de lecteurs qui auraient développé un lien suffisamment fort avec leur bibliothèque de quartier pour souhaiter laisser sur son site ou sur son catalogue un commentaire sur le dernier ouvrage paru. Spontanément, ne souhaite-t-on pas d'abord en faire profiter la communauté de ses pairs (experts) plutôt que d'anonymes voisins (profanes) ? ${ }^{136}$

Ainsi, Patrick Hernebring compare deux projets de collections numériques menés par la bibliothèque municipale de Toulouse : d'une part la bibliothèque numérique Rosalis ${ }^{137}$, portail mis en place par la bibliothèque qui présente 60.000 documents numérisés et d'autre part la collection Eugène Trutat mise en ligne via le programme The Commons de Flickr, qui comprend 30 fois moins de documents. La bibliothèque Rosalisest plus riche en documents et a mobilisé des moyens humains et financiers très conséquents, mais les chiffres de fréquentation de ces deux collections sont comparables. En effet, Rosalis draine un public que Patrick Hernebring appelle le public «naturel » des bibliothèques, alors que Flickr permet de toucher une communauté préexistante et bien plus importante en nombre ${ }^{138}$. Le projet Rosalis intègre également un volet qui permet la participation, mais ses résultats sont très décevants alors que la collection Trutat a été enrichie par des commentaires d'internautes sur Flickr ${ }^{139}$. Cela montre là aussi qu'il est plus facile de solliciter la participation de communautés préexistantes que celle d'internautes « isolés ».

Hervé Le Crosnier soulève cependant une limite à l'utilisation de sites comme Flickr pour diffuser les collections des bibliothèques et recueillir les contributions des usagers. En participant à ces programmes, les institutions renforcent économiquement les sites agrégateurs existants : faut-il accepter ce fait ou essayer de construire des communautés indépendantes ${ }^{140}$

\footnotetext{
${ }^{136}$ Cécile Touitou, op. cit., p. 76- 77.

${ }^{137}$ http://rosalis.bibliotheque.toulouse.fr/ Consulté le 5 octobre 2013

${ }^{138}$ Patrick Hernebring, op. cit

${ }^{139}$ Patrick Hernebring, «Rosalis, à la croisée des chemins », Bulletin des Bibliothèques de France, vol. 58 / 5,

${ }^{140}$ Hervé Le Crosnier, op. cit.
} 2013. 
Il est possible d'aller plus loin, dans la phase de mobilisation des usagers, que le recours à des relais et des communautés préexistantes. Le projet Working Together que nous avons déjà évoqué est particulièrement ambitieux dans ses actions de recrutement de participants. Ce programme a pour objectif de faire venir à la bibliothèque les populations socialement exclues en utilisant les techniques de co-construction et de collaboration. L'enjeu est donc d'entrer en contact avec des populations avec lesquelles il est justement difficile de construire des liens en temps normal. Les bibliothécaires spécialistes du développement communautaires se sont appuyés sur plusieurs techniques pour approcher ces habitants ${ }^{141}$. Ils ont utilisé la méthode des relais, qu'ils appellent " approche facilitée par un tiers », c'est-à-dire en sollicitant les services sociaux qui travaillent avec les personnes socialement exclues. Ils sont également entrés en contact avec les habitants en faisant du porte-à-porte et des promenades dans le quartier pour toucher les usagers dans les lieux qu'ils fréquentent quotidiennement. Les bibliothécaires sont aussi allés à la rencontre d'habitants en participant à des évènements communautaires, en utilisant le bouche-à-oreille, etc. Ces techniques, qui impliquent un travail considérable de mise en place, permettent d'entrer en contact avec les habitants au cœur de leur mode de vie et de toucher des habitants qui ne fréquentent jamais la bibliothèque.

\section{Trouver l'intérêt qui va susciter la participation}

Après avoir ciblé le public que l'on veut recruter, il faut s'interroger sur les motivations qui vont le pousser à participer au projet de co-construction. Dans la nouvelle économie de la connaissance, beaucoup d'initiatives reposent sur les contributions d'usagers. Selon Bernard Stiegler, l'argent n'est plus la source de motivation principale, ou en tout cas ce n'est plus un intérêt unique ${ }^{142}$. D'autres sources de motivation peuvent être mobilisées: la passion, le désir de reconnaissance, et, point sur lequel il insiste, la question du sens que le contributeur donne au projet, qui prend selon Bernard Stiegler une place centrale.

Il existe de nombreux moyens d'attirer les participations des usagers en bibliothèque, mais encore faut-il identifier la façon dont on peut les solliciter. Selon Valérie Beaugier, animatrice du club Lékridézados, le public adolescent, pourtant réputé difficile à toucher en bibliothèque, peut facilement être sollicité pour des projets de participation : "On peut les motiver très facilement, encore faut-il avoir des choses à leur proposer ».

De nombreux projets de co-construction échouent en partie parce qu'ils n'arrivent pas à soulever un intérêt à participer pour l'usager ${ }^{143}$. Les appels à participation lancés «dans le vide» restent souvent sans réponse. Un internaute exprime ainsi très clairement la nécessité de cibler les personnes que l'on souhaite mobiliser :

\footnotetext{
${ }^{141}$ Outil $\mathrm{n}^{\circ} 1$ «Entrée dans la communauté » dans «Trousse d'outils pour des bibliothèques à l'écoute de la communauté », op. cit., p. 36-49.

${ }^{142}$ Quentin Noirfalisse, op. cit.

${ }^{143}$ Bertrand Calenge, «Des publics utilisateurs aux publics collaborateurs : une fausse bonne idée? », Bertrand Calenge : carnet de notes, 2012.
} 
Mais ce que j'observe de moi-même et des autres (...) [est qu']on est prêt à passer du temps suite à une interpellation personnelle (...) [plutôt] qu'à un appel général lancé à l'assemblée. Qu'une personne me sollicite et je pourrais lui consacrer $1 / 2$ heure ou 3/4 sans difficulté. Mais si je reçois un simple mail : «merci de répondre à l'enquête », je vais en conclure que d'autres le feront aussi bien. ${ }^{144}$

Il faut donc essayer de mettre en avant un intérêt personnel qu'aurait l'usager à participer. Pour prendre un exemple simple, il ne suffit pas de dire «Venez participer aux collections », appel qui risque de rester sans réponse. En revanche, dire «Venez choisir les bandes dessinées que vous pourrez lire à la bibliothèque » est plus motivant et suscitera plus de participations.

Pour déterminer quels intérêts peuvent être mis en avant, il faut cibler un public et identifier des besoins, des attentes parmi cette communauté. La bibliothèque d'Oakland offre un exemple singulier de cette recherche d'adéquation aux besoins des habitants. Après un violent incendie en 1991, qui a fait plusieurs victimes et de considérables destructions, la «Temescal Branch library » a créé une bibliothèque d'outils, prêtés gratuitement aux habitants pour aider à la reconstruction $^{145}$. Cet exemple met en valeur la réactivité que peut avoir une bibliothèque pour répondre aux besoins très concrets de la communauté. Cette collection de 3500 outils, livres et DVD pratiques, s'appuie aussi sur la participation d'habitants volontaires pour l'entretien et l'organisation de cette tool lending library (bibliothèque d'outils).

Dans le projet Working Together, les bibliothécaires sont allés plus loin et ont essayé que la participation ne soit pas suggérée par la bibliothèque, mais proposée par le public lui-même. Ce sont les usagers qui, à la suite de l'identification d'un besoin, doivent reconnaître l'intérêt de participer aux collections :

Vos discussions informelles avec les membres de la communauté révèleront bon nombre de leurs besoins et intérêts. Lorsque cela semble approprié, vous pouvez leur demander s'ils seraient intéressés à prendre part au développement d'une collection. Par exemple, un groupe d'adolescents qui parlent de l'astrologie pourraient être intéressés à choisir de la documentation sur ce domaine. Demandez-leur s'ils voudraient aider la bibliothèque lorsqu'elle sélectionne des livres sur l'astrologie. Quelques membres de la communauté pourraient avoir besoin de temps pour se faire à cette idée. ${ }^{146}$

Les questions à se poser sont les suivantes : quelles sont les attentes du public que l'on souhaite toucher ? Ces attentes sont à mettre en rapport avec

\footnotetext{
${ }^{144}$ Commentaire en réaction au billet de blog Ibidem.

${ }^{145}$ http://oaklandlibrary.org/locations/tool-lending-library Consulté le 13 décembre 2013

146 « Trousse d'outils pour des bibliothèques à l'écoute de la communauté », op. cit., p. 106.
} 
l'objectif de la bibliothèque, défini en amont lors de la phase de la préparation du projet.

Nous avons établi une liste de plusieurs types de motivations à participer qui peuvent être utilisées pour mobiliser des volontaires pour le projet de coconstruction :

- Pouvoir partager ce que j'aime avec d'autres personnes

- Découvrir ce que je ne connais pas

- Apporter une aide : j'ai des connaissances dans ce domaine qui peuvent être utiles

- Avoir accès en avant-première aux nouveautés

- Intérêt pour la vie de la cité en général, qui dépasse le champ de la bibliothèque

- Curiosité de savoir comment la bibliothèque fonctionne de l'intérieur, de voir «l'envers du décor»

- Développer un sentiment d'appartenance, une impression de devenir un usager «privilégié »

- Voir mes contributions mises en valeur

- Envie de contact, de socialisation, de rencontrer des personnes qui partagent un même intérêt

- Sentir une émulation collective : partager des goûts, avoir envie de lire/écouter ce que partagent les autres

- Etc.

Ces différents types d'intérêts peuvent évidemment être combinés et mobilisés en même temps. On note que les motivations à la participation sont nombreuses et variées. La diversité des raisons qui guident la participation résulte en une diversité des profils des participants, notée chez la plupart des bibliothécaires que nous avons rencontrés. Les projets de co-construction des collections, lorsqu'ils sont préparés de façon à désamorcer les obstacles systémiques (cf. préparation du projet), permettent de réunir des usagers d'âges, de profils, de conditions sociales, etc. très variés. Ils permettent également de faire participer au-delà des « habitués »: par exemple, dans le cercle des auditeurs de la Croix Rousse, qui compte une vingtaine de participants, seule une personne est membre du club de lecture de la bibliothèque et une autre avait déjà participé à des animations. Six personnes seulement avaient le profil d' «habitués » de la bibliothèque.

Afin de garantir cette diversité des profils, il convient de bien préciser dans la communication autour du projet qu'aucune compétence particulière n'est demandée pour participer. Ceci permet que tous les usagers se sentent potentiellement concernés, et évitent de se dire que ce n'est pas pour eux. 


\section{Sous quelle forme?}

D'autres questions sont à se poser sur la forme donnée à la participation. L'objectif d'un projet de co-construction des collections n'est pas que les contributions restent isolées les unes des autres, mais plutôt de donner le sentiment de participer à une entreprise collective, de favoriser, par la configuration choisie, les échanges et les enrichissements mutuels. Il faut donc créer une communauté et faire sentir aux usagers participants l'appartenance commune à un même cercle. L'exemple de Gallica est ici signifiant : par des actions de médiation participative très efficaces sur les réseaux sociaux, les responsables du projet ont réussi à créer une véritable communauté autour de la fameuse bibliothèque numérique, communauté à laquelle ils ont même donné un nom : les «Gallicanautes ». Au sein de la bibliothèque, plusieurs formes d'organisation sont possibles pour cette communauté d'usagers participants. Les noms que l'on peut leur donner sont divers : cercle d'usagers, club, collectif, etc.

Une question à résoudre est celle de savoir s'il faut donner une existence institutionnelle à ces groupes d'usagers, au sein de l'organigramme de la bibliothèque. Selon nous, il est préférable d'éviter, si cela est possible, d'institutionnaliser la co-construction, car cela risque de décourager la participation d'usagers qui ne souhaitent pas d'engagement officiel. La reconnaissance d'une existence institutionnelle dans l'organigramme risque également d'élargir le champ de compétence de ce cercle d'usagers au fonctionnement plus général de la bibliothèque, ce qui n'est pas souhaité. Les usagers eux-mêmes préfèrent souvent que leur existence dans la structure reste libre et informelle. Ainsi à Méricourt, il a été question, une fois la nouvelle médiathèque inaugurée, de donner une existence institutionnelle au collectif médiathèque en le transformant en association. Les usagers du collectif ont été consultés et ont majoritairement souhaité garder cette existence informelle. Cette absence d'officialisation de la participation n'empêche pas les usagers de répondre présent à chaque fois que la médiathèque fait appel à eux et de rester très investis dans 1'établissement. La bibliothèque les considère comme de véritables ambassadeurs (c'est d'ailleurs le nom qu'ils se donnent eux-mêmes) même s'ils n'ont pas d'existence « officielle ».

Plutôt que d'institutionnaliser le projet de co-construction en demandant aux usagers un engagement officiel, mieux vaut faire appel à d'autres moyens pour les faire revenir et pour faire durer leur participation dans le temps.

\section{B. Faire durer la participation}

\section{Animer}

Les tâches d'animation sont centrales dans un projet de co-construction des collections : c'est par ce travail que l'on fait revenir les usagers, et que l'on permet à une action de co-construction des collections de dépasser le seuil de l'animation 
ponctuelle et de s'inscrire dans la durée. Le temps consacré au travail d'animation du projet est variable : dans certains cas cela diffère peu du temps consacré à la préparation d'autres animations. Dans des démarches de mobilisation plus ambitieuses, l'énergie et le temps dépensés peuvent très vite prendre une ampleur considérable.

Le bibliothécaire a un rôle clé pendant le temps de l'animation. Il doit faire en sorte d'offrir un cadre propice aux échanges, afin que la réunion soit la plus enrichissante et la plus constructive possible. Il a donc un rôle d'animateur, mais doit aussi savoir s'effacer pour laisser une expression libre aux usagers participants. Dans le même temps, il doit veiller à ce que la répartition de la parole soit respectée. Les personnalités des usagers, comme celles des bibliothécaires dans le fonctionnement interne, sont plus ou moins affirmées, et il faut faire en sorte que tout le monde puisse trouver une place. Par exemple, dans le club Lékridézados, les jeunes les plus à l'aise font une critique de livres filmées et mise en ligne sur le site Actu SF. Les plus timides ont également la possibilité de contribuer par une critique écrite, également valorisée sur le site et pourront éventuellement être filmés s'ils se sentent plus à l'aise par la suite. Il est possible également d'organiser des tours de table, afin de garantir à chacun une fenêtre d'expression. Dans tous les cas, le bibliothécaire doit veiller à ce que le déroulement de la réunion reste propice à l'échange, et que les apports soient mutuels.

La configuration de l'animation doit aussi refléter l'égalité entre les participants, qui est un principe du projet de co-construction. Dans ce cadre, le bibliothécaire doit se positionner comme un égal vis-à-vis des autres usagers, dont l'avis n'a pas un poids supérieur à celui d'un autre. Il faut toujours insister sur le fait que, dans le projet de co-construction, les usagers sont de véritables codécideurs, et que leur avis n'est pas seulement consultatif. La configuration spatiale doit aussi refléter l'égalité des conditions. Il vaut mieux par exemple éviter les configurations frontales, avec les bibliothécaires d'un côté sur une estrade et les usagers en face dans le public. On peut préférer des installations en rond, autour d'une table.

Au quotidien, hors des séances avec les usagers, le bibliothécaire garde un rôle d'animateur de la communauté. Selon nous, la fidélisation des usagers se fera en instaurant le moins de contraintes possibles, pour éviter de donner l'impression d'un engagement contraignant ou de reproduire un cadre scolaire. Paradoxalement, permettre aux usagers de rater librement des séances est aussi le meilleur moyen de les faire revenir. En revanche, il faut pouvoir proposer une plus-value à la participation, en répondant à la question que peuvent se poser les usagers : qu'estce que ça m'apporte de participer à ce projet ? Il est alors possible de jouer sur les intérêts à participer évoqués dans le paragraphe précédent : donne l'impression de participer à une communauté, à un projet commun; donner des plus-values à la participation, comme celle de découvrir les nouveautés en avant-première, ou de pouvoir réserver directement les ouvrages choisis... 


\section{Valoriser, créer des liens et célébrer}

Pour faire durer l'engagement des usagers dans le projet de participation, il faut à la fois valoriser les contributions, créer des liens et célébrer.

La participation des usagers est volontaire et bénévole, c'est pourquoi elle mérite d'être mise en valeur. D'une part, cela permet à l'usager de se sentir reconnu, remercié pour ses contributions et lui donne le sentiment d'avoir participé à un projet commun. D'autre part, la mise en avant des contributions des usagers renvoie une bonne image de la bibliothèque, participative et inclusive. L'idée est de démontrer, aussi à l'usager lui-même, qu'il a des ressources à apporter à la bibliothèque, et que ses contributions méritent d'être mises en valeur. Les modes de valorisation de la participation dépendent très largement du projet de coconstruction. Nous en donnerons ici trois exemples, mais d'autres modes de valorisation peuvent être inventés et utilisés.

Le projet «Transcribe Bentham », initié par l'University College of London a pour objectif de transcrire les 60000 manuscrits non édités du philosophe anglais Jeremy Bentham. Pour mettre en valeur les contributions, et encourager les participations, le «benthamometer» mesure l'avancement du projet ${ }^{147}$. Les contributeurs reçoivent des points en fonction de leur participation, ce qui leur permet de faire progresser leur statut (de probationer, employé à l'essai à prodigy, prodige $)^{148}$. Enfin, un classement sur la page d'accueil met en valeur les meilleurs contributeurs (Transcribe Bentham top contributors).

Nous avons déjà évoqué le « collectif médiathèque » qui a suivi tout le projet de construction de la nouvelle médiathèque de Méricourt (qui n'est pas un projet de co-construction des collections, mais qui illustre bien ce point). Une exposition, intitulée «Le lecteur est un héros » a été créée à la fin du projet et exposée dans l'espace culturel de la ville afin de mettre en valeur tout le travail effectué par les membres du collectif ${ }^{149}$. C'est à la fois une marque de reconnaissance pour les participants et une manière de montrer au reste du public qu'eux aussi peuvent participer.

Enfin, la participation des adolescents au club Lékridézados à Montreuil est également valorisée par une carte spéciale de membre du club, qui leur donne accès dans la bibliothèque à un espace qui leur est réservé et où ils peuvent s'installer pour lire ou préparer leurs critiques.

Pour encourager la participation, il faut également jouer sur le sentiment d'appartenance à une communauté, en créant des liens. Par exemple, l'application de gestion bibliographique CiteULike a été créée pour permettre d'ajouter des tags sur des contenus universitaires mais n'a pas bien fonctionné. Evelyne Broudoux note à propos de cette application que, même dans un cadre scientifique, le tagging

${ }^{147}$ http://www.transcribe-bentham.da.ulcc.ac.uk/td/Benthamometer Consulté le 20 novembre 2013

${ }^{148}$ http://www.transcribe-bentham.da.ulcc.ac.uk/td/Help:User_levels Consulté le 20 novembre 2013

149 « «Le lecteur est un héros », derrière la palissade, une exposition - Site de Méricourt », [En ligne: http://www.mairie-mericourt.fr/Le-lecteur-est-un-heros-derriere]. Consulté le 20 novembre 2013. 
ne fonctionne pas sans possibilité d'interaction entre les usagers ${ }^{150}$. Le projet de correction collaborative Trove ${ }^{151}$ au contraire fonctionne très bien, car il a réussi à construire sa propre communauté d'usagers, en leur permettant de communiquer entre eux notamment à travers le très actif forum des contributeurs ${ }^{152}$. Il faut garder en tête lors d'un projet de co-construction l'importance de la constitution de communautés, de l'animation de groupe. Les résultats sont pauvres si les acteurs ne peuvent y investir leurs motivations.

La création de liens se fait également à travers des moments de célébration, qui ne sont pas à négliger dans le projet de co-construction. Célébrer la participation permet d'acter une réalisation collective, autour d'un moment convivial qui est l'occasion d'échanger autour du projet, de créer des liens mais aussi de reconnaître l'apport des usagers et de la démarche de collaboration. Le projet Working Together donne dans sa trousse d'outils plusieurs pistes pour célébrer une action de co-construction des collections ${ }^{153}$. Autre exemple, la bibliothèque de la Croix Rousse a organisé une séance spéciale avec le cercle des auditeurs lors de la réception des CD qu'ils avaient choisi. Les usagers ont participé à l'ouverture des cartons et à l'équipement des nouveaux $\mathrm{CD}$, en les mettant en valeur par une étiquette spécifiant que ces documents résultent du choix du cercle. Le logo figurant sur cette étiquette a d'ailleurs été dessiné par un usager membre du cercle. Cette séance a également permis de définir une playlist qui serait jouée le lendemain dans la bibliothèque pour l'inauguration de la nouvelle discothèque.

\section{EXPERIMENTER ET APPRENDRE DES EXPERIENCES}

Les projets de co-construction des collections doivent enfin toujours être conduits dans une démarche expérimentale. Il n'est jamais possible d'être assuré à l'avance de la réussite d'un projet de co-construction. De nombreux facteurs jouent sur la décision de participer et, s'il est possible de favoriser le recrutement comme nous l'avons vu, il n'est jamais possible de prévoir à l'avance la nature de la participation.

Afin d'éviter un échec retentissant, il convient de lancer le projet d'abord à petite échelle, à titre expérimental. Puis, selon les résultats, il est possible d'ajuster l'organisation du projet pour mieux répondre aux besoins. Il ne faut donc jamais surestimer à l'avance la participation ou la qualité de l'apport des usagers. Par exemple, après la mise en ligne de la collection Eugène Trutat sur Flickr, la bibliothèque de Toulouse a été déçue par le contenu des tags identifiant les photographies. La médiathèque aurait voulu que la mise en ligne des collections permette d'identifier des lieux photographiés par Trutat car la description

150 Evelyne Broudoux, «Indexation collaborative: traces de lecture et constitution de communautés », in Bibliothèque 2.0 à l'heure des médias sociaux, Paris, France, Éd. du Cercle de la librairie, 2012, (« Bibliothèques »), p. 125 - 134 .

\footnotetext{
${ }^{151}$ http://trove.nla.gov.au/ Consulté le 11 novembre 2013

${ }^{152}$ http://trove.nla.gov.au/forum/ Consulté le 20 novembre 2013

153 « Trousse d'outils pour des bibliothèques à l'écoute de la communauté », op. cit., p. 109.
} 
bibliographique des photographies était souvent lacunaire. Cependant, la grande majorité des tags sont des noms communs descriptifs (arbre, route, maison, etc.) et n'apportent pas d'informations susceptibles d'abonder l'indexation (qu'ils ont pu en revanche parfois trouver dans les commentaires) ${ }^{154}$. La participation peut donc parfois donner des résultats décevants par rapport à l'objectif initial.

Il faut également garder en tête la règle du 90-9-1 qui s'applique aux projets collaboratifs avec une communauté en ligne : moins de $1 \%$ de la communauté contribue régulièrement, $9 \%$ participe occasionnellement et $90 \%$ sont des observateurs qui ne contribuent jamais ${ }^{155}$. Cette règle ne s'applique qu'aux projets collaboratifs sur internet mais elle est révélatrice de la difficulté qu'on peut parfois avoir à mobiliser les participations régulières.

De plus, il est nécessaire de se rappeler que tous les projets évoqués dans ce mémoire sont valables dans un certain contexte. Toute expérience n'est pas toujours transposable à un autre environnement. C'est pourquoi tout projet de coconstruction doit faire l'objet d'une analyse préalable du territoire, afin d'identifier les ressources et les besoins présents dans la communauté, et de proposer une action adaptée à l'environnement local.

Pendant la mise en œuvre, le projet de co-construction des collections doit constamment faire l'objet d'une évaluation, afin de réajuster les actions si nécessaire : quels résultats a-t-on obtenu par rapport à l'objectif initial ? quel est l'apport de la participation ? quels moyens ont été investis pour quels résultats ?

Enfin, il faut oser «se lancer », de manière expérimentale, en gardant à l'esprit que tout ne peut être prévu à l'avance et que c'est en faisant que les questions se résolvent. Au lieu d'anticiper tous les risques possibles, mieux vaut se demander ce qu'un tel projet peut apporter à la bibliothèque :

Ce que l'on risque ? La présence active d'une partie de la population que l'offre culturelle initiale touchait peu, une régulation probable des incivilités (le partage d'un lieu avec des adultes actifs calme considérablement les imprévisibles ardeurs adolescentes), une appropriation possible de la bibliothèque et de son offre propre par la réduction de la distance culturelle entre le lieu et les habitants. ${ }^{156}$

\footnotetext{
${ }^{154}$ Patrick Hernebring, op. cit., p. 118.

${ }^{155}$ Règle du $1 \%$ sur Wikipedia : http://fr.wikipedia.org/wiki/R\%C3\%A8gle_du_1_\%25 Consulté le 20 novembre 


\section{CONCLUSION}

Dans ce mémoire plusieurs idées fortes ont été avancées :

Nous avons voulu montrer que la co-construction des collections avec les usagers est possible : d'une part, de nombreux projets existent déjà et fonctionnent bien. D'autre part, nous avons souligné qu'elle pouvait être envisagée sous de multiples formes (co-acquisition, co-gestion de la collection, co-création de contenus et médiation documentaire participative) et concerner tout aussi bien des collections physiques que numériques. La co-construction en bibliothèque est non seulement possible, mais elle s'inscrit dans une tendance plus globale de demande de participation, en réponse à deux injonctions principales : celle d'accroître la proximité de l'institution avec les citoyens et celle de proposer un service public plus efficace et mieux adapté aux besoins locaux.

La co-construction va plus loin que la simple participation, en ce sens qu'elle implique une démarche de construction en commun avec les usagers. Elle permet d'ouvrir des espaces d'échanges et d'enrichissements mutuels, dans le cadre d'un changement plus global de la relation de la bibliothèque à l'usager. Cette transformation implique d'une part d'établir une confiance en l'usager-citoyen : reconnaitre sa légitimité à enrichir de ses savoirs, de ses idées, de ses actions la collection et la vie de l'établissement. D'autre part, cela suppose de passer d'un usager essentiellement passif à un citoyen proactif.

Un autre apport majeur de l'entreprise de co-construction des collections est celui de transformer la façon dont on appréhende l'offre de ressources de la bibliothèque. La collection, dans le contexte du nouveau système de transmission de l'information bouleversé par le web, doit être pensée uniquement par rapport aux usages et aux besoins de la communauté, et permettre de valoriser les ressources du territoire.

Dans ce cadre, le bibliothécaire ne doit pas craindre d'être remplacé dans ses fonctions par les participants bénévoles. Son rôle au contraire est central, mais renouvelé : d'un gestionnaire de collection, il devient animateur et médiateur. Il identifie les ressources présentes sur un territoire, les met en valeur et suscite les participations. Face aux craintes et aux réticences qui pourraient naître, un nécessaire équilibre doit être trouvé entre la participation et la préservation des impératifs de neutralité et de pluralité des collections, pour lequel le rôle du bibliothécaire est essentiel.

Les expériences étudiées, qui servent d'illustration à la réflexion, sont encore récentes et peu nombreuses, c'est pourquoi il est parfois difficile de tirer des conclusions à partir de ces exemples. Cependant, elles montrent que co-construire avec les usagers apporte un réel enrichissement de la relation de la bibliothèque à son public. Ces projets réussissent bien pour l'instant, et l'enjeu est désormais de réussir à les inscrire dans la durée.

Hervé Le Crosnier écrit: "Il n'y a plus depuis longtemps de modèle canonique de la bibliothèque. ${ }^{157}$ La co-construction, dans ce contexte, a le mérite

${ }^{157}$ Hervé Le Crosnier, op. cit. 
de renouveler la réflexion sur la place de la bibliothèque dans la cité, et sur sa relation à l'usager. Certes, les exemples analysés sont encore souvent au stade de l'expérimentation, et ne peuvent pas encore être généralisés. Mais cela ne doit pas empêcher de continuer à inventer et à tester de nouvelles formes de coconstruction. Le projet le plus poussé dans la réflexion, celui de la future médiathèque de Lezoux, est justement au stade où ces idées doivent se traduire par des organisation et actions concrètes. De nombreuses questions sont encore à résoudre mais les idées sont là. 


\section{Bibliographie}

\section{LES ENJEUX DE LA CO-CONSTRUCTION ET DE LA PARTICIPATION}

ALLEGRETTI, Giovanni, «Les défis de la démocratie participative : Une refondation politique et culturelle », Le Monde diplomatique, octobre 2011, [En ligne :

http://www.monde-diplomatique.fr/2011/10/ALLEGRETTI/21111].

BACQUÉ, Marie-Hélène et MECHMACHE, Mohamed, «Pour une réforme radicale de la politique de la ville », Le pouvoir d'agir, 2013.

BAYET, Antoine et JACOB, Yvane, «Le « design de services » : quand le design veut permettre de mieux vivre ensemble », Regards sur le numérique, 2010, [En ligne : http://www.rslnmag.fr/post/2010/11/29/le_design-de-services_quand-le-design-veutpermettre-de-mieux-vivre-ensemble.aspx].

BLONDIAUX, Loïc et SINTOMER, Yves, «L'impératif délibératif », Rue Descartes, $\mathrm{n}^{\circ}$ 63, avril 2009, p. 28-38.

LEADBEATER, Charles et MILLER, Paul, The pro-am revolution: how enthusiasts are changing our society and economy, London, Royaume-Uni, Demos, 2004, 77 p.

NOIRFALISSE, Quentin, «Vers une économie de la contribution », OWNI, 30 novembre 2011, [En ligne : http://owni.fr/2011/11/30/vers-une-economie-de-lacontribution/].

NOVEL, Anne-Sophie, « Co-construire, ça veut dire quoi ? », Le Co-Lab, 2012, [En ligne : http://www.co-lab.fr/livres/co-construire-ca-veut-dire-quoi/].

SOICHOT, Marine, «Le deficit model : "Les gens ne savent rien, il faut y remédier" », Pris $(m)$ e de tête, 2009, [En ligne : http://www.prismedetete.net/ogm\%C2\%A0et-ideesrecues-les-limites-du-deficit-model/].

SPENCER, Thierry, « Co-construction : un pari gagnant pour les entreprises ! »,[En ligne : http://room.sfrbusinessteam.fr/article/construction-pari-gagnant-pourentreprises].

VAUFREY B, Christine, «Vulgarisation, médiation et co-construction des savoirs scientifiques et sociaux », Thot Cursus, 2012, [En ligne :

http://cursus.edu/article/5406/vulgarisation-mediation-construction-des-savoirsscientifiques/]. 


\section{LA PARTICIPATION EN BIBLIOTHEQUE}

CHAPDELAINE, Vincent, «Vers une bibliothèque participative », Découvrir, le magazine de l'Afcas, mars 2013, [En ligne :

http://www.acfas.ca/publications/decouvrir/2013/03/vers-bibliotheque-participative].

CHOURROT, Olivier, « Messages de lecteurs, le cahier de suggestions en bibliothèque », Bulletin des Bibliothèques de France, vol. 42 / 4, 1997, [En ligne : http://bbf.enssib.fr/consulter/bbf-1997-04-0030-005].

CORBIERE, Miranda, « Children's participation in the architecture of the library », Enssib, 2012, ( «Journée d'études "Enfants et jeunes en bibliothèque : regards européens" »), [En ligne : http://www.enssib.fr/bibliotheque-numerique/document60148].

DUJOL Lionel, «La bibliothèque, un espace de participation », 2013, [En ligne : http://fr.slideshare.net/hulot/la-bibliothque-un-espace-de-participation-23394251].

GALAUP, Xavier, L'usager co-créateur des services en bibliothèques publiques : l'exemple des services non-documentaires, Mémoire DCB sous la direction de Dominique Lahary, Enssib, 2007.

MARTEL, Marie D., « Construire et rénover des bibliothèques en Amérique en 2012 : ça prend une communauté », Bibliomancienne, [En ligne :

http://bibliomancienne.wordpress.com/2012/07/05/construire-et-renover-desbibliotheques-en-amerique-en-2012-ca-prend-une-communaute/].

MERCIER, Silvère, «Les bibliothèques participatives restent à inventer ! », Bibliobsession, 2008, [En ligne : http://www.bibliobsession.net/2008/12/09/lesbibliotheques-participatives-restent-a-inventer/comment-page-1/].

REMY, Patricia, «Ouvrir un espace d'intervention aux usagers... », Bulletin des Bibliothèques de France, vol. 48 / 1, 2003, [En ligne : http://bbf.enssib.fr/consulter/bbf2003-01-0099-007].

PÉRÈS-LABOURDETTE LEMBÉ, Victoria, « La bibliothèque quatrième lieu, espace physique et/ou en ligne d'apprentissage social, Un nouveau modèle de circulation des savoirs », Agence Gutenberg 2.0, 2012, [En ligne : http://www.enssib.fr/bibliothequenumerique/document-56998]. 
SANDOZ, David, Repenser la médiation culturelle en bibliothèque publique participation et quotidienneté, Mémoire DCB sous la direction de Bernard Huchet, Enssib, 2010.

VAN BESIEN, Hughes, « Comités d'usagers : le retour?», Bulletin d'informations de l'ABF, 2000 .

«Trousse d'outils pour des bibliothèques à l'écoute de la communauté », Projet Working Together, 2008, [En ligne :

http://www.librariesincommunities.ca/resources/Trousse-doutils-FR-Finale.pdf].

$27^{\mathrm{E}}$ REGION, « Résidence $\mathrm{n}^{\circ} 12$ : Les nouveaux usages de la médiathèque », 2013, [En ligne : http://fr.slideshare.net/27eregion/residence-

lesnouveauxusagesdelamediathequelight].

\section{LES COLLECTIONS}

BERTRAND, Anne-Marie, «Collections et publics en bibliothèque », ADBDP : journées 1999, 1999, [En ligne:

http://www.adbdp.asso.fr/ancien/association/je1999/bertrand.htm].

CALENGE, Bertrand, Bibliothèques et politiques documentaires à l'heure d'Internet, Paris, France, Éditions du Cercle de la librairie, 2008, 264 p., («Bibliothèques »).

CALENGE, Bertrand, Conduire une politique documentaire, Paris, France, Éd. du Cercle de la librairie, 1999, 386 p., (« Bibliothèques »).

CALENGE, Bertrand, « Construire des collections ou construire des connexions ? », Bertrand Calenge : carnet de notes, 2013, [En ligne :

http://bccn.wordpress.com/2013/04/07/construire-des-collections-ou-construire-desconnexions/].

CALENGE, Bertrand, « La collection entre offre et demande ? », Bulletin des Bibliothèques de France, vol. 46 / 2, 2001, [En ligne : http://bbf.enssib.fr/consulter/bbf2001-02-0040-003].

GAUTIER-GENTÈS, Jean-Luc, « Réflexions exploratoires sur le métier de directeur de bibliothèque », Bulletin des Bibliothèques de France, vol. 44 / 4, 1999, [En ligne : http://bbf.enssib.fr/consulter/bbf-1999-04-0014-002]. 
LANKES, R. David, «Beyond the Bullet Points: Bad Libraries Build Collections, Good Libraries Build Services, Great Libraries Build Communities », Virtual Dave...Real blog, 2012, [En ligne : http://quartz.syr.edu/blog/?p=1411].

SWORDS, David A., Patron-driven acquisitions: history and best practices, Berlin, Allemagne, 2011, 205 p., («Current topics in library and information practice »).

\section{LES PUBLICS}

BERTRAND, Anne-Marie, Bibliothécaires face au public, Paris, France, Bibliothèque publique d'information, Centre Georges-Pompidou, 1995, 248 p., («Études et recherche »).

JEANNOT, Gilles, Les usagers du service public, Paris, France, Presses universitaires de France, 1998, 126 p., («Que sais-je ?», 3359).

QUATREBARBES, Bertrand de et GRUSON, Claude, Usagers ou clients ?: écoute, marketing et qualité dans les services publics, Paris, France, Éd. d'organisation, 1998, 391 p., («Collection Service public »).

\section{LES OUTILS COOPERATIFS EN LIGNE}

AÏOUTZ, Renaud, «Les communautés de lecteurs et les outils coopératifs : place et plus-value des médiations institutionnelles », médiathèque départementale de l'Hérault, 2011, [En ligne : http://footnotes.fr/2011/12/les-communautes-de-lecteurs-et-les-outilscooperatifs/].

AMAR, Muriel et MESGUICH, Véronique, Bibliothèques 2.0 à l'heure des médias sociaux, Paris, France, Éd. du Cercle de la librairie, 2012, 217 p., («Bibliothèques »).

CALENGE, Bertrand, «Ambition collaborative et projet politique : quel espace pour une bibliothèque ? », Bertrand Calenge : carnet de notes, 2008, [En ligne :

http://bccn.wordpress.com/2008/12/18/ambition-collaborative-et-projet-politique-quelespace-pour-une-bibliotheque].

CALENGE, Bertrand, «Des publics utilisateurs aux publics collaborateurs : une fausse bonne idée ? », Bertrand Calenge : carnet de notes, 2012, [En ligne :

http://bccn.wordpress.com/2012/02/11/des-utilisateurs-aux-collaborateurs-une-faussebonne-idee/]. 
DUJOL Lionel, « La bibliothèque 2.0 : impliquer l'usager », 2008, [En ligne : http://fr.slideshare.net/hulot/la-bibliothque-20-impliquer-lusager].

DUJOL, Lionel, « Le catalogue 2.0 ou le mythe de l'usager participatif? », La bibliothèque apprivoisée, 2009, [En ligne :

$\mathrm{http}: / /$ labibapprivoisee.wordpress.com/2009/10/14/le-catalogue-2-0-ou-le-mythe-delusager-participatif/].

HERNEBRING, Patrick, «Rosalis, à la croisée des chemins », Bulletin des

Bibliothèques de France, vol. 58 / 5, 2013, [En ligne : http://bbf.enssib.fr/consulter/bbf2013-05-0015-003.pdf].

MOIREZ, Pauline, MOREUX, Jean-Philippe et JOSSE, Isabelle, « Etat de l'art en matière de crowdsourcing dans les bibliothèques numériques », 2013, [En ligne : http://www.bnf.fr/documents/crowdsourcing_rapport.pdf].

QUEYRAUD, Franck et SAUTERON, Jacques, Outils Web 2.0 en bibliothèque: manuel pratique, Paris, Association des bibliothécaires de France, 2008, 132 p.

SMITH-YOSHIMURA, Karen, « Social Metadata for Libraries, Archives, and Museums, Parts 1, 2 \& 3 », OCLC, 2011, [En ligne :

http://www.oclc.org/research/publications/library/2012/2012-01r.html].

\section{CONTEXTE ET HISTOIRE DES BIBLIOTHEQUES}

BERTRAND, Anne-Marie, Bibliothèque publique et public library: essai de généalogie comparée, Villeurbanne, France, Presses de l'enssib, 2010, 229 p., («Papiers. Série Généalogies »).

BERTRAND, Anne-Marie, Les bibliothèques, Paris, France, la Découverte, 2011, 126 p., (« Repères », 247).

BERTRAND, Anne-Marie, Les bibliothèques municipales: enjeux culturels, sociaux, politiques, Paris, France, Éd. du Cercle de la librairie, 2002, 147 p., («Bibliothèques »).

CHARTIER, Anne Marie, HÉBRARD, Jean, FRAISSE, Emmanuel[et al.], Discours sur la lecture (1880-1980), Service des études et de la recherche, Bibliothèque publique d'information, Centre Georges Pompidou, 1989, 536 p.

EDWARDS, Julie Biando, RAUSEO, Melissa S. et UNGER, Kelly Rae, « Community Centered: 23 Reasons Why Your Library Is the Most Important Place in Town », Public Libraries Online, 30 avril 2013, [En ligne :

http://publiclibrariesonline.org/2013/04/community-centered-23-reasons-why-yourlibrary-is-the-most-important-place-in-town/]. 
HENRY, Lucie, Les partenariats des bibliothèques publiques en France et au Royaume-Uni: Des instruments stratégiques?, Mémoire de Master 2 Sciences de l'Information et de la Communication Métiers du livre (option bibliothèque), Université Paris Ouest Nanterre La Défense, 2009, [En ligne : http://www.enssib.fr/bibliothequenumerique/documents/48969-les-partenariats-des-bibliotheques-publiques-en-france-etau-royaume-uni-des-instruments-strategiques.pdf].

MORRIS, David, « The Public Library Manifesto: Why Libraries Matter, and How We Can Save Them », YES! Magazine, 6 mai 2011, [En ligne :

http://www.yesmagazine.org/happiness/the-public-library-manifesto].

VARRY, Dominique, Histoire des bibliothèques françaises: 1789-1914, Paris, France, Éd. du Cercle de la librairie, 2009, 922 p. 
Table des annexes

ANNEXE 1 : PLAN D'USAGE DE LA FUTURE MEDIATHEQUE DE

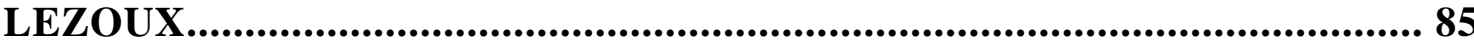

ANNEXE 2 : LES DIFFERENTES COMMUNAUTES AUTOUR DE LA

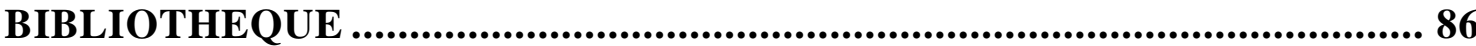





\section{ANNEXE 1 : PLAN D'USAGE DE LA FUTURE MEDIATHEQUE DE LEZOUX}

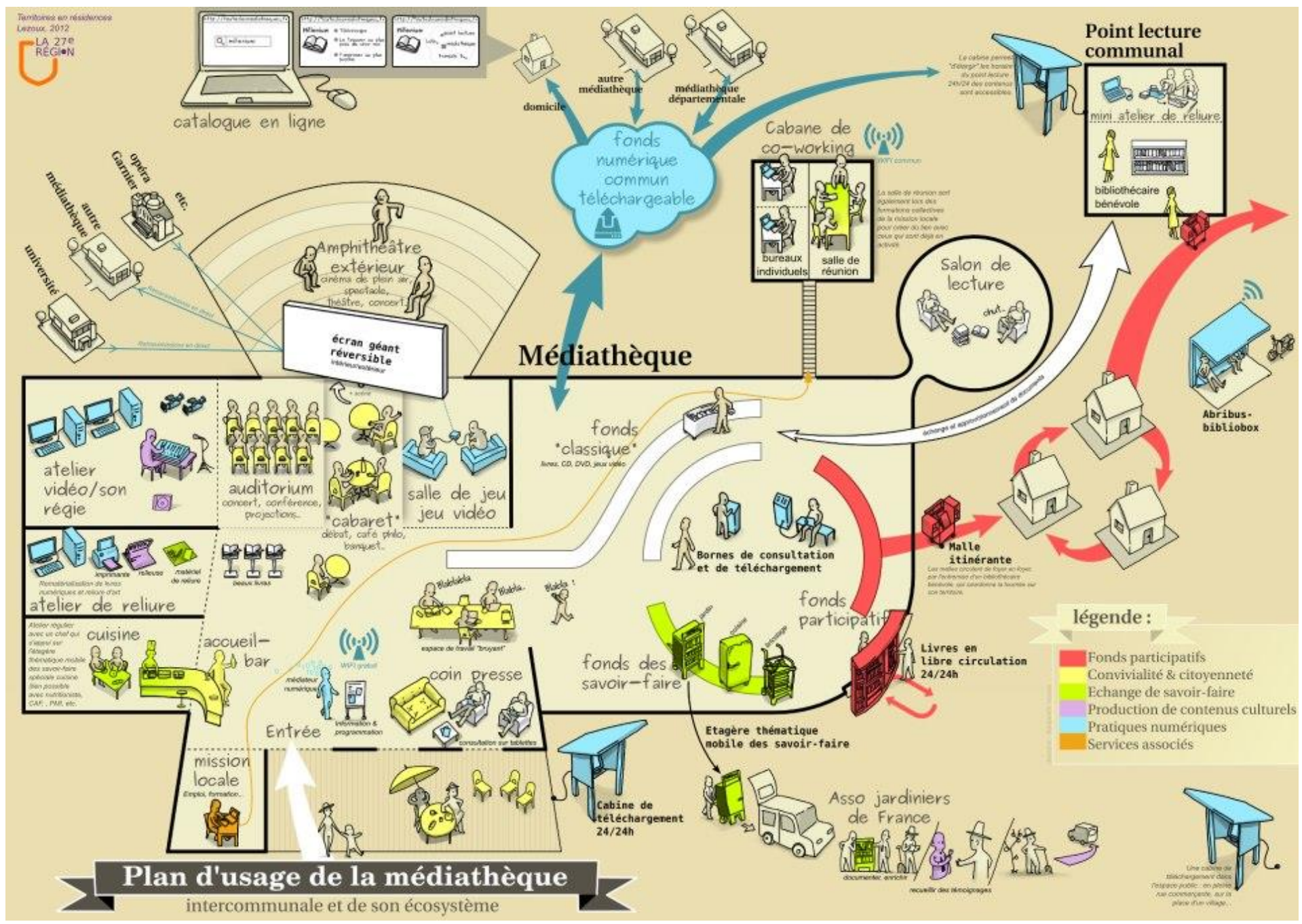

Source : $\underline{\text { http://blog.la27eregion.fr/Penser-la-mediatheque-de-demain }}$ 


\section{ANNEXE 2 : LES DIFFERENTES COMMUNAUTES}

\section{AUTOUR DE LA BIBLIOTHEQUE}

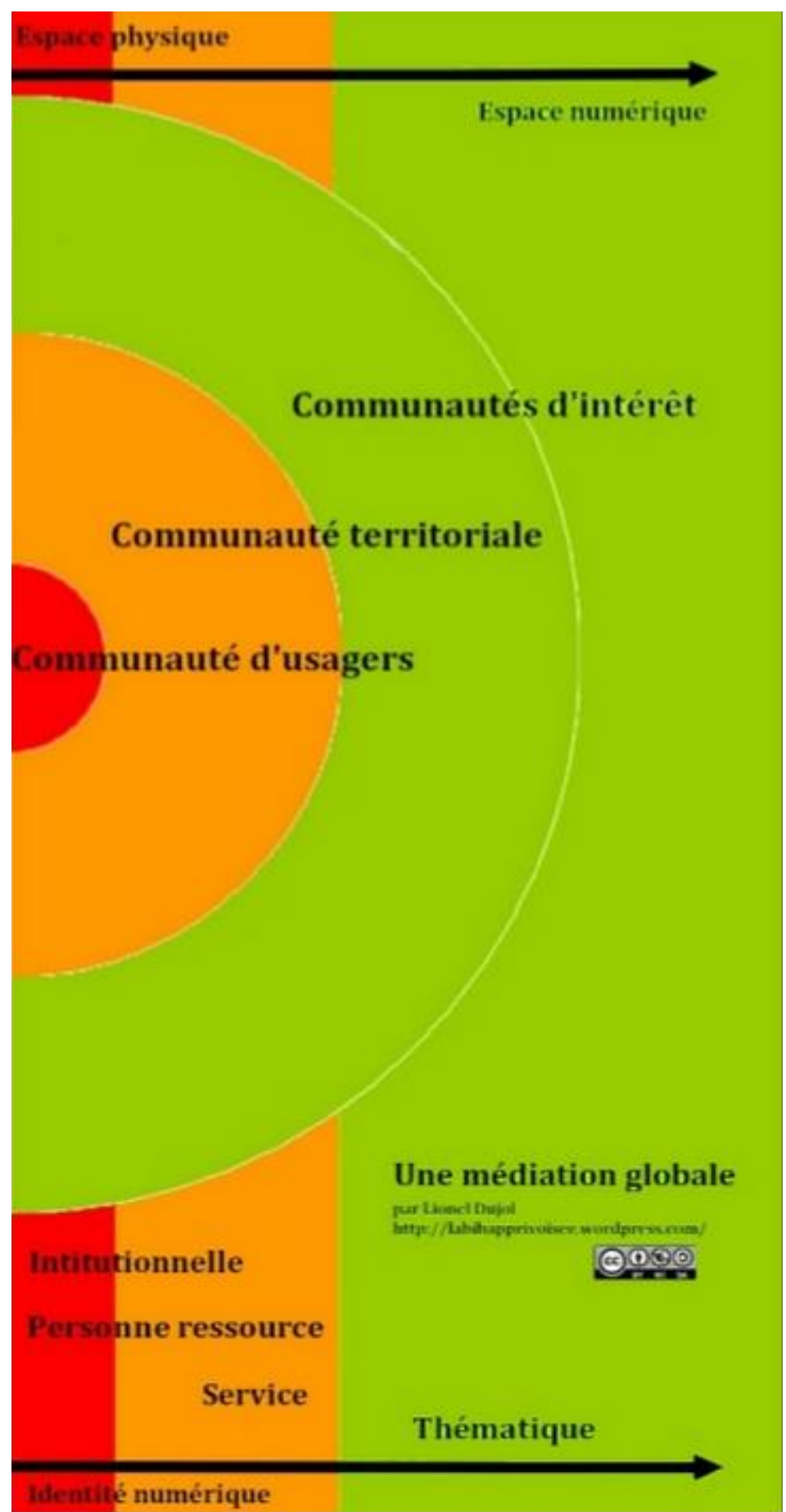

Source : DUJOL, Lionel, «Une médiation dans quel espace documentaire? », 2011, [En ligne : http://fr.slideshare.net/hulot/une-mdiation-dans-quel-espacedocumentaire-10397483]. 


\section{Table des matières}

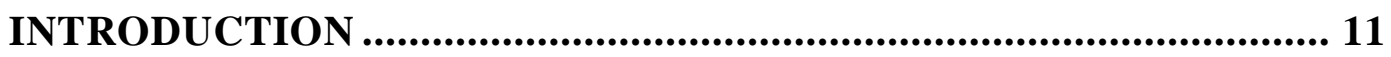

PARTIE 1 : CONTEXTE ET DEFINITION DE LA COCONSTRUCTION DES COLLECTIONS. 15

I. Une ancienne idée neuve ........................................................... 15

A. Une certaine frilosité des bibliothèques à faire participer les usagers aux collections ............................................................. 15

1. L'héritage de l'histoire des bibliothèques publiques françaises : la conservation des collections avant le souci du lecteur ........................ 15

2. La collection, domaine réservé du professionnel ?.............. 17

B. Une injonction à la participation qui renouvelle les modes d'association des usagers au fonctionnement des bibliothèques.

1. L'exigence d'une plus grande proximité entre l'institution et les citoyens 20

2. L'influence des bibliothèques anglo-saxonnes tournées vers la « community »

3. Des premières formes de participation : les comités d'usagers 22

II. Définir la co-construction des collections

A. Ce que la co-construction des collections n'est pas ................. 24

1. Tous les cas où l'usager reste passif ............................... 24

2. Toutes les formes de participation qui n'impliquent pas de démarche de construire en commun.

3. Toutes les formes de participation des usagers où la décision appartient au bibliothécaire ................................................... 26

B. De la participation à la co-construction.............................. 27

1. Passer d'un usager passif à un usager actif, acteur puis moteur de la collection

2. Renverser la logique de constitution des collections : ne plus construire pour, mais avec

3. Passer d'une logique verticale à un rapport horizontal avec l'usager 29

C. Typologie des formes de co-construction des collections .... 31

1. La participation des usagers aux acquisitions.................... 31

2. La participation des usagers à la gestion et l'organisation de la collection 31

3. La co-création de contenus

4. La médiation participative autour des collections 


\section{PARTIE 2 : LES ENJEUX DE LA CO-CONSTRUCTION DES}

I. Penser autrement la collection................................................... 35

A. Une collection plus proche de son public .............................. 35

1. Rapprocher le contenu de la collection des besoins et attentes du public $\quad 36$

2. Organiser la rencontre de la collection et des usagers ........... 37

a) La co-construction hors les murs ....................................... 37

b) Un moyen de dépasser l'opposition entre offre et demande? 38

B. $\quad$ Valoriser les compétences des usagers.................................... 39

1. Considérer les usagers comme une ressource ...................... 39

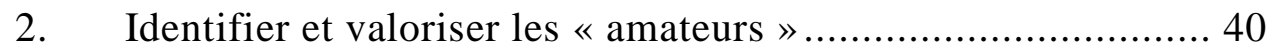

3. Adopter des formes de recommandation par les pairs ........... 41

II. La reconquête du public.......................................................... 42

A. Une relation renouvelée de la bibliothèque à son public............ 42

1. Du point de vue de l'usager : prendre conscience de son droit à contribuer 42

2. Du point de vue de la bibliothèque : activer la communauté des usagers 45

B. $\quad$ Faciliter le lien entre les bibliothécaires et les usagers ............ 48

1. Donner des clés pour une meilleure compréhension de la

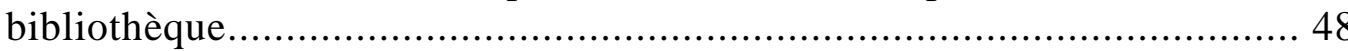

2. Faciliter les contacts ............................................... 49

III. Les questionnements soulevés ............................................... 50

A. L'appréhension d'une perte de contrôle sur les collections ....... 51

B. $\quad$ Un questionnement sur la place du bibliothécaire .................... 52

C. Des contraintes administratives et des marges étroites............. 54

D. La question de la représentativité des usagers ........................ 55

PARTIE 3 : COMMENT CONDUIRE UN PROJET DE COCONSTRUCTION DES COLLECTIONS ? ......................................... 58

I. Préparer le projet en amont ........................................................ 58

A. Faire de la participation un axe fort de sa politique d'établissement .................................................................................. 58

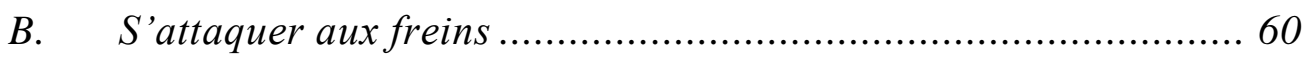

C. Encadrer la participation .................................................... 61

II. Organiser la participation....................................................63

A. Comment mobiliser ?.............................................................. 63

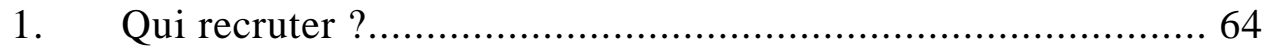

2. Trouver l'intérêt qui va susciter la participation .................. 66 


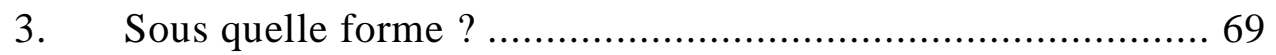

B. $\quad$ Faire durer la participation .............................................. 69

1. Animer ......................................................................... 69

2. Valoriser, créer des liens et célébrer................................ 71

III. Expérimenter et apprendre des expériences ........................... 72

CONCLUSION................................................................................. 75

BIBLIOGRAPHIE ......................................................................... 77

TABLE DES ANNEXES .................................................................. 83

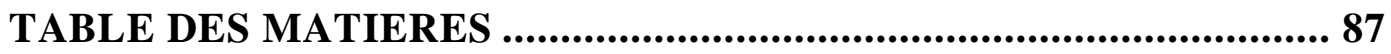

